\title{
FOLDING AS UTILITY, AND RESPONSIVENESS: PROTOTYPING IN OTTAWA
}

\author{
By \\ Stephen Logan \\ A thesis submitted to the Faculty of Graduate and Postdoctoral Affairs \\ in partial fulfillment of the requirements for the degree of \\ Master of Architecture \\ in Architecture \\ Carleton University \\ Ottawa, Ontario \\ (C) 2018 \\ Stephen Logan
}




\section{Abstract}

This thesis studies the utility of folding and how it could be a beneficial addition to structures with regards to responsiveness. Folding has been used previously as a design technique for architectural forms. The built forms, however, rarely fold themselves. This thesis explores the forms that can be created through folding structures and the potential opportunities for use that they present. The folding techniques were discovered primarily through drawings and models that developed into folding structures that are responsive to the environment around them and informational input. Three folding structures were developed as an exhibition of the folding methods and the ways in which they can be used. These three structures are sited through Ottawa, Canada and serve as both useful, interactive public infrastructures and an addition to making these public areas more dynamic. 


\section{Table of Contents}

\begin{tabular}{|c|c|}
\hline Section & 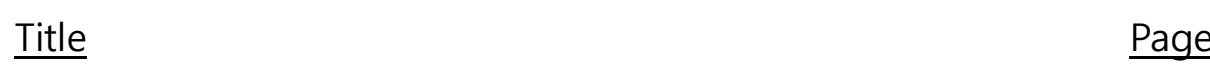 \\
\hline- & Abstract \\
\hline - & 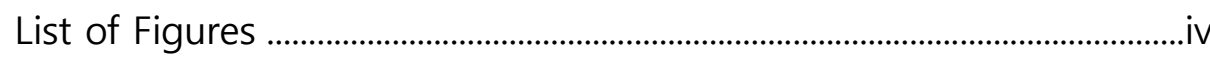 \\
\hline 1 & Introduction \\
\hline 2 & Folding in Theory \\
\hline 3 & Folding as Utility, and Responsiveness \\
\hline 4 & Public Space: Ottawa \\
\hline 5 & Development Process \\
\hline 6 & Prototypes: Responsive Folding Structures \\
\hline 7 & Confederation Park ........ \\
\hline 8 & 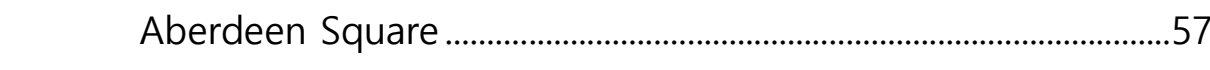 \\
\hline 9 & 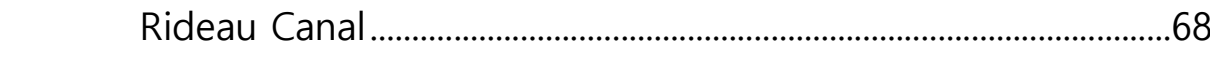 \\
\hline 10 & Conclusion ......................... \\
\hline- & Epilogue \\
\hline- & Glossary of Folds \\
\hline- & Bibliography ................................... \\
\hline
\end{tabular}




\section{List of Figures}

\begin{tabular}{|c|c|}
\hline Figure No. & Description \\
\hline 2.1 & P. Eisenman - Frankfurt Rebstockpark Concept Illustrations.............................................. \\
\hline 2.2 & 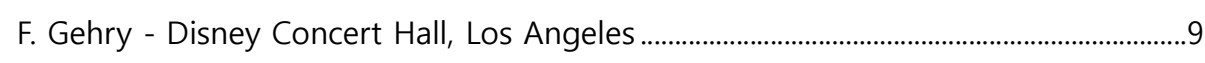 \\
\hline 2.3 & 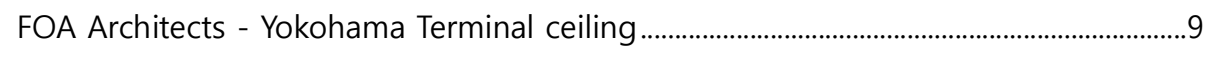 \\
\hline 2.4 & FOA Architects - Yokohama Terminal landscape \\
\hline 2.5 & 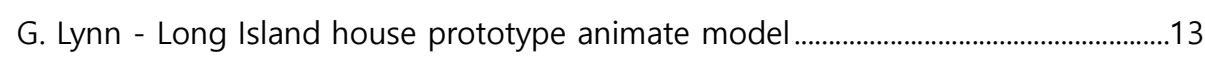 \\
\hline 2.6 & 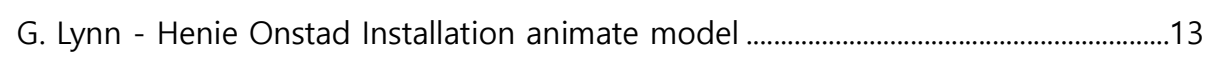 \\
\hline 3.1 & S. Logan - Index of folding objects \\
\hline 3.2 & S. Logan - Index of folding objects \\
\hline 3.3 & 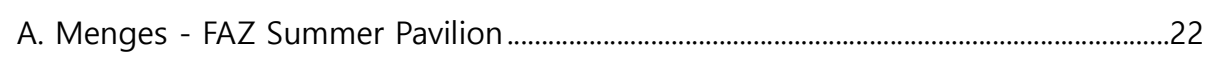 \\
\hline 3.4 & 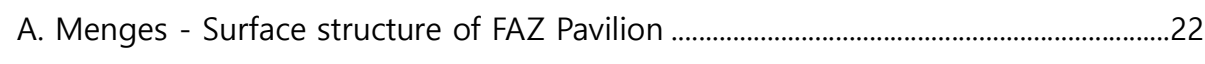 \\
\hline 3.5 & 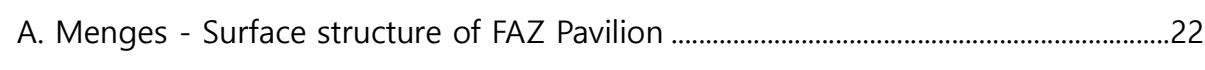 \\
\hline 3.6 & C. Hoberman - Expanding sphere illustration .............................. \\
\hline 3.7 & 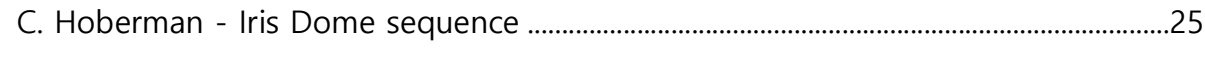 \\
\hline 3.8 & C. Hoberman - Tesselate automatic sun-shading system ..................... \\
\hline 5.1 & 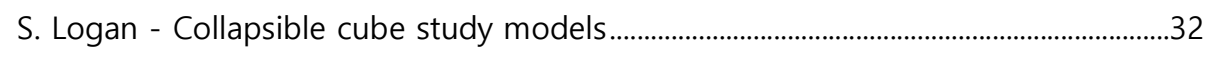 \\
\hline 5.2 & 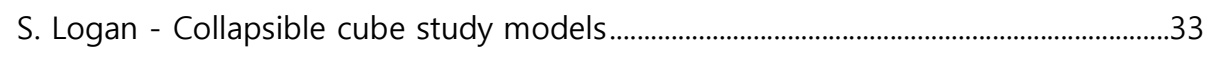 \\
\hline 5.3 & 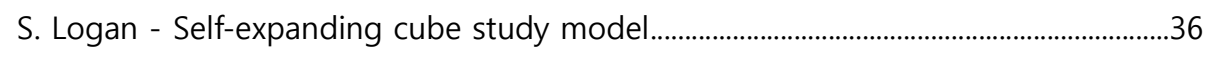 \\
\hline 5.4 & 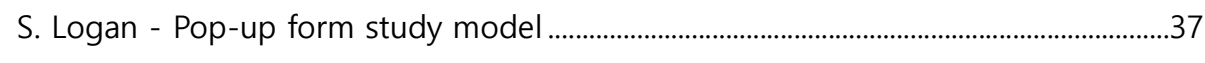 \\
\hline 5.5 & 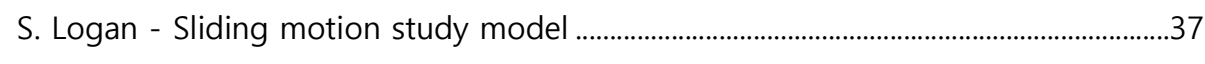 \\
\hline 5.6 & 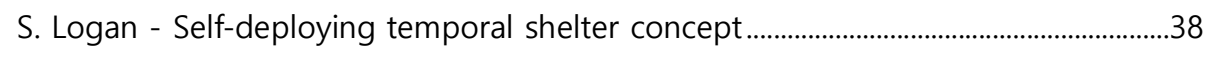 \\
\hline 5.7 & S. Logan - Weather activated responsive folding bus shelter concept...........................38 \\
\hline 5.8 & S. Logan - Folding bench prototype \\
\hline 6.1 & S. Logan - Ottawa site map of structure locations.........................................................44 \\
\hline 7.1 & S. Logan - Confederation Park structure site plan....................................... \\
\hline 7.2 & S. Logan - Confederation Park structure bench plan .....................................................49 \\
\hline 7.3 & 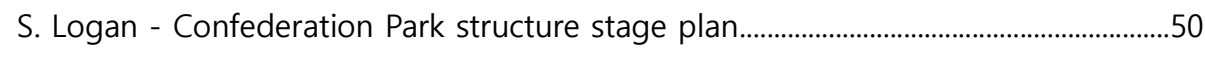 \\
\hline 7.4 & S. Logan - Confederation Park structure bench section ...................................................51 \\
\hline 7.5 & 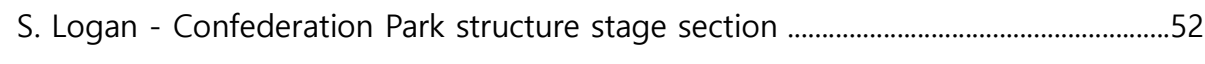 \\
\hline 7.6 & S. Logan - Confederation Park structure folding bench isometric ...................................53 \\
\hline 7.7 & S. Logan - Confederation Park structure axonometric series …………..........................54 \\
\hline
\end{tabular}




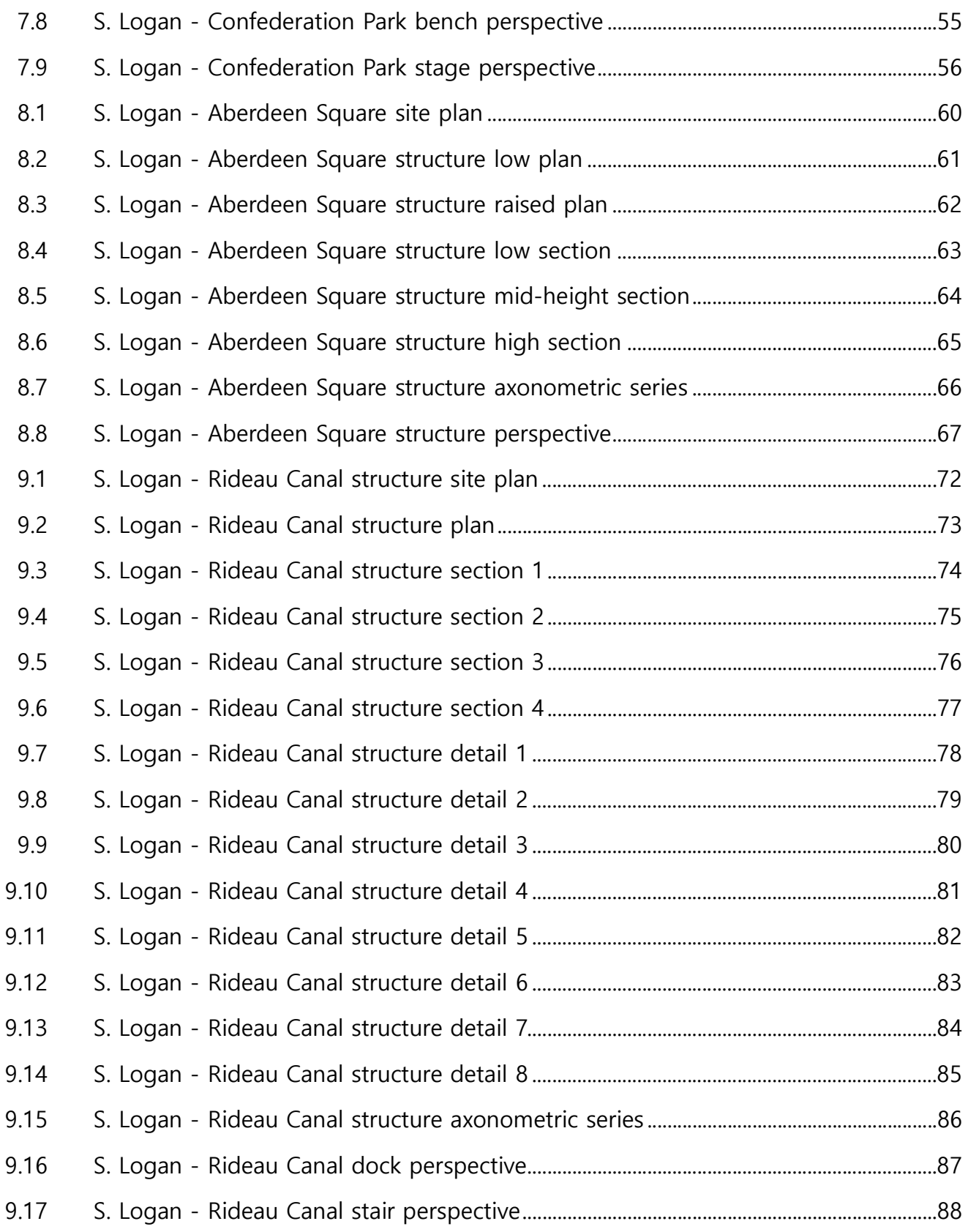




\section{Introduction}


This research-by-design thesis studies the concept of folding and applies it to a series of installations in Ottawa, Canada. The final project is a responsive dock/stair designed to be used along the edge of the Rideau Canal. Responsiveness in folding is of interest to this thesis because it provides interaction between architecture and its users. Here this folding occurs in public infrastructure such as benches or shelters to connect with the everyday public infrastructure as opposed to the specialized, temporal pavilion or façade that is usually developed with folding and responsive architecture. The intention is to have folding act as a utility. It allows the design to respond to environmental and activity-based changes. By responding to these changes the structures provide new opportunities for use. The resulting permanent structures have an aspect of temporality that could be seasonal, scheduled, or spontaneous. A utility based, responsive architecture is inspired by the simplicity, and functionality of both commonly folded objects and specially designed projects.

The responsiveness of a structure is rooted in its ability to react to its surroundings or other given information based on the current situation or necessity. Temporality accepts that the structure can and will change thereby redefining the conventional parameters of permanent space; the structure changes as the needs change. The application of responsiveness and temporality in an architectural form and used in a public setting provide an opportunity for the designed responsive folding structures 
to be an active architecture that enhances a site's usability. The implementation not only creates architecture worth seeing, but, architecture that through responsiveness changes the very nature of the public realm.

This thesis uses a number of literary sources. Its position is outside much of the theoretical framework that was established in the early 1990's in relation to folding, but it is incumbent for this thesis to acknowledge and understand these texts. As a research-by-design thesis the main focus was on developing a robust, viable prototype, and a related set of drawings that articulates the main design intentions of the project. In the following section I outline the architectural theory that defines the fold. My own process was a non-digital folding architecture, one that responds most to the work of Chuck Hoberman and his remarkable expanding structures. 
Folding in Theory 
Peter Eisenman's concept of the fold is largely inspired by Gilles Deleuze and his 1988 writing Le Pli: Leibniz et le Baroque (The Fold: Leibniz and the Baroque). The fold, to Eisenman, holds the potential to act as more than merely a device of action. It goes beyond the physical and creates opportunities to act upon existing conditions for the betterment of a society. ${ }^{1}$ When writing about folding he has referenced his 1990-91 Frankfurt Rebstockpark project as an example of a formal folding that can have a social impact that is ultimately more telling than the folded form of a building.

Greg Lynn was mentored by Eisenman, and in the early 1990's, was at the forefront of digital modelling as method of form generation for architecture. He applies folding, pliancy and suppleness to his digital models to animate them. Animate, or animation in Lynn's terms is defined as "evolution of a form and its shaping forces".2 Making these models animate provided a process in which Lynn could mould and change the form of his designs to work with a dynamic site relative to the project. This relationship between the dynamism of a site and the animate folding digital model produced a final form that would then be the basis of a developed architectural design.

The fold in both Eisenman and Lynn's condition is an expression of forces made static. This thesis takes a different position. While the basic form of the work is far more orthogonal, its responsiveness to time, forces, and use is more sophisticated. Using responsive architecture to acknowledge changes in needs and responding to people's requirements to develop a truly lasting, public architecture.

1 Peter Eisenman, "Unfolding Events, Frankfurt Rebstockpark and the Possibility of a New Urbanism," in Written into the Void, ed. Peter Eisenman, (London, Yale University Press, 2007), 17.

2 Greg Lynn, Animate Form (New York, Princeton Architectural Press, 1999), 9. 


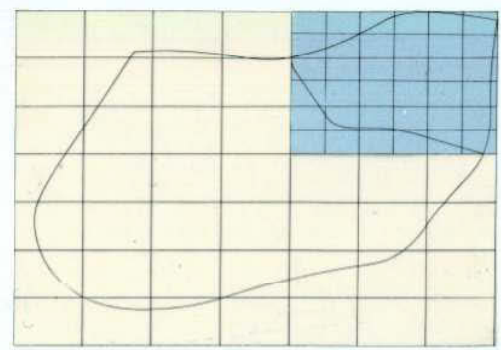

SUPEAPOSTION OF NET

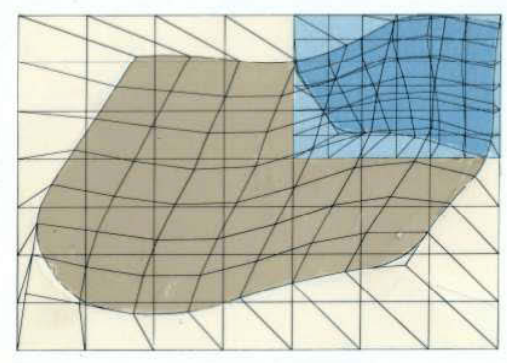

TRANSFORMATON OF NET

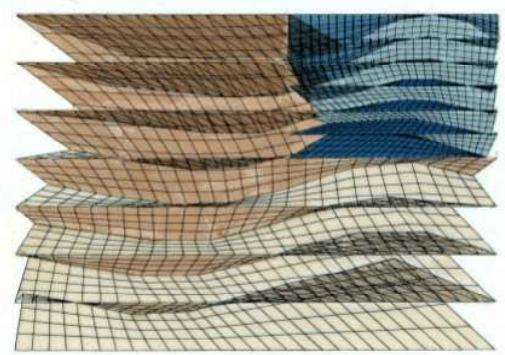

FOLDED NET
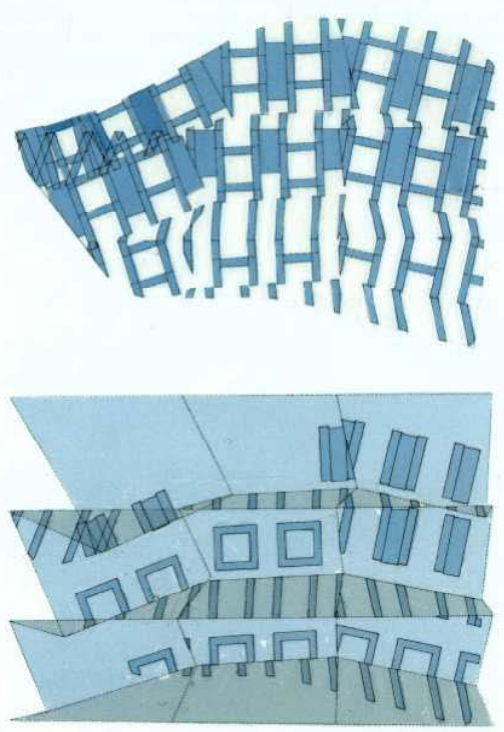

TYPOLOGICAL FABRIC BULLING TYPOLOG

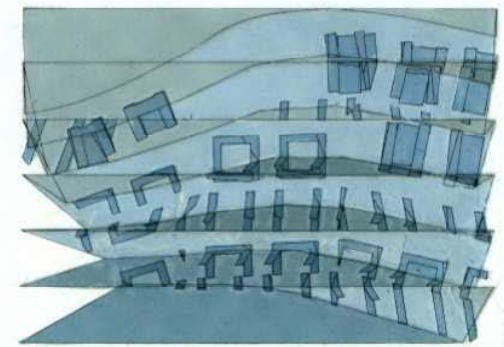

FOLDED TYPOLOGY

\section{REBSTOCKPARK}

CONCEPT DIAGRAMS

Figure 2.1 - Concept drawings by Peter Eisenman for his unbuilt 1990-91 Rebstockpark project in Frankfurt, Germany. The plan was influenced by Deleuze's theories of the fold and was evident throughout Eisenman's writings and drawings of the project. 
Chuck Hoberman's folding structures express a fascination with the intricacies of mechanics. A combination of sculptural art and mechanical engineering led to the development his dynamic structures and installations. Hoberman finds the beauty in the movement of a series of connected parts that expand and retract through patented mechanical systems. ${ }^{3}$ His Hoberman Sphere has been adapted as an icon, museum exhibit, performance installation, and children's toy. ${ }^{4}$ The mechanical systems used in his projects allow them to be responsive and adaptable to their environment. ${ }^{5}$ Hoberman's structures are more akin to the folding structures developed through this thesis. Both utilize movement and shape changing forms to meet the needs of their programs. Although Hoberman's early work is often more like transformable artworks, his later work is particularly adaptable to building elements such as responsive sun shading systems. ${ }^{6}$

Other prominent designs that have been described as folded include Frank Gehry's 2003 Disney Concert Hall in Los Angeles, California and Foreign Office Architects' 2002 Yokohama International Passenger Terminal in Japan. In Gehry's case the form is derived from the shape of wind loaded sails atop a sailboat. ${ }^{7}$ The folds and curves of the building are not the critical element of the function of the design, and instead are metaphorical, formal developments that evolve as part of the aesthetic design process; they are beautiful sculptural elements. The fold is physically visible, but, rigid and unmoving. The Yokohama Terminal is more sophisticated with the fold serving a critical structural need but equally unmoving. Here the crisp folds of the ceiling

\footnotetext{
3 Tom Waters, "The Unfolding World of Chuck Hoberman," Discover, March 1, 1992, http://discovermagazine. com/1992/mar/theunfoldingworl6

4 "Hoberman Company Profile and Selected Works: 1990-2012," Hoberman Associates Inc., accessed March 22, 2018, http://www.hoberman.com/HobermanPortfolio.pdf

5 Tim McKeough, "Chuck Hoberman's Buildings Adapt to the Environment," Fast Company, April 1, 2010, https://www.fastcompany.com/1588653/chuck-hobermans-buildings-adapt-environment

6 McKeough, "Chuck Hoberman's Buildings Adapt to the Environment."

$7 \quad$ Frank Gehry, Sketches of Frank Gehry, Internet Video, directed by Sydney Pollack, New York: Sony Pictures Classics, 2006.
} 
impart strength in the structure and span long distances, and the more subtle folds of the outdoor landscape create variety throughout the levels of the terminal while maintaining a non-disruptive relationship with the waterfront. This subtle folding also allowed for the open spaces of the terminal to be used as public space for gathering, meandering, or pop-up events. ${ }^{8}$ The folded structures of this thesis, however, would take a reversed approach to the Yokohama Terminal with regards to public space. Instead of creating public space out of a folded structure, the folded structure will be installed within an existing public site to promote a more dynamic use.

Deleuze's philosophy of folding, Eisenman's take on Deleuze with regards to architecture, Hoberman's use of movement within structures, and Lynn's interaction with a dynamic environment are the elements that are explored and utilized as inspiration. While Eisenman and Lynn have both used folding as a methodology towards designing, the buildings and structures they create, in the end, do not fold in action, only in static form. Folding may play a part in the story behind the built forms, but, folding as an active component of that story is lost in the rigidity of the completed building. Hoberman's folds are visually stunning and have been used as showcase pieces at popular shows and events. ${ }^{9}$ His structures, however, often change the quality of a space rather than the form of a space. People do not inhabit Hoberman's structures and they are not constructed in settings where they can be interacted with by the public. The folding structures developed through this thesis physically fold and move, can be interactive with the public, and are a representation of a community advancing its public image and infrastructure.

\footnotetext{
$8 \quad$ David Langdon, "AD Classics: Yokohama International Passenger Terminal/Foreign Office Architects (FOA)," Arch Daily, last modified October 7, 2014, https://www.archdaily.com/554132/ad-classics-yokohama-internationalpassenger-terminal-foreign-office-architects-foa; "Yokohama International Port Terminal, Yokohama, Japan," Farshid Moussavi Architecture, accessed March 22, 2018, https://www.farshidmoussavi.com/node/15\#yokohama_international_ port_terminal_yokohama_japan_15_44

9 "Company Profile and Selected Works: 1990-2012", Hoberman Associates, Inc., accessed March 22, 2018, http://www.hoberman.com/HobermanPortfolio.pdf
} 


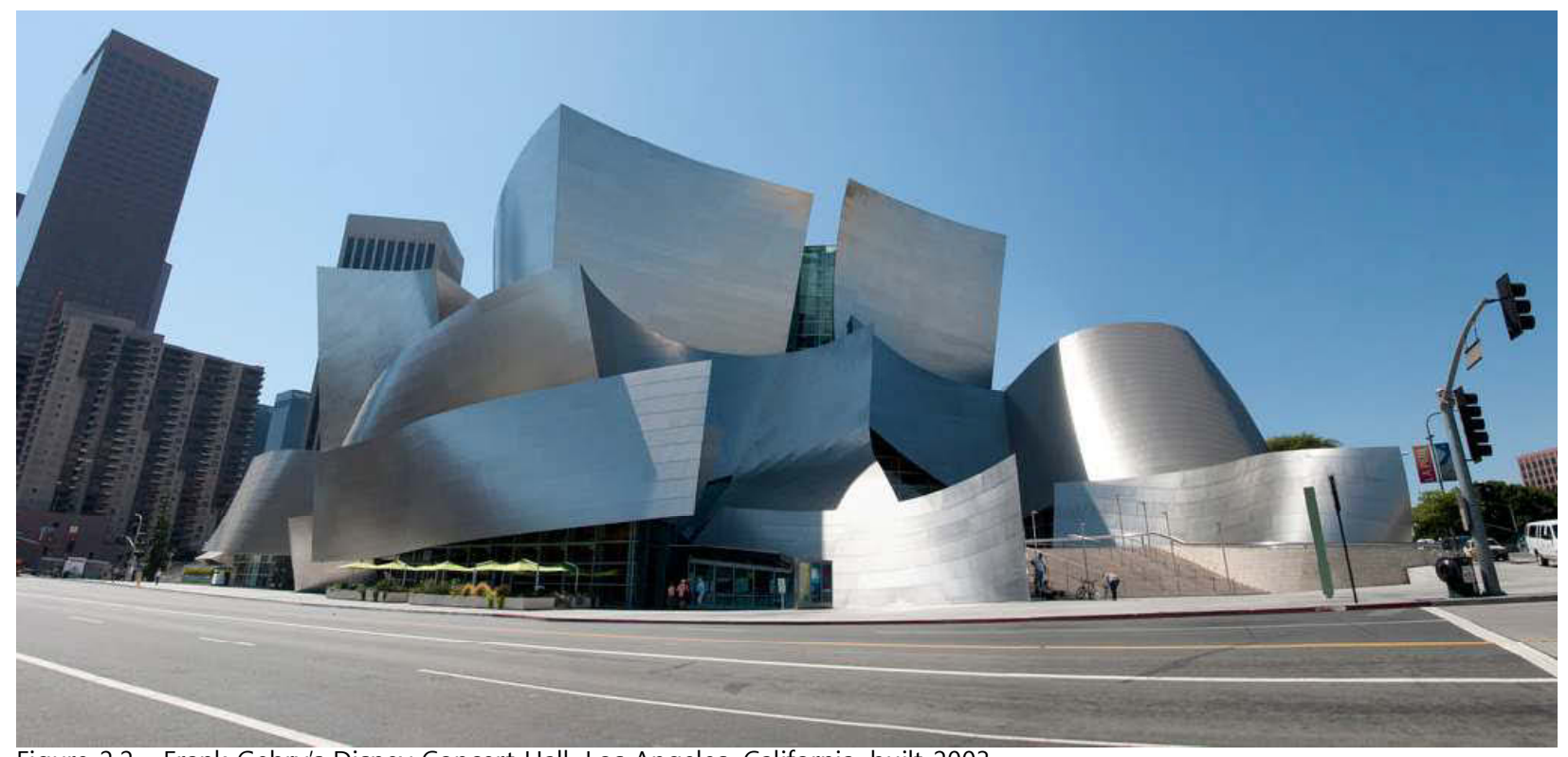

Figure 2.2 - Frank Gehry's Disney Concert Hall, Los Angeles, California, built 2003.

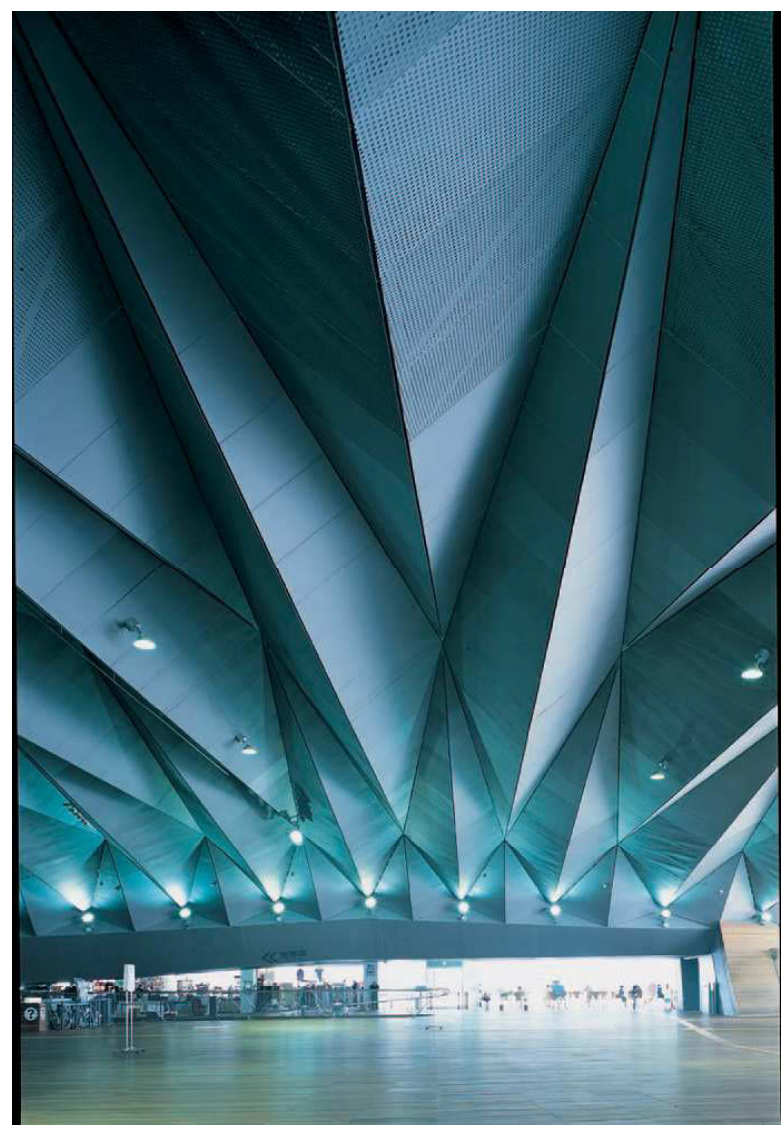

Figure 2.3 - Folded ceiling of the Yokohama International Passenger Terminal, Foreign Office Architects, built 1995.

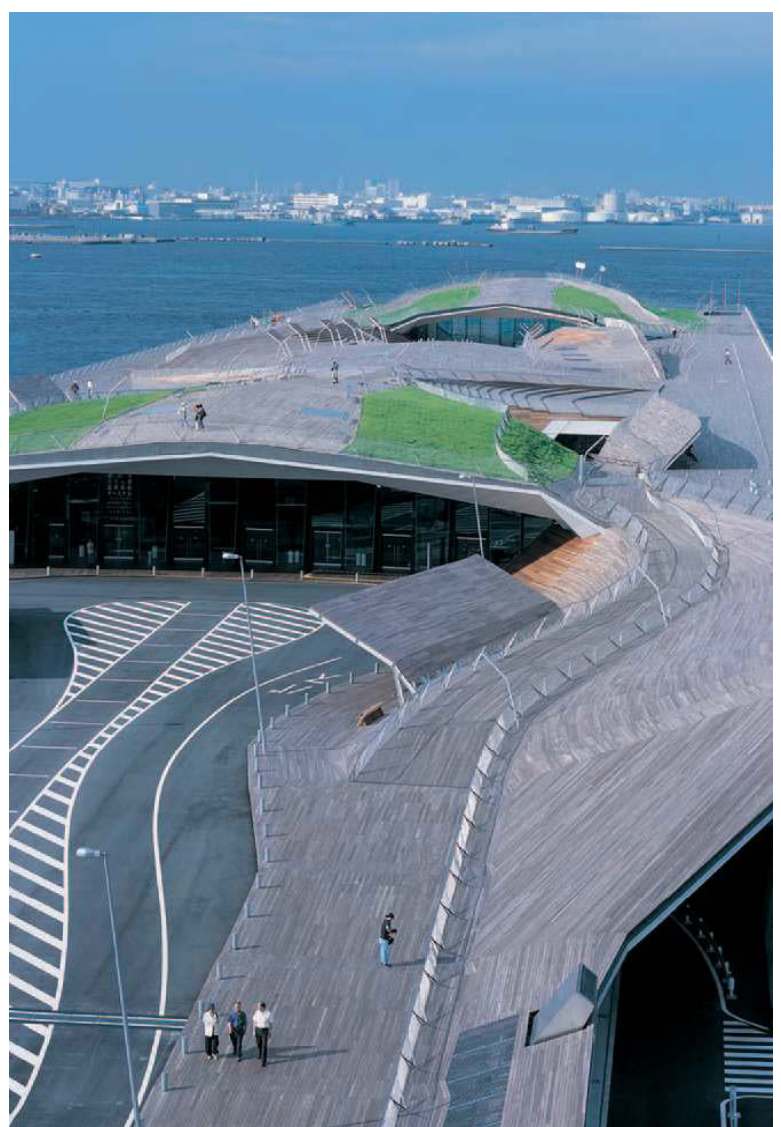

Figure 2.4 - Subtle folding landscape of the Yokohama International Passenger Terminal, Foreign Office Architects, built 1995. 
To express these ideas as structures, three separate projects were developed with the intention to show that these ideas are not singular and can be adapted to various scenarios. The three structures are sited in and around downtown Ottawa. In the interest of being able to provide a detailed analysis of the folding involved, he final structure is more thoroughly developed. While all three projects demonstrate the type of folding involved in this thesis, this one best exemplifies the intentions of this thesis.

In the process of researching for this thesis I became aware of a collection of texts titled Folding in Architecture compiled originally in 1993 by Greg Lynn. A selection of these texts referenced Gilles Deleuze who wrote about folding as an idea that is more than just a physical action. The theory put forth by Deleuze and other architects and authors who reference him (Greg Lynn, Peter Eisenman, John Rajchman) provided an interesting juxtaposition to the type of folding that I pursued in this project. Their views provided a background of folding in architecture from which I could develop a more utilitarian folding architecture.

Gilles Deleuze, wrote about the fold and folding in The Fold - Leibniz and the Baroque. For Deleuze, folding and unfolding were beyond the physical sense that is to compress and expand. Rather than solely a practical action, the fold acts as a representation for further meaning. The fold is attributable to "envelopingdeveloping, involution-evolution" where the object being folded is one in its own. Organisms, Deleuze writes as an example, are able to fold and unfold their own parts, "Thus an organism is enveloped by organisms one within another (interlocking of germinal matter), like Russian dolls. The first fly contains the seeds of all flies to come, each being called in its turn to unfold its own parts at the right 
time. And when an organism dies, it does not really vanish, but folds in upon itself, abruptly into the again newly dormant seed by skipping all intermediate stages. The simplest way of stating the point is by saying that to unfold is to increase, to grow; whereas to fold is to diminish, to reduce, to 'withdraw into the recesses of a world." 10 In more words Deleuze figures that a folded object is compressed and stored while an unfolded object is the active object, one that can be used. While this observation is often true, it is not all encompassing. An object that folds and unfolds can be useful in both or multiple states. Greg Lynn, however, would argue that it is the action and continued sequence of folding that provides an approach to architectural design. ${ }^{11}$

Lynn's compilation of texts Folding in Architecturereferenced Deleuze and his concept of folding. Lynn notes that although theories about folding in architecture were published at nearly the same time that they were ultimately overtaken by digital modelling, the theories did not derive from the use of computers. The theories are about "compositional, organizational, visual and material sensibilities", and not about the advent of digital modelling and the possibilities it brought forth. ${ }^{12}$ Although Lynn's thoughts on folding serve as a point of interest, Lynn's contributions to folding via digital algorithms do not align with the views of this thesis. The digital models that Lynn creates grow, shrink, rotate, stretch, and fold over or into themselves. These movements, when seen in motion are complex and can look chaotic, the likes of which would not occur without digital intervention. ${ }^{13}$ This thesis is not showcasing the potentially infinite complexities of

\footnotetext{
10 Gilles Deleuze, The Fold - Leibniz and the Baroque, trans. Tom Conley, (Minneapolis, University of Minnesota Press, 1993), 8-9.

11 Greg Lynn, "Architectural Curvilinearity: The Folded, the Pliant and the Supple," in Folding in Architecture, ed. Greg Lynn (Academy Press, 2004), 27.

12 Greg Lynn, "Introduction", in Folding in Architecture, ed. Greg Lynn (Academy Press, 2004), 10-11.

13 Greg Lynn, Animate Form, (New York, Princeton Architectural Press, 1999), video disc.
} 
how structures can fold through the use of digital algorithms; rather, it explores the opportunities presented through the use of folding-unfolding as a utility for a dynamic architecture.

Lynn's own design process often involved making his digital models animate as a method of creating a heterogeneous architecture that, influenced by deconstruction, is supple and fluid. The animation of these models displays the evolution of his forms and the ways in which they came to their final form, they are not just moving because they can. ${ }^{14}$ His architecture attempted to be what he refers to as stable rather than static to develop a relationship with the urban context. ${ }^{15}$ The folding and bending of animate models intended to show motion and force occurring at the same moment as the formal conception. These models are achieved through rigourous mathematics involving geometries and calculus with the computer acting as the tool for visualization. ${ }^{16}$ The final forms of Lynn's animate models, though, did not move. The beauty and dynamism of the forms exists more in the animate stages rather than the frozen form at the end of the sequence. The folding, twisting, expanding, contracting, or sliding etc. of the computerized form can be mesmerizing and engaging, but, once it stops the fascination is lost. No longer is the physical form pliant or supple, but hard, and a result of the precuring actions because it does not return to any of those previous moments nor does it fold further into a new form. The designed structures of this thesis celebrate the fold by retaining the potential for the fold to act, allowing the structure to hold multiple forms. The various forms can be activated as needed in response to the surrounding environments.

\footnotetext{
$14 \quad$ Lynn, Animate Form, 9.

15 Michael Speaks, "It's Out There...The Formal Limits of the American Avant Garde," in Architectural Design Profile no 133, Hypersurface Architecture. (1998).

$16 \quad$ Lynn, Animate Form, 9.
} 


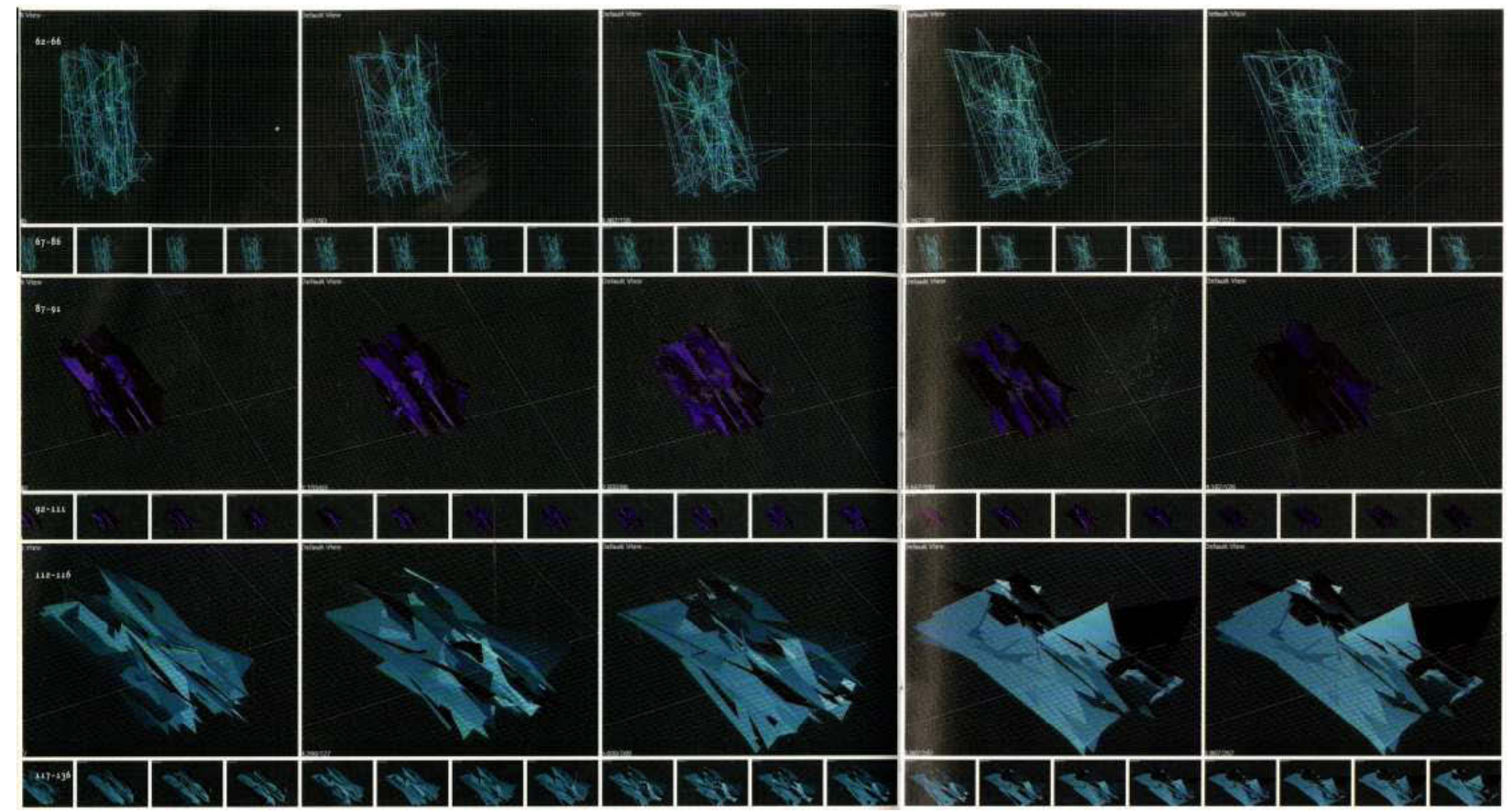

Figure 2.5 - Animate model sequence of a prototype for a house in Long Island by Greg Lynn in 1994

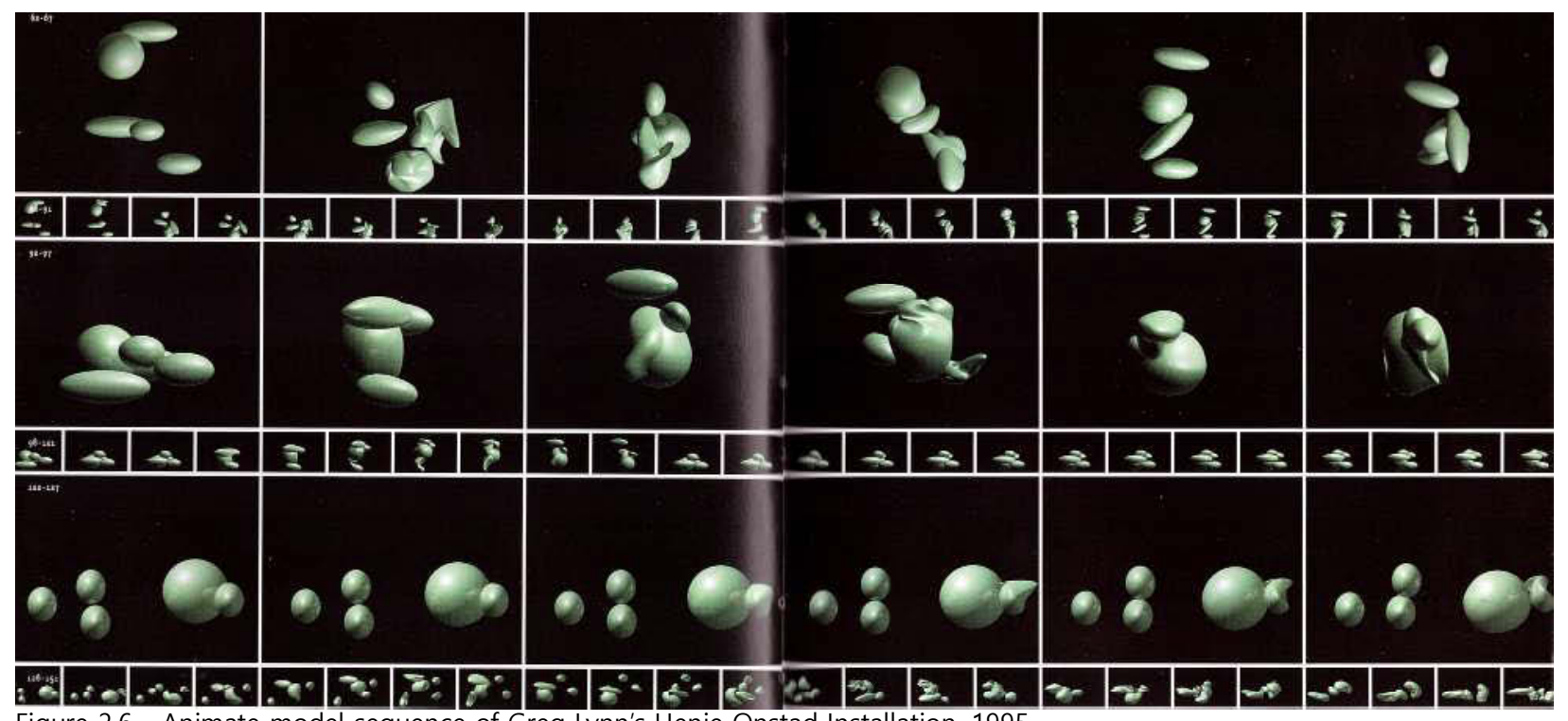

Figure 2.6 - Animate model sequence of Greg Lynn's Henie Onstad Installation, 1995. 
Folding acts as a response to a previous action or a need, as can be taken from Deleuze's work, that each fold could lead to the next. ${ }^{17}$ We have to then ask, however, what necessitates a response? Lynn would argue that the dynamism of the urban context should be a catalyst for architecture to focus on its exteriority. This position is critiqued by Michael Speaks in his 1998 essay It's Out There... where he compares the viewpoints of both Lynn and Peter Eisenman (Eisenman being Lynn's former employer and mentor). While Lynn's thoughts about a dynamic urban context are understandable, his approach to responding to the dynamism still produce an unmoving form, forms that contradict some previous statements in which he said architecture must move. ${ }^{18}$ When Lynn says architecture must move, he does not believe that a literal building must move, but rather a building should be defined by the forces of a dynamic site instead of static forms. ${ }^{19}$ What forms, though, could be produced if the architecture did literally move?

Eisenman on the other hand to Lynn is concerned with a dislocative architecture that is focused on its interiority. Interiority, to Eisenman, is a metaphysic of architecture that is related to the functionalist human, while the exteriority deals with politics and philosophy, something with which architecture should never concern itself. ${ }^{20}$ What is critical from this critique in relation to the structures of this thesis is that as per Lynn, the structures are working with a dynamic urban context, however, their movement does not stop after the design process, the movement is ingrained in their interiority. The focus is on the form and how that form can serve a human as a function of a public infrastructure. In its exteriority the structures act as promotional tools, an

\footnotetext{
17 Deleuze, The Fold - Leibniz and the Baroque, 10.

18 Michael Speaks, "It's Out There... The Formal Limits of the American Avant Garde," in Architectural Design Profile no 133, Hypersurface Architecture, (1998), 26-31.

19 Cynthia Davidson, Anywise, (Cambridge: MIT Press, 1996), 97.

20 Speaks, "It's Out There... The Formal Limits of the American Avant Garde," 26-31.
} 
asset with which a community can display its progression and dedication to the development of its public realm. The response then is two-fold, serving as a function that responds to necessity and acting as a symbol for a greater community.

For Eisenman, folding is a process rather than a product and the product at the end of a folding process is merely a representation of change or motion, because, as Mario Carpo writes in reference to this sentiment about Eisenman, "buildings don't move". ${ }^{21}$ The difference between the buildings referenced by Lynn, Eisenman, and Carpo and the structures of this thesis is in the definition. Buildings by definition involve roofs supported by walls, often enclosed and in a typical building construction, filled with services and sealed off from the exterior. The responsive folding structures developed here are more open-ended, designed to create forms that provide a sense of space, but are still exterior. The task is not to reinvent buildings as we know them, but rather, create structures that can take advantage of the opportunities presented by folding. This would be a kinetic architecture, driven by the ability to fold and unfold that is responsive to the pressures that surround it. ${ }^{22}$

Between Deleuze, Lynn, and Eisenman are differing arguments for what folding is or could be when applied to architecture. These viewpoints tend to fall within a conceptual spectrum and are not as concerned with the physical folding of a built object or structure. The folding that is explored in the designed structures of this thesis maintain the folds used to conceptualize and design a structure through to its built form to utilize them as a way of providing a dynamic, responsive architecture.

$21 \quad$ Mario Carpo, "Ten Years of Folding," in Folding in Architecture, ed. Greg Lynn, (Academy Press, 2004), 15; Peter Eisenman, "Alteka Office Building," in Folding in Architecture, ed. Greg Lynn, (Wiley Academy, 1993), 28.

22 William Zuk and Roger H. Clark, Kinetic Architecture, (New York: Van Nostrand Reinhold Company, 1970), 8-9. 
Folding as Utility, and Responsiveness 
In its most simple form, folding as it occurs in a sheet of paper, draws distant points on a two-dimensional plane nearer to each other by engaging the third dimension. ${ }^{23}$ It is this element of folding that provides compression; a reduction in planar area as a trade off for an increase in volume. Folding, in the physical sense, can also be associated with a multitude of other 'movement' words. Bend, crease, layer, crumple, expand, collapse, extend, open, close, roll, wrinkle, wrap, ply can all be different forms of folding. These actions correspond with both ourselves and the objects we interact with daily. As indexed in Figures 3.1 and 3.2, many objects that we use or interact with articulate a number of folding techniques. Often it is the folding that correlates to the storage of the object while it is the unfolded state that allows for its intended use. Many computers today are in the form of 'notebooks' borrowing from the traditional form of a paper book that are folded closed when not in use and unfolded for operation. Sometimes this relationship is reversed and sometimes folding is the actual method of use. The knots used to tie laces or rope in general is a series of folds pulled tight. The human body and the bodies of all living things are filled with joints that can act as a method of utility or as form generation. Like a living thing, the designed folding structures use the action of folding allowed by implemented joints to alter its usability. This comes as a change in form of the collection parts that is the structure. The structures possess multiple potential forms which provides multiple potential methods of use.

23 Hélène Frichot, "Deleuze and the Story of the Superfold", in Deleuze and Architecture, ed. Hélène Frichot and Stephen Loo (Edinburgh University Press, 2013), 81. 


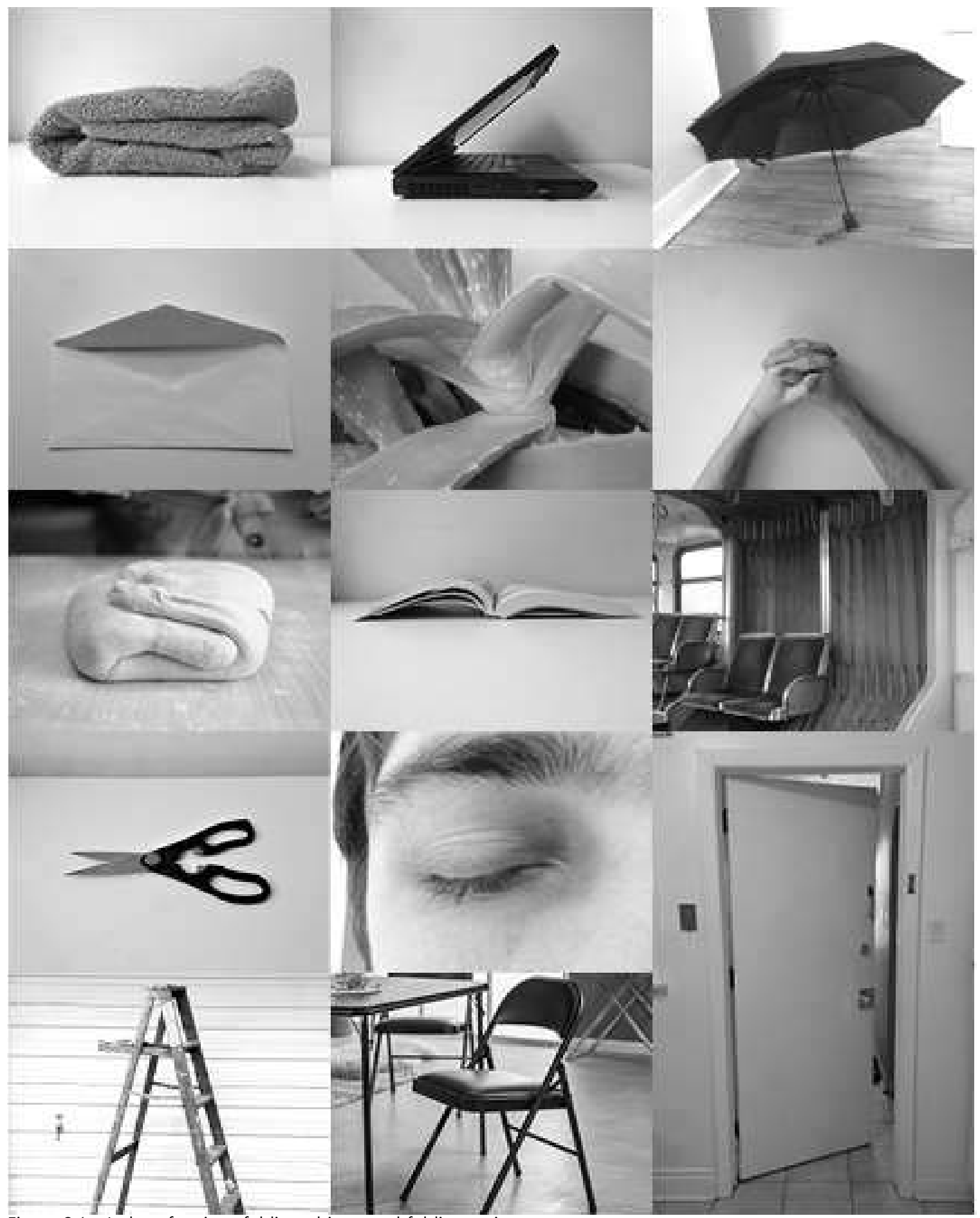

Figure 3.1 - Index of various folding objects and folding actions 


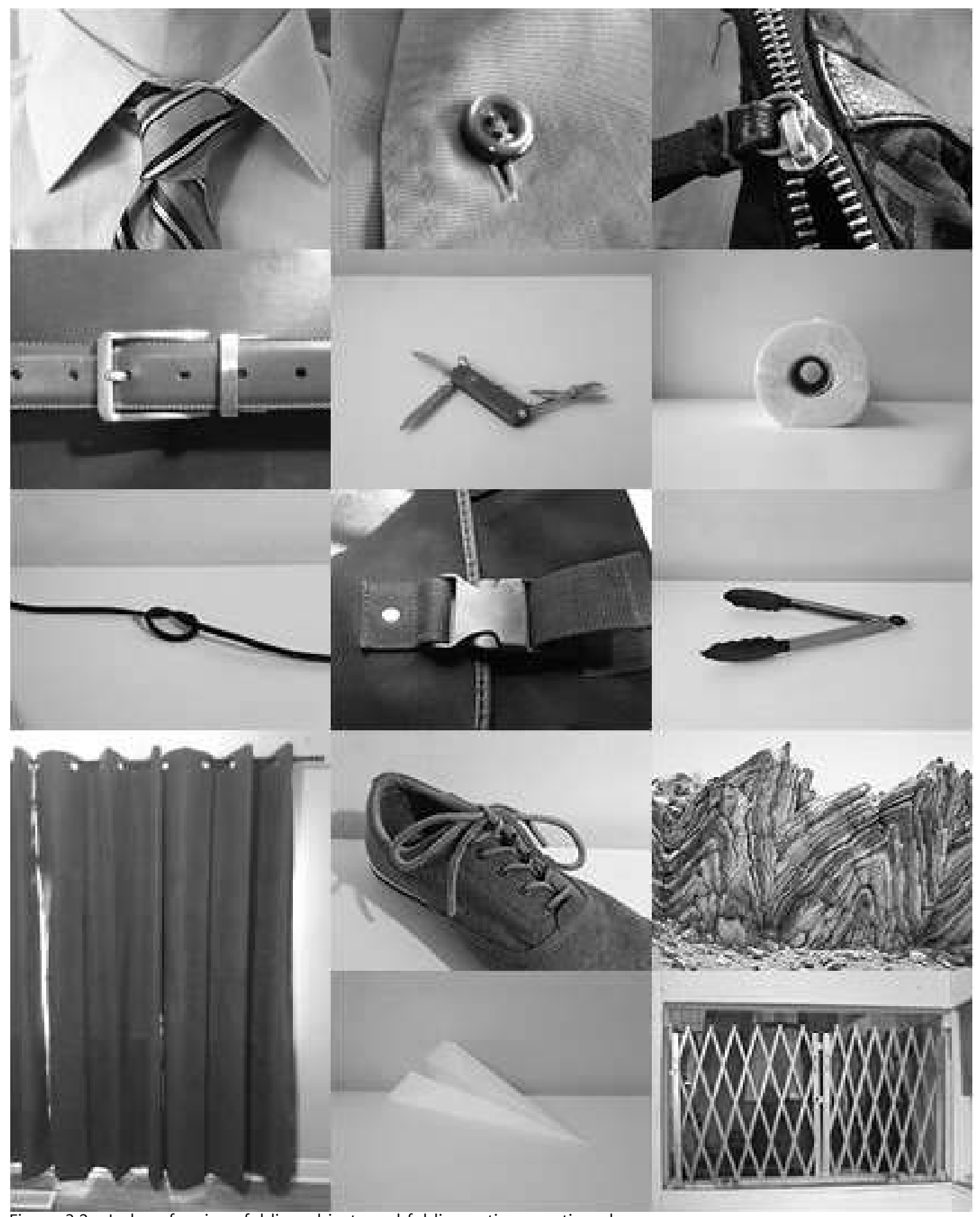

Figure 3.2 - Index of various folding objects and folding actions continued 
Folding and unfolding structures would ultimately be structures of a temporary nature. Where temporary structures are typically deconstructable and removable, like tents or some pavilions, the intention of the designed folding structures of this thesis is to provide temporary forms as functions of permanent structures. These are built-in-place, bespoke, structures that fold or unfold as necessary to provide its best suited form for the current situation. One structure or space must change its state from active to inactive as a result of the structure responding to a given change. This temporality, combined with responsiveness, gives purpose to the fold and is ingrained in its function. Peter Eisenman likens this to René Thom's catastrophe theory by stating that while a single grain of sand can trigger a landslide, all the determining factors were already in place before the movement of that one grain. ${ }^{24}$ Without temporality, it would be permanent and have no motion, making the fold unnecessary. If it is not responding to another factor, there is no reason to move, again making the fold unnecessary. Working with temporality provides options in the designed structures or spaces; the architecture does not need to be a 'one stop shop' that accommodates all the surrounding pressures and characteristics of a site. This allows for the structures to break away from what might be considered typical architecture. The structures have an opportunity to influence activity around them in more than a static manner, the use of the structures can change as the needs of the citizens change. ${ }^{25}$ The needs of the user are ultimately the more concerning factor to be considered. It seems that recently the objects used to fulfill one's desires seem less important than the fact that the desire is satisfied. The object (or structure in this case) is merely a means to an end, the temporary experience reigns above as the

24 Peter Eisenman, "Unfolding Events, Frankfurt Rebstockpark and the Possibility of a New Urbanism," in Written into the Void, ed. Peter Eisenman, (London, Yale University Press, 2007), 17.

25 Mariana Pestana, "Building Alternative Possible Worlds," in This is Temporary, How Transient Projects are Redefining Architecture, ed. Cate St.Hill (Newcastle, RIBA Publishing, 2016), 142. 
ultimate desire. ${ }^{26}$ This puts responsive folding architecture into a position in which its function is ultimately more important than its form. The fold can move beyond its physical application and work with the existing dynamic urban environment to introduce new social practices. ${ }^{27}$ In the form of a temporary structure, it would act as an advertisement, (as temporary structures have for centuries), with an agenda that is political in nature rather than commercial. ${ }^{28}$

Temporality goes hand in hand with responsiveness. Responses to an action or necessity are often a temporary matter. In the same manner, the things we fold, we fold for what is likely a temporary time frame (unfold for active use, fold for inactive storage). The responsiveness ingrained in the structure is a function of its foldability. Factors that can demand a response are dependent on the type of structure and its location. What takes place around or is planned for each individual structure determines its transformation between designed forms. The projects designed for this thesis have unique factors to which they respond. There do exist projects in which folding and responsive structures have used embedded characteristics of a material to manage their method of folding. An example of materiality embedded folding is the FAZ Summer Pavilion by Achim Menges in Frankfurt in 2010. Its exterior skin is a series of thin wood veneer scales that take advantage of inherent material properties of wood to curl and uncurl with changes in ambient humidity. ${ }^{29}$ When the wood curls up it makes the pavilion porous and open to the breeze. Likewise, when it folds down, the pavilion becomes a hard shell. The change involved in this pavilion is not a change in function, but a change in the quality of space.

\footnotetext{
26 Eisenman, "Unfolding Events, Frankfurt Rebstockpark and the Possibility of a New Urbanism," 13.

27 Eisenman, "Unfolding Events, Frankfurt Rebstockpark and the Possibility of a New Urbanism," 17.

28 Barbara Chabrowe, "On the Significance of Temporary Architecture," in The Burlington Magazine Vol 116, No. 856, (July 1974): 384-388+391. http://www.jstor.org/stable/877732.

29 "FAZ Summer Pavilion," Achim Menges, accessed March 21, 2018, http://www.achimmenges.net/?p=4967
} 


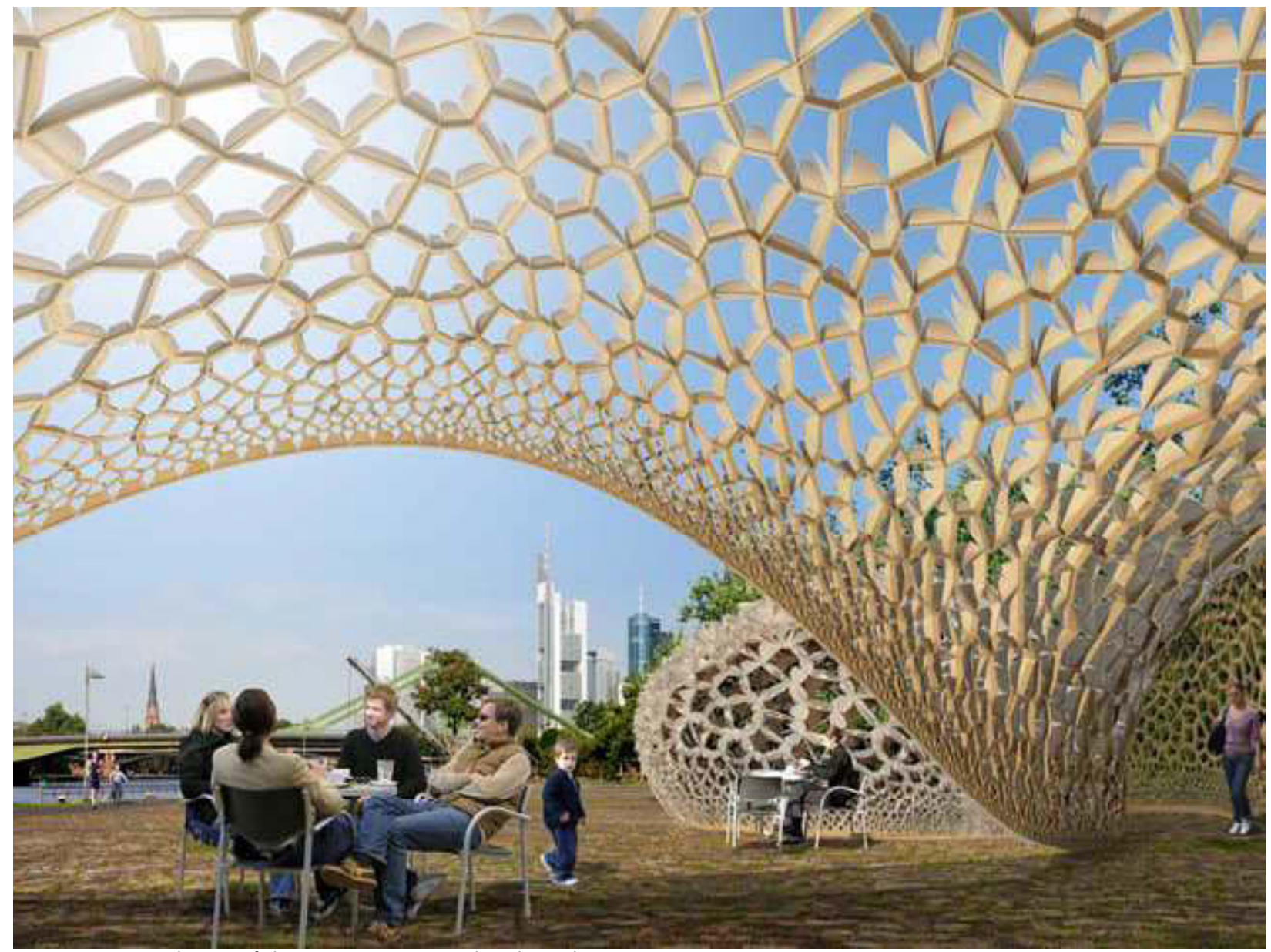

Figure 3.3 - Rendering of the FAZ Summer Pavilion by Achim Menges

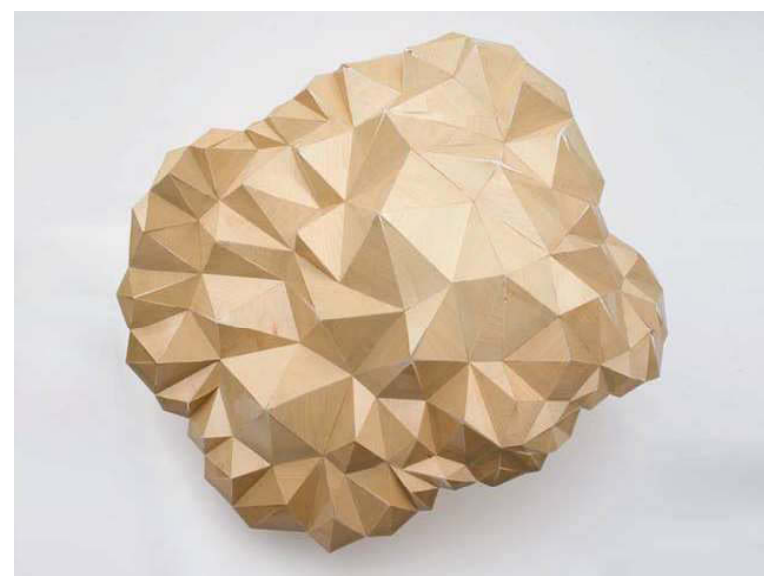

Figure 3.4 - Closed state of the responsive surface structure in the FAZ Pavilion

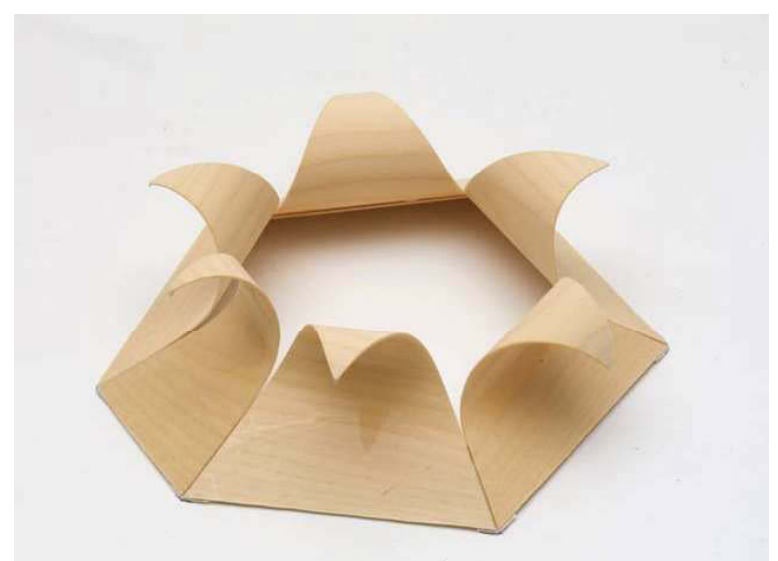

Figure 3.5 - Open state of the responsive surface structure in the FAZ Pavilion 
The structures designed in this thesis seek a change in the form of the space concomitant with a change in function and/or environment. This is the ability to fold and unfold into various states of space, whether that be a change of season or time of day, a necessity in the case of an event, or an overall change in the common use of a space. For these reasons the focus is on spaces that do not have a strictly defined program, spaces that can host a number of varying activities that are temporary in nature. The scale of the folds required for these structures to host multiple programs and the time frame in which the fold must be accomplished do not allow for embedded material characteristics to perform the required task. The folds, then, are performed by mechanical joints not unlike those created by Chuck Hoberman in his collection of moving and folding objects, and installations. At a smaller scale the materials that fold are able to support themselves as they move and change shape. The joints do not require as much freedom. At a larger scale these characteristics require additional support to maintain the same dynamic. ${ }^{30}$ To change the form of a space a structure must have components large enough to create multiple forms of useable space, and at this scale components are not easily created out of a single material that can take advantage of its properties.

Hoberman's work is a strong inspiration for the way in which this thesis approaches folding. The use of mechanical joints and rigid materials are an aspect that this thesis shares with his work. Connections that are built into the structures that have predetermined paths of travel. Rather than a structure being moved by outside forces, the forces are part of the structure as one

30 Tom Waters, "The Unfolding World of Chuck Hoberman," in Discover Magazine, March 1, 1992, http://discovermagazine.com/1992/mar/theunfoldingworl6 
big machine. ${ }^{31}$ An idea that Deleuze would see as inferior to an organism. ${ }^{32}$ Where they differ is in the interaction of the structures with the viewers/users. Although accomplished by very different means, many of Hoberman's projects, like the FAZ Pavilion, alter the quality of a space around them as well but are viewed from afar as an installation art piece. The folded structures designed here are intended to be walked on, sat upon, or generally used by passers by or engaged citizens. This puts an emphasis on the durability of the materials and the joints in them. To stand up to both weather elements and wear and tear in a public setting takes careful consideration of the materials used and the environments around them. To be considered a utility, the object must work, reliably and consistently. The fold provides multiple opportunities for use and acts as the utility to transform the space from one use to the next.

$31 \quad$ Waters, "The Unfolding World of Chuck Hoberman."

32 Deleuze, The Fold - Leibniz and the Baroque, 8. 


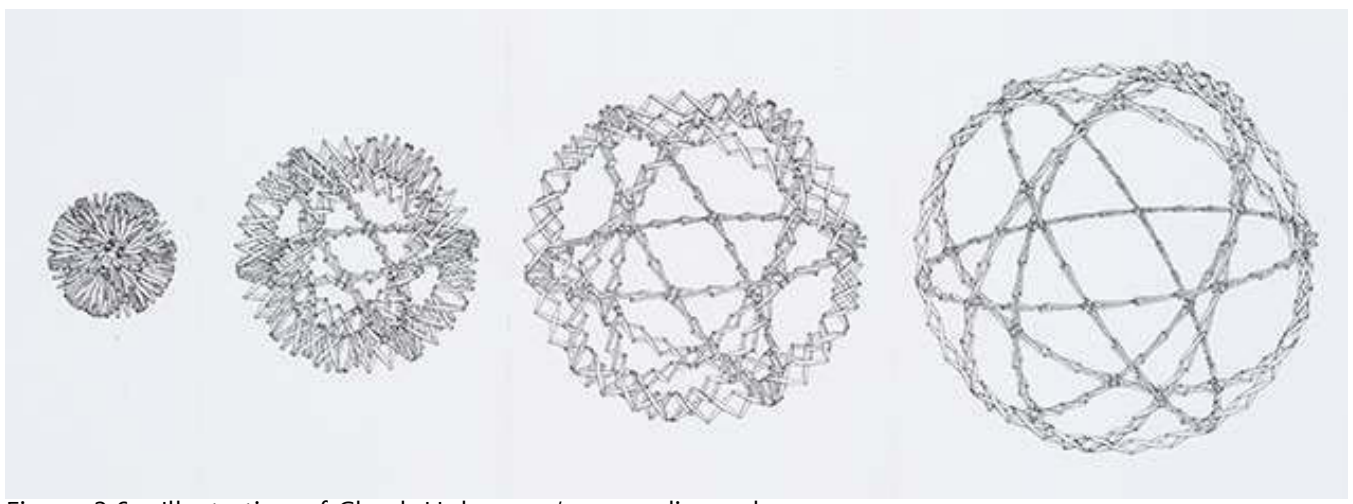

Figure 3.6 - Illustration of Chuck Hoberman's expanding sphere

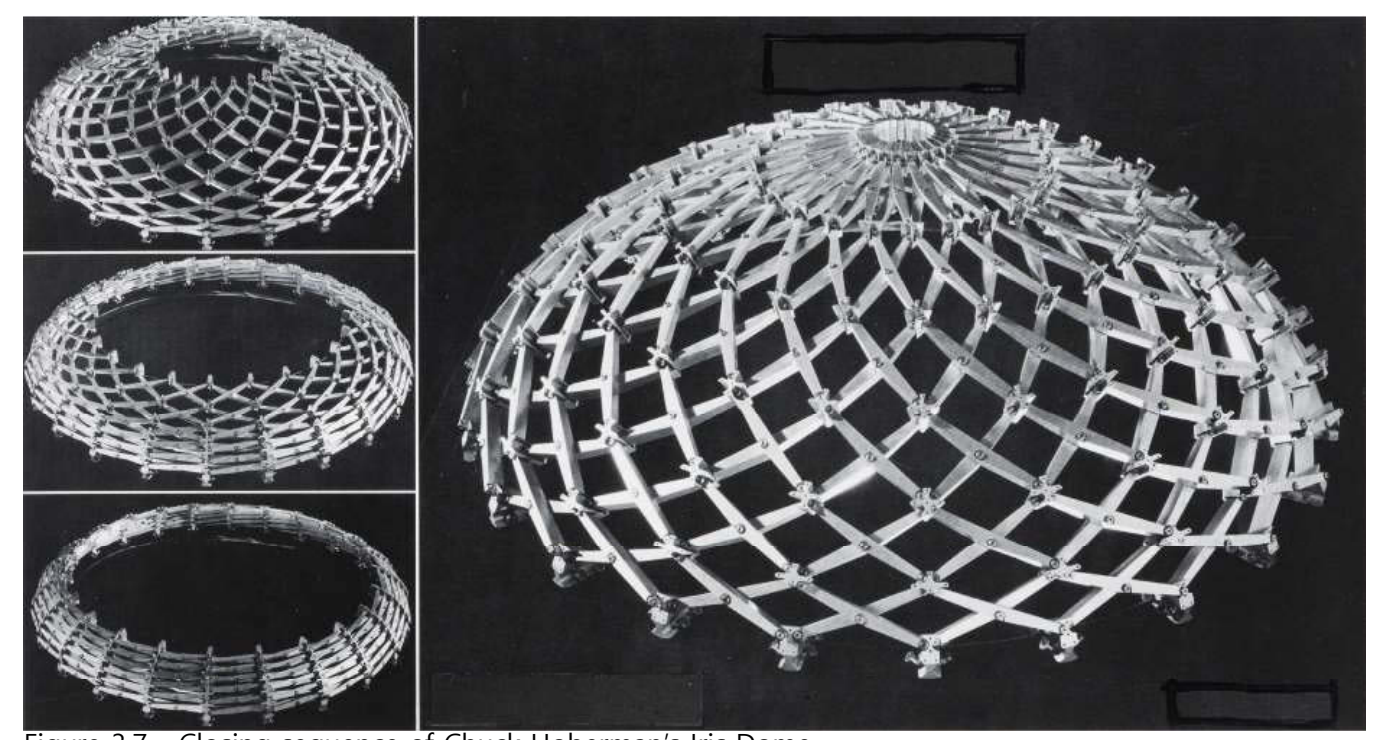

Figure 3.7 - Closing sequence of Chuck Hoberman's Iris Dome
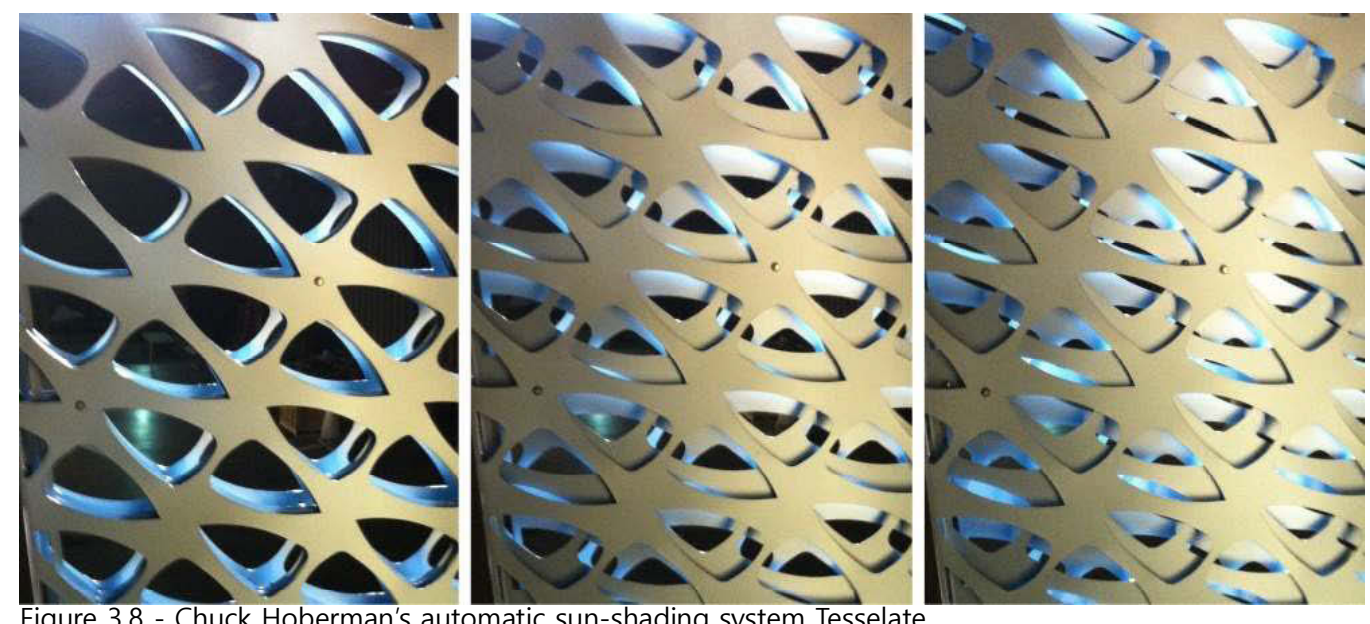

Figure 3.8 - Chuck Hoberman's automatic sun-shading system Tesselate 


\section{Public Space: Ottawa}


This thesis is sited in Ottawa, Canada, along the Rideau Canal, in Confederation Park, and at Aberdeen Square. This is to position it in the public realm to capture and work with its heterogenic nature. The designed structures in this thesis act as prototypes for a larger array of potential folding structures. The intention is that these structures can be designed and implemented in any cities' public spaces. Ottawa in this case served as a convenient choice for access and for gaining an understanding of the current activities in the chosen sites.

One year in Ottawa sees a range of temperatures from potentially $-30^{\circ} \mathrm{C}$ in the winter months and up to $30^{\circ} \mathrm{C}$ in the midst of summer. Wide temperature ranges, high levels of precipitation, and inclement weather are all factors to be considered when designing for public areas. It can be difficult to design public infrastructure that remains beneficial throughout the seasons. While Ottawa typically embraces the winter weather it often involves the implementation of additional infrastructure that is added before each winter season and removed in spring. The installation of all the temporary pieces takes time, money, and labour that could be saved if the infrastructure already had the ability to accommodate changing conditions.

There are a variety of ways in which people use public space and its amenities. Like the weather, some of these are predictable, however, the public realm can be spontaneous at times. The activity of individuals in a daily routine are based out of necessity, we constantly have desires that need to be met in order to maintain a balanced life. Henri Lefebvre wrote of this need in his text The Right to the City. He describes how humans go through cycles of accumulating and spending energies throughout a day via our physical senses like seeing, hearing, touching, tasting, and playing. We also, however, seek creativity, information, symbolism, and 
the imaginary. These expressions that we seek, Lefebvre writes, are moments that can break up what might become a mundane routine in a scheduled day. ${ }^{33}$ This understanding of human need was clear to Lefebvre in the 1960s and is still relevant today. People are complex beings that cannot be completely satisfied or fulfilled in a life with no excitement or adventure; we seek to be engaged and involved. ${ }^{34}$ The needs specified by Lefebvre is a multiplicity that is within and essential to our lives. John Rajchman, in Lynn's Folding in Architecture, references Deleuze in his understanding of this folding and unfolding aspect of our lives. Just as we are foldable creatures, our lives are foldable in the sense that we cannot be exactly sure what will happen next. ${ }^{35}$ What will entangle us? What energies will be accumulated and spent?

Ottawa has long had a moniker as "the town that fun forgot". Originally coined by MacLean's columnist Allan Fotheringham in the early 1970's, the nickname has lived on, even though Ottawa has and is changing. ${ }^{36}$ There is no shortage of events that take place within Ottawa, although, you may have to do a quick search to find them. Since the city is the governmental hub of Canada it can also be known as a government town. A place that is boring, but stable. These given descriptions tend to overshadow what is available in the city, the fun is not waved in front of your face, it requires a little looking. ${ }^{37}$ Despite this, Ottawa is growing in popularity, and advancing its infrastructure, notably in the construction of a new light rail

\footnotetext{
33 Henri Lefebvre, "The Right to the City" in Writings on Cities, ed. Eleonore Kofman and Elizabeth Lebas, (Blackwell Publishers, 1996), 147.

34 Galen V. Bodenhausen, "Consumerism and its Antisocial Effects can be Turned On - or Off," Association for Psychological Science, accessed March 14, 2018, https://www.psychologicalscience.org/news/releases/ consumerism-and-its-antisocial-effects-can-be-turned-onor-off.html

35 John Rajchman, "Out of the Fold," in Folding in Architecture, ed. Greg Lynn, (Academy Press, 2004), 79

36 Graham Lanktree, "Can Boring Ottawa Shed Its Image as the Town that Fun Forgot?" Metro Ottawa, August 30, 2012, http://www.metronews.ca/news/ottawa/2012/08/30/can-boring-ottawa-shed-its-image-as-thetown-that-fun-forgot.html

37 Amen Jafri, "The City that Fun Forgot?," YouTube Video, 33:26, posted August 11, 2014, https://www. youtube.com/watch?v=CKk_kRSTaOc
} 
train line. ${ }^{38}$ Annual tourism reports and population projections suggest that Ottawa will continue to grow. ${ }^{39}$ While these are good signs that maybe Ottawa can shake its negative moniker, the installation of a folding, changing architecture could be a point that provides an opportunity to accumulate and spend the energies of which Lefebvre writes. These structures can act as notable points that express the opportunities they present to interact with the dynamism of the public realm.

In Ottawa, like in many other cities, these public spaces are in the form of parks, squares, trails, or installations. A rough average based on a map of Ottawa shows more than two public parks per square kilometer. These parks also include a variety of activities that cover sports, games, and leisure. ${ }^{40}$ This creates an opportunity for the implementation of a new dynamic structure that can play host to multiple different programs. An increase in engaging elements within public spaces provides a greater chance that the city's public spaces are successful in creating an active, inviting atmosphere.

38 "Confederation Line," O-Train, accessed March 19, 2018, http://www.ligneconfederationline.ca/

39 "Economic Development Update Tourism Edition: Visitor Profile," Department of Economic Development and Innovation, City of Ottawa, last modified Winter 2016, http://www.ottawachamber.ca/wp-content/ uploads/2017/04/1473.pdf; "Population Projections," City of Ottawa, accessed March 19, 2018, https://ottawa. ca/en/city-hall/get-know-your-city/statistics-and-economic-profile/statistics/growth-projections-2006-0/10population-projections

40 "GeoOttawa," City of Ottawa, accessed March 24, 2018, http://maps.ottawa.ca/geoottawa/ 


\section{Development Process}


This thesis developed primarily through analog techniques as both a conscious decision and a preferred method of work. By working with physical models, the physical limitations of various forms are better understood. How and why certain patterns fold in their respective ways is learned by doing it repeatedly. The computer, personally, is not a generator of ideas. It is a producer of multiples and finished products rather than a tool to develop through the creative stages of a project.

What began as an exploration of geometric forms and their respective efficiencies and inefficiencies turned into a study of the patterns in which a flat surface can be manipulated into a volume and how a volume can be compressed into a flat surface. A series of cubes modelled in card stock provided insight into the methods in which a volume could be folded down into a more compressed object. Each cube was formed with a different folding technique on its sides that allowed its top and bottom to maintain a vertical relationship while reducing the space between them. The various folding patterns yielded results in which each had advantages and disadvantages: 
Triangulated Sides

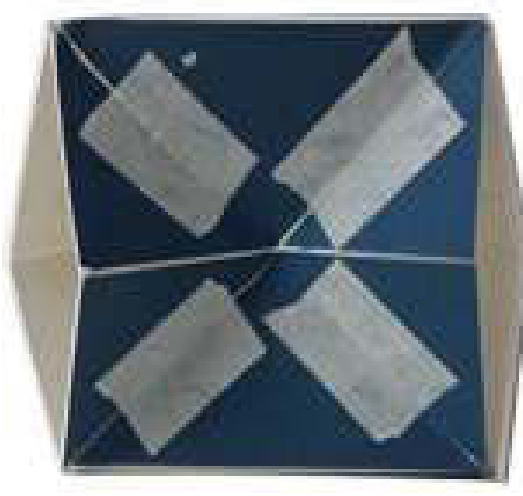

Torsional

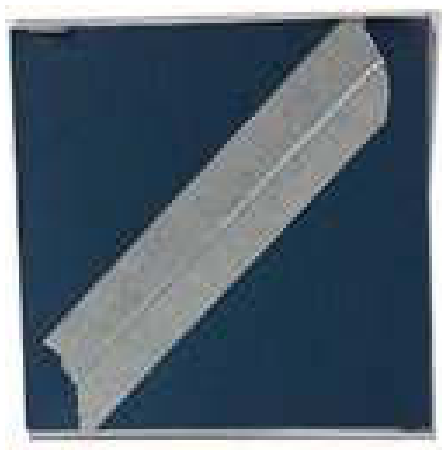

EXPANDED

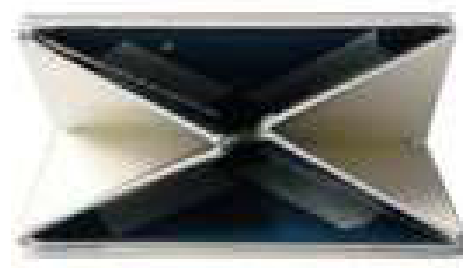

TRANSITION
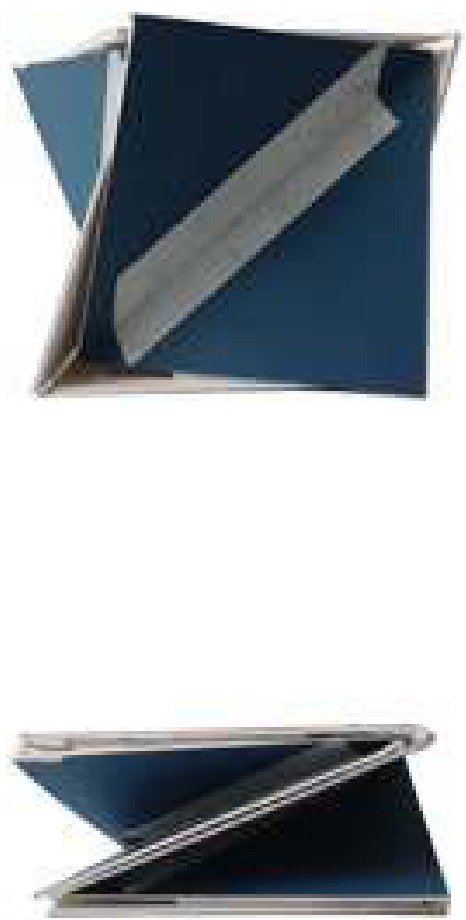

Figure 5.1 - Series of $10 \times 10 \times 10 \mathrm{~cm}$ collapsible, cardstock cube study models with tape acting as hinged joints. The cubes demonstrate methods of turning a volume into a sheet form. 
Simple Compression
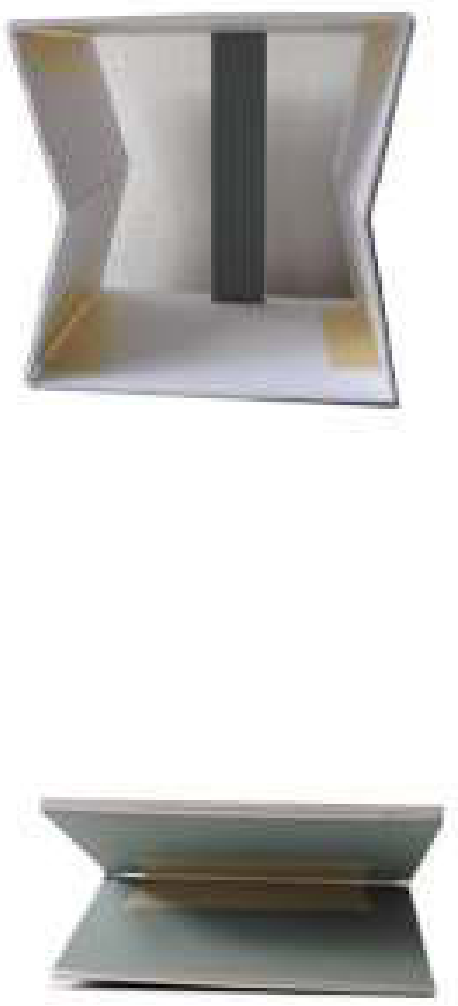

\section{TRANSITION}

EXPANDED
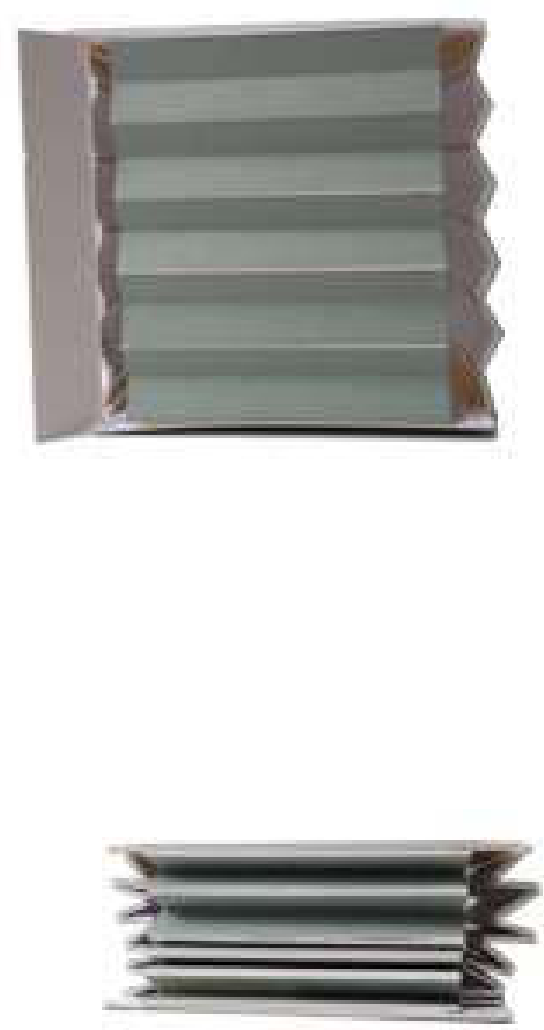

\section{COLLAPSED}

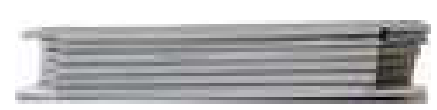

Figure 5.2 - Series of $10 \times 10 \times 10 \mathrm{~cm}$ collapsible, cardstock cube study models (continued) 
The triangulated pattern folded as intended and into a considerably compressed object, however, the interior would have to be completely empty to function properly.

The diagonal folds with rotational force would be an efficient method of energy use to compress, however, as the cube rotates, the valley folds of each side want to occupy the center of the cube causing interference and stopping the rotation.

The simple horizontal fold creates a very compact object with only four layers in a compressed state, but, only allows for two supporting sides for the fold to be completed.

The accordion style folds do not compress into as small of an object as some others, however, it does leave vacant space in the centre; it is also difficult to manage the large quantity of folds to ensure it occurs correctly.

The outcome of this exercise provided an understanding of general folding patterns. Patterns of fewer folds are more simple to control while having folds in multiple directions provided better rigidity of the whole object/structure. The question became about how the space within these volumes could be utilized, as the fold is a temporary action. There is no reason for a fold if the existing form is to be permanent. The space created by unfolding these objects into volumes is then best occupied by means of a temporary function. 
The next iteration in the folding volumes explored what mechanisms could be used as a means of creating the required movement. A scaled-up model of the cube with triangulated sides integrated working mechanisms in hinges and springs. While it did prove successful in automatically unfolding back into a cube shape there was a clear disconnect between the scale of the volume and the scale of the mechanisms. This can be clearly seen where tape had to be used in place of real hinges for the object to function without interference (Figure 5.3). Other larger scale models with mechanisms failed to materialize into functioning objects. With a working (although rough) model of a collapsible volume the next iterations began to explore different forms, methods of folding, and ideas for real world use potential.

Sketches and further models began to develop a useful form that could lead to inspiration for programmatic elements that could inhabit folding structures. Additional methods of movement and folding were explored, mainly the use of a track system for guidance in the fold. Taking guidance from the 'fold-for-storage, unfold-for-use' utility of some of the objects identified earlier, the idea became that the structures being produced could take on the characteristic of being available when it is needed, and put away when it is not. The approach to this was to have the structures become part of the ground plane where they could fold down into a more planar orientation that, when folded, is only recognizable as an outline or change of material in the ground surface. When necessity arises for a structure, or shelter, an automated series of mechanics could unfold and lift the various panels into a useable form. Initial ideas included structures such as bus or rain shelters. 

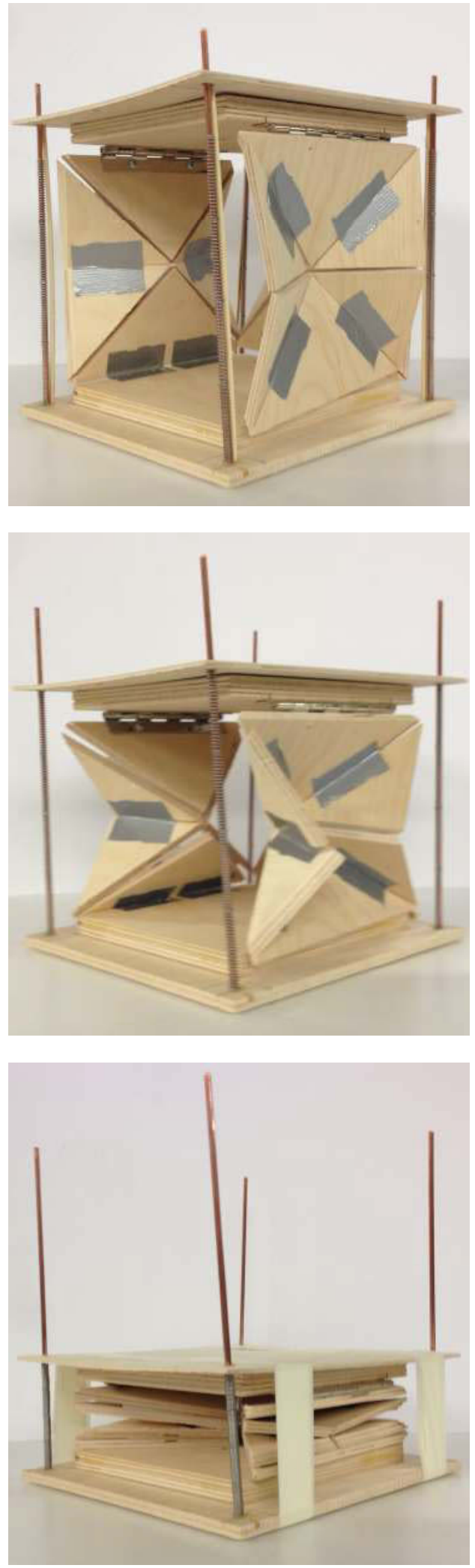

Figure 5.3 - Upscaled plywood model of the 'triangulates sides' cardstock model. Springs around the four posts allow for automatic expansion after a forced collapsing.

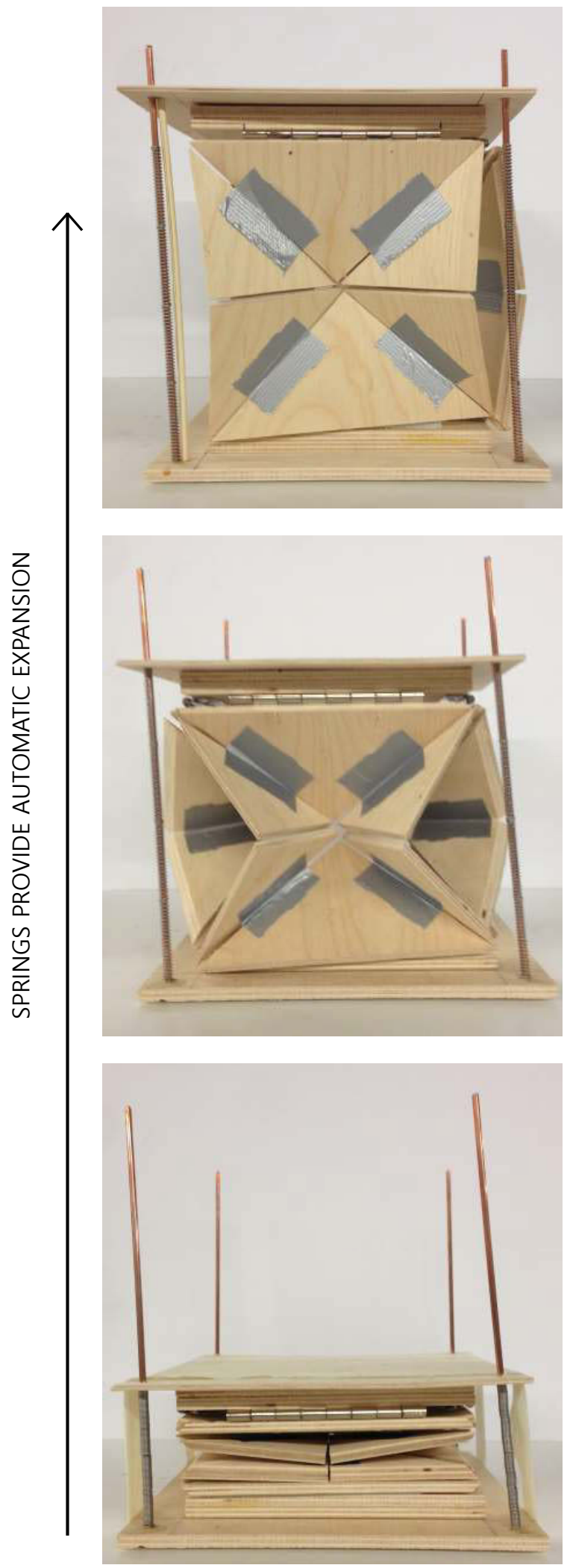




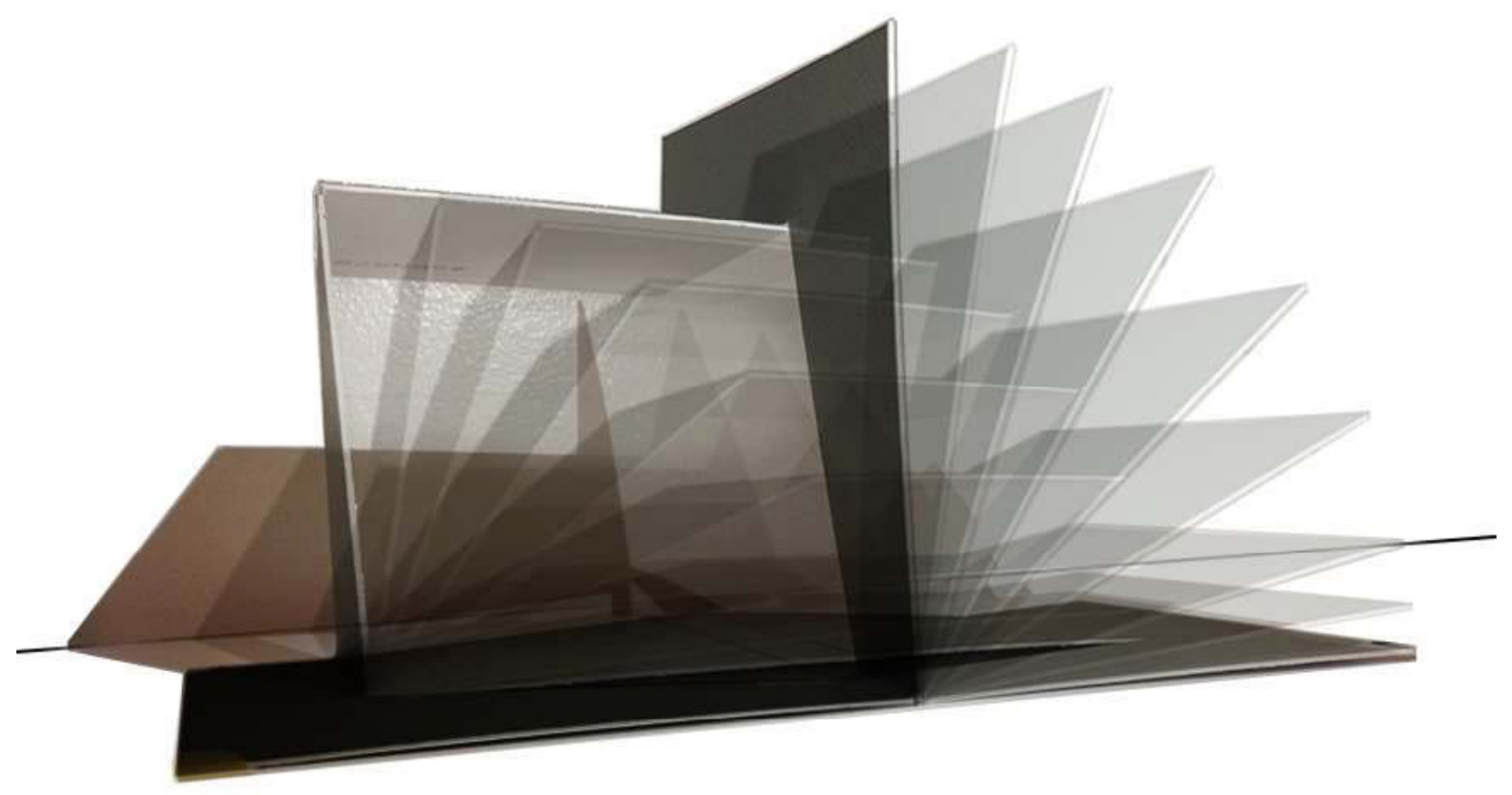

Figure 5.4 - Single sheet of cardstock cut and scored to create designed folds. As one side folds up, the cut and scored portion creates a covered space. Sequential images overlayed to indicate motion.

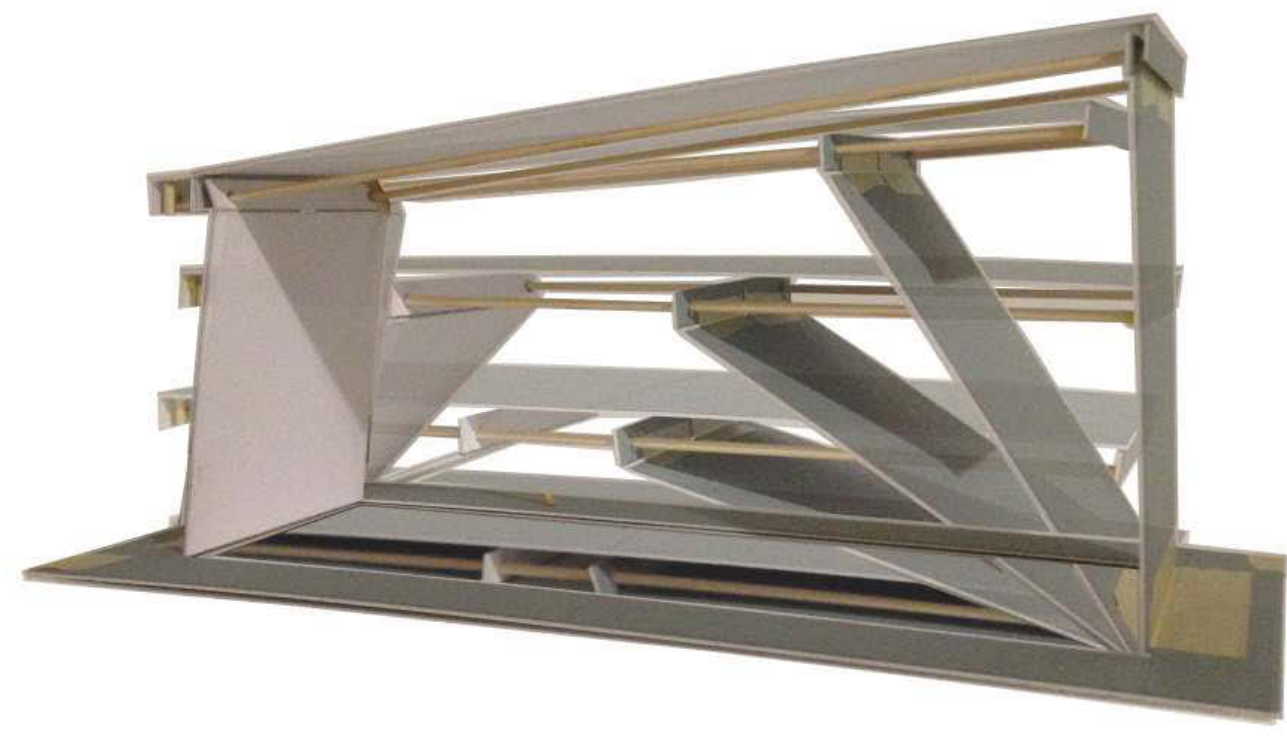

Figure 5.5 - Cardstock model of a roof connected to supporting walls on a track system. As the walls fold up from the ground their tops slide along the tracks and lift the roof vertically. Sequential images overlayed to indicate motion. 


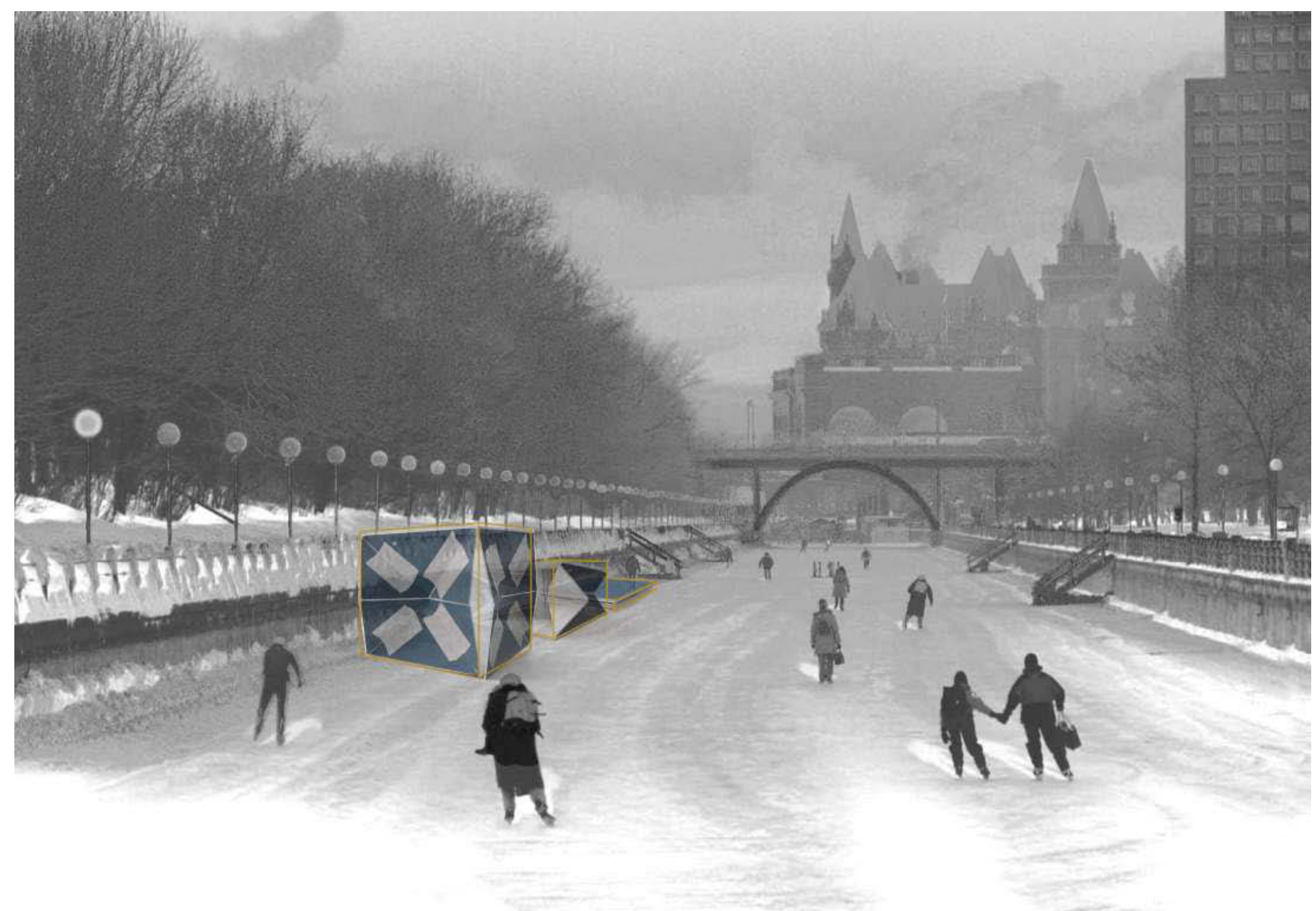

Figure 5.6 - Early concept of a removable self-deploying shelter for use in temporal environments. This idea involved a new style of shelter or canteen along Ottawa's Rideau Canal Skateway that could be collapsed for easier transportation and storage.

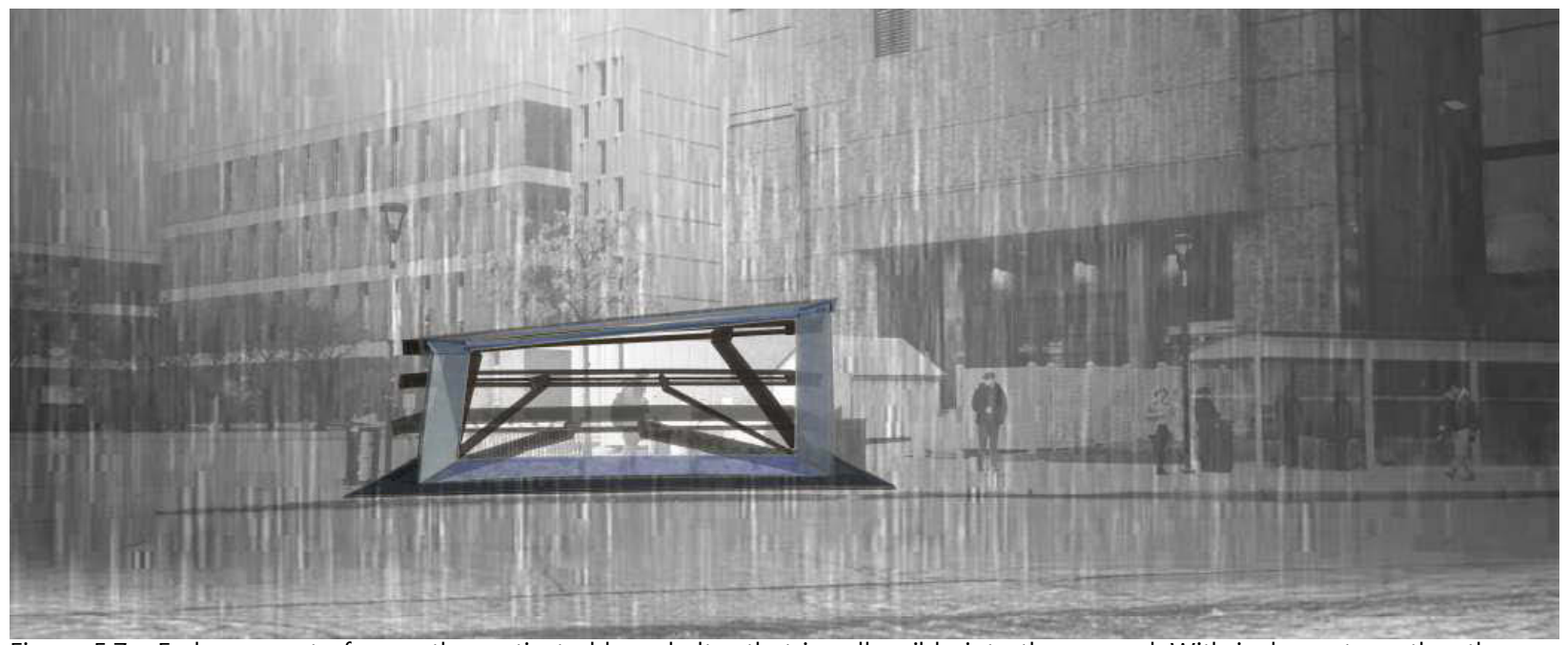

Figure 5.7 - Early concept of a weather activated bus shelter that is collapsible into the ground. With inclement weather the shelter would automatically rise from its passive state in the ground plane to provide shelter. 
This approach of folding for storage and unfolding for use was applied at a smaller scale in the form of a bench that is built into a wall as an independent study. The bench is constructed with a series of alternating wood slats that slide between one another. The bench is connected to the substructure of a wall and floor at two pivot points and when folded down acts as a continuation of the wall and floor, flush with both surfaces. When pulled up from the interior corner the bench forms the opposite 90-degree angle to that of the wall and floor creating a surface to sit on and the support to keep it in place. The piece flush with the wall swings up to form the seat and the piece flush with the floor swings up to form the support (Figure 5.8). This project provided a clearer understanding of the intricacies involved in constructing a neatly folding object. The measurements required need to be very precise and tolerances must be worked into the design. Materials are not always perfect, and minor inconsistencies in one spot could prove to be a larger problem in a different folded state.

While unfolding for use and folding for storage may offer a clean and organized approach to a folding infrastructure, the sentiment towards folding here is that it should act as a utility and provide opportunities for use. If these structures only fold to put themselves away they are not offering any opportunities of themselves in the folded position. This brought forth the challenge of finding multiple forms of use in a single structure, as opposed to an on/off-folding/unfolding response. With multiple folded or unfolded states, the structures can offer useable infrastructure for anytime of the day or year. The approach to this idea is to have a more interactive default state, rather than the previous hidden away state. 

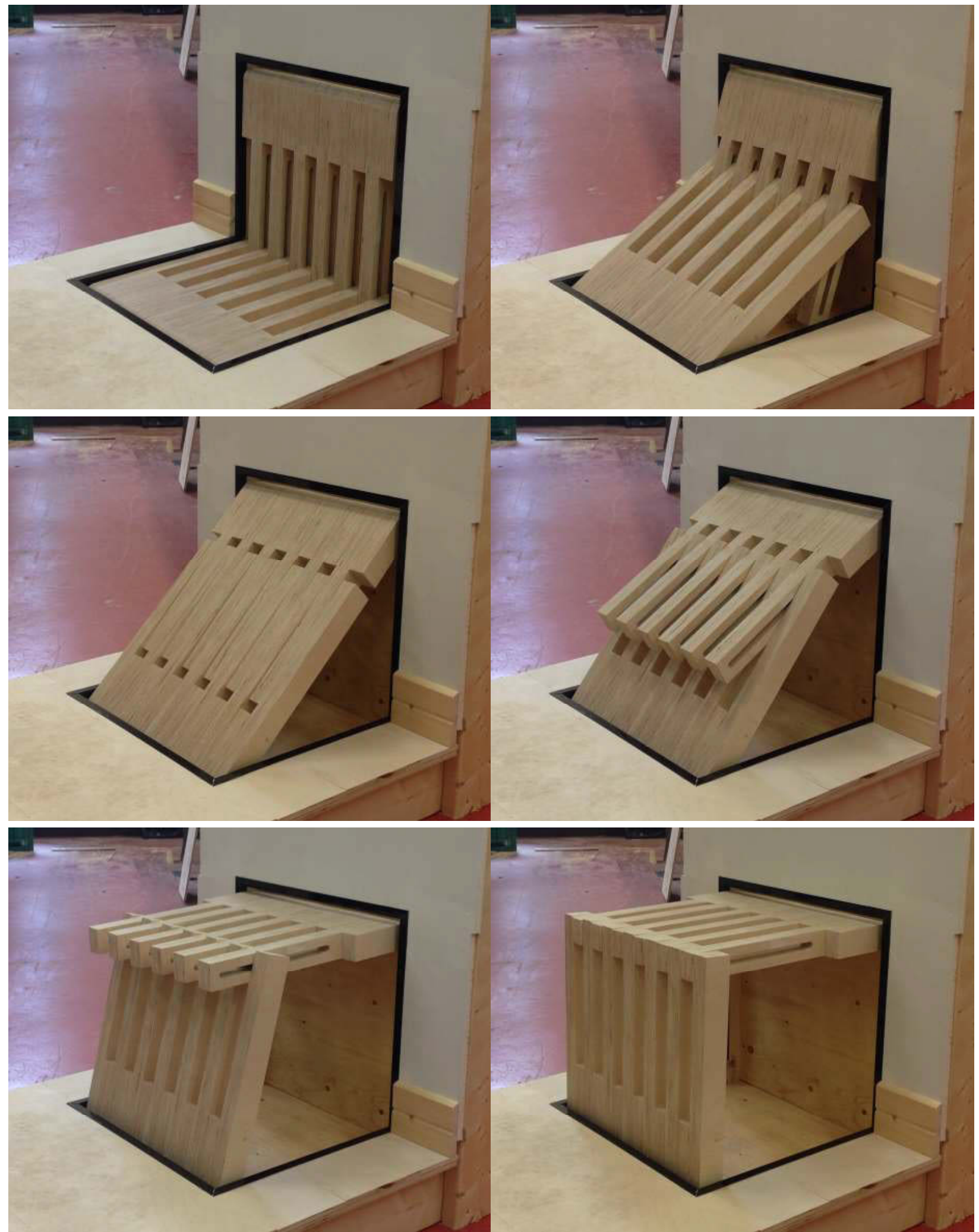

Figure 5.8 - Prototype of a wood slat bench that hides away into a wall-floor assembly and is lifted out to form the opposite 90-degree fold to serve as a bench. Formed from CNC cut plywood and hinged at its corner and ends by steel rods. This smaller scale project provided insight to the larger, human scale projects. 


\section{Prototypes: Responsive Folding Structures}


Three sites in the public domain of Ottawa were chosen for exploration in prototyping structures that fold as a response to an external need. The sites were chosen to display an array of situations and activities that would occur around the designed structures to cover a broader range of folding forms.

The sites include:

Confederation Park - This park is located in downtown Ottawa and is bordered by popular streets on three sides - Laurier Avenue to the south, Elgin Street to the west, and Mackenzie King Bridge to the north. The fourth side is bordered by the Rideau Canal.

Aberdeen Square - This public square is located Lansdowne Park that recently went through a major redevelopment, completed in 2016. Retail shops, entertainment, and restaurants surround the square. It is also located next to a large heritage building that hosts frequent events.

Rideau Canal - This canal winds through the heart of Ottawa flowing to the north into the Ottawa River and is popular pedestrian route along its banks for sightseers or exercisers. It is a popular tourist destination especially in winter for skating.

The structures designed for each location share the same philosophy. They are intended to be used by the public, be beneficial towards activities and events, and be rugged enough to withstand constant exposure and use. The structures all possess both fixed and moving parts. The fixed portions of the structures act as the foundation for the folding components to move on pivot 
points or guides that control the folding motions. The folding components are joints that move as required to generate one of the predetermined forms of each individual structure. The joints must remain in working order for these structures to function and while a foldable material might create a clean, continuous, creased fold, the types of fabrics or rubbers that might provide this would not hold up over constant exposure to the elements. Wear and tear and folding back and forth would damage to material to the point of breakage.

The installation of the following structures allows for multiple opportunities of use because they are able to take on multiple forms. An added benefit is a reduction in labour involved in what would typically be the construction and removal of a temporary structure at the start and end of an event. Each of the structures plays a role in hosting or assisting in accommodating an event. Currently, these events involve removable, temporary structures that take time and money to deliver, construct, deconstruct, and remove. A permanent structure that adapts to remain a beneficial piece of infrastructure after an event retains value and avoids having abandoned structures for a duration of time in which the events are not taking place.

The focus in designing these structures is providing a utility that benefits the public space. A working product that provides such is the ultimate goal. Each of the following structures is designed with that mindset. 


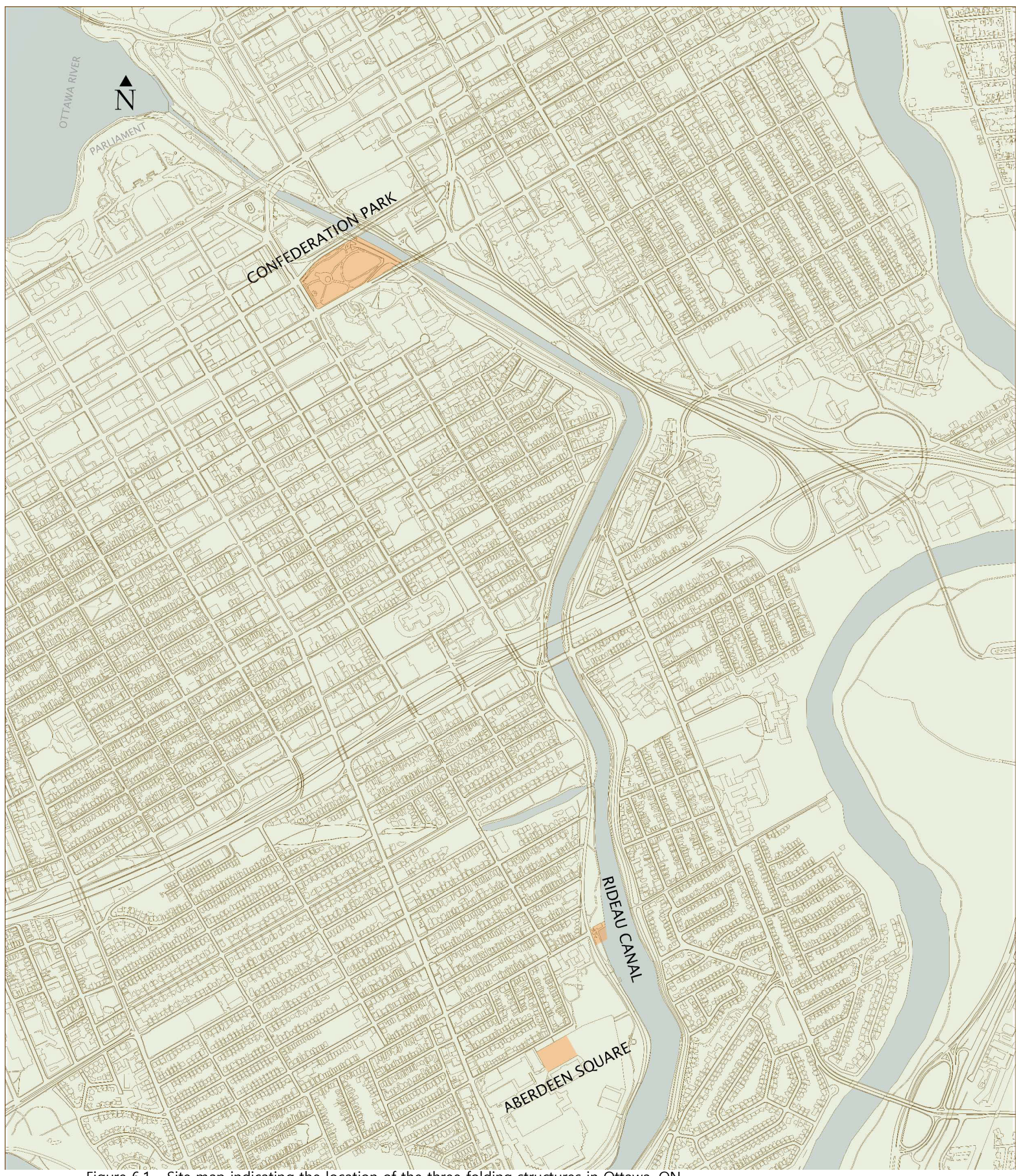

Figure 6.1 - Site map indicating the location of the three folding structures in Ottawa, ON 


\section{Confederation Park}


Confederation Park is a ceremonial park that opened in 1967 celebrating one hundred years of Canada. It is home to a number of memorial pieces and serves as part of the city's Confederation Boulevard. ${ }^{41}$ Being surrounded by busy roads and located between Ottawa City Hall and the National Arts Centre can make for a loud area, however, a plethora of trees are able to drown out some of the noise making for decent place to rest, gather, or escape from the city. This makes it a popular destination for passersby, tourists, or anyone looking for open space to engage in sports or other activities. Much of the park is just open grass area that allows for flexibility with regards to use. This also allows the park to host several events on an annual basis, some of which include musical acts requiring a temporary stage to be built on site. Both summer and winter seasons see the installation of a stage, Ottawa International Jazz Festival in the summer and Winterlude concerts in the winter. ${ }^{42}$ The logistics of delivering and constructing a temporary stage can take two days or more to complete and requires money for rentals and labour. The proposed folding structure for Confederation Park is a series of large flat panels that can fold up to form a stage but also provide useful public infrastructure for the time in which the stage form is not in use.

This structure, in its completely unfolded form would act as part of the ground plane. It could be walked over with the only noticeable difference being a change in material. Its most common form would be a series of long benches that are folded into form by alternating wood slats inspired by the previously constructed wood slat, independent study bench. This idea is captured in Figure 7.6 showing a progression of folding from flat pack to upright rigid bench. At the time of an event the benches would fold back flat to become the series of rigid panels that, as a whole, can fold and slide upward, carrying with it a roof structure while a stage floor rises from underneath. What this provides is additional rest area to what is already

41 "Confederation Park," National Capital Commission, accessed June 13, 2018, http://ncc-ccn.gc.ca/places-to-visit/parkspaths-and-parkways/confederation-park

42 Winterlude is an annual event in Ottawa that includes musical performances, art installations, food and drink fests, and other group activities. It typically runs in the first half of February and some of the programs take place on the ice surface of the Rideau Canal. 
installed at the park; the ability to fold these flat gives back the open, unobstructed area; and opportunities to host larger scale events without requiring days of setup and intrusive construction methods.

This structure is operated by a few different mechanisms. The benches would be lifted into place by pulling the outer most pivot joint on either end in toward the middle. These points end up being the front and back bases of the bench in the upright position. The pivot joints at each of the wood slat connections are profiled in such a way as to only allow folding in a specific direction and to a specific degree. The result is the folding of the bench to designed angles and positions that can be returned to its flat position with a reversal of the action. For the stage to erect, the stage floor, and roof that sits on top of it in the stored position are pushed up via a hydraulic until the floor is in the correct position. From this point a series of winches can pull the far edges of the wood slat panels in towards the stage base until they are 90-degrees upright, in turn raising the roof structure to its temporary position. The folds occur where the wood slat panels meet the ground and the roof. The panels must pivot 90-degrees at each of these locations to make the erected structure possible. These folds are folds at a joint, not a crease in a material.

This structure is responsive to informational input. The human element tells it when to fold flat, when to form benches, and when to become a stage. 


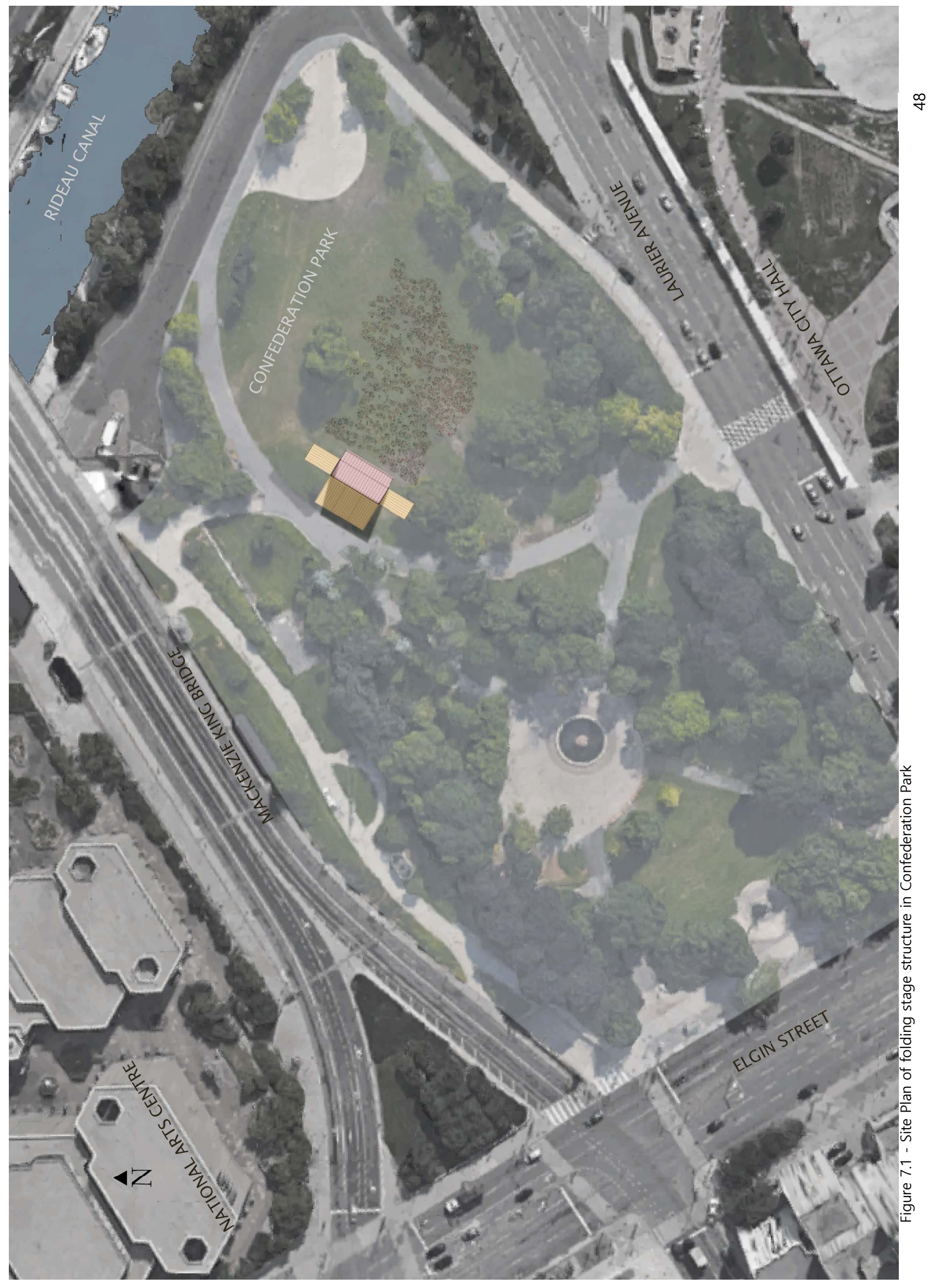




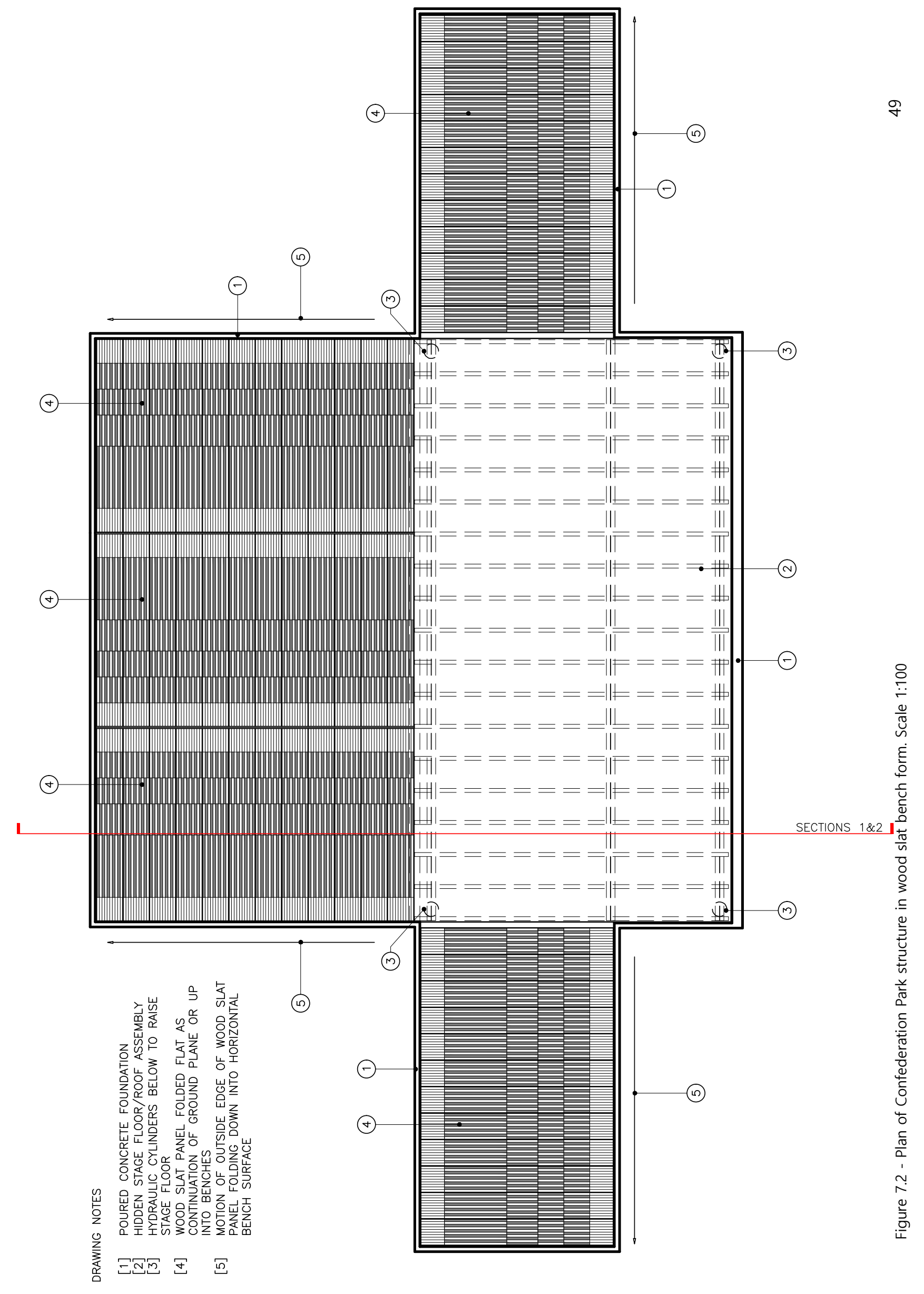




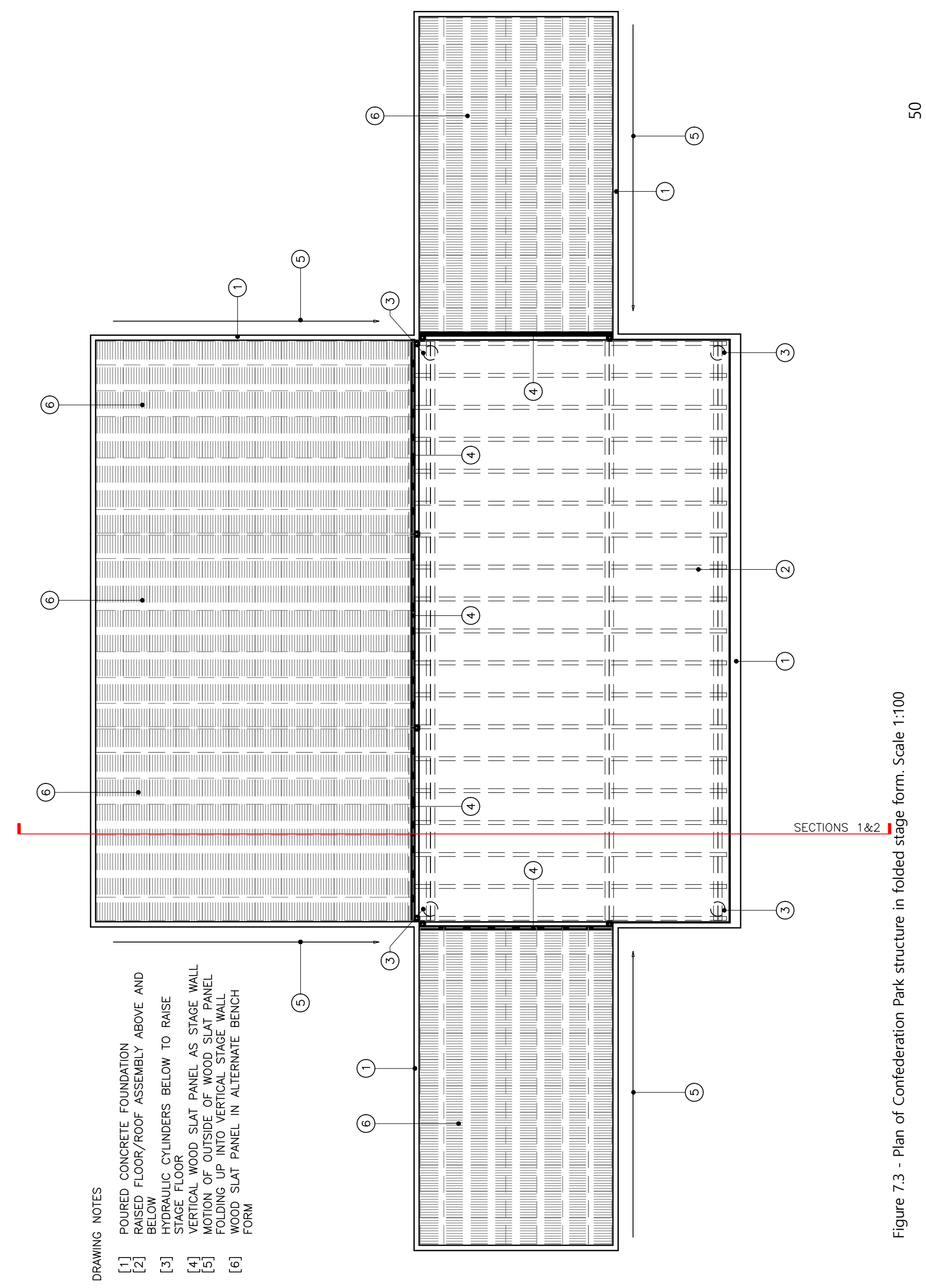




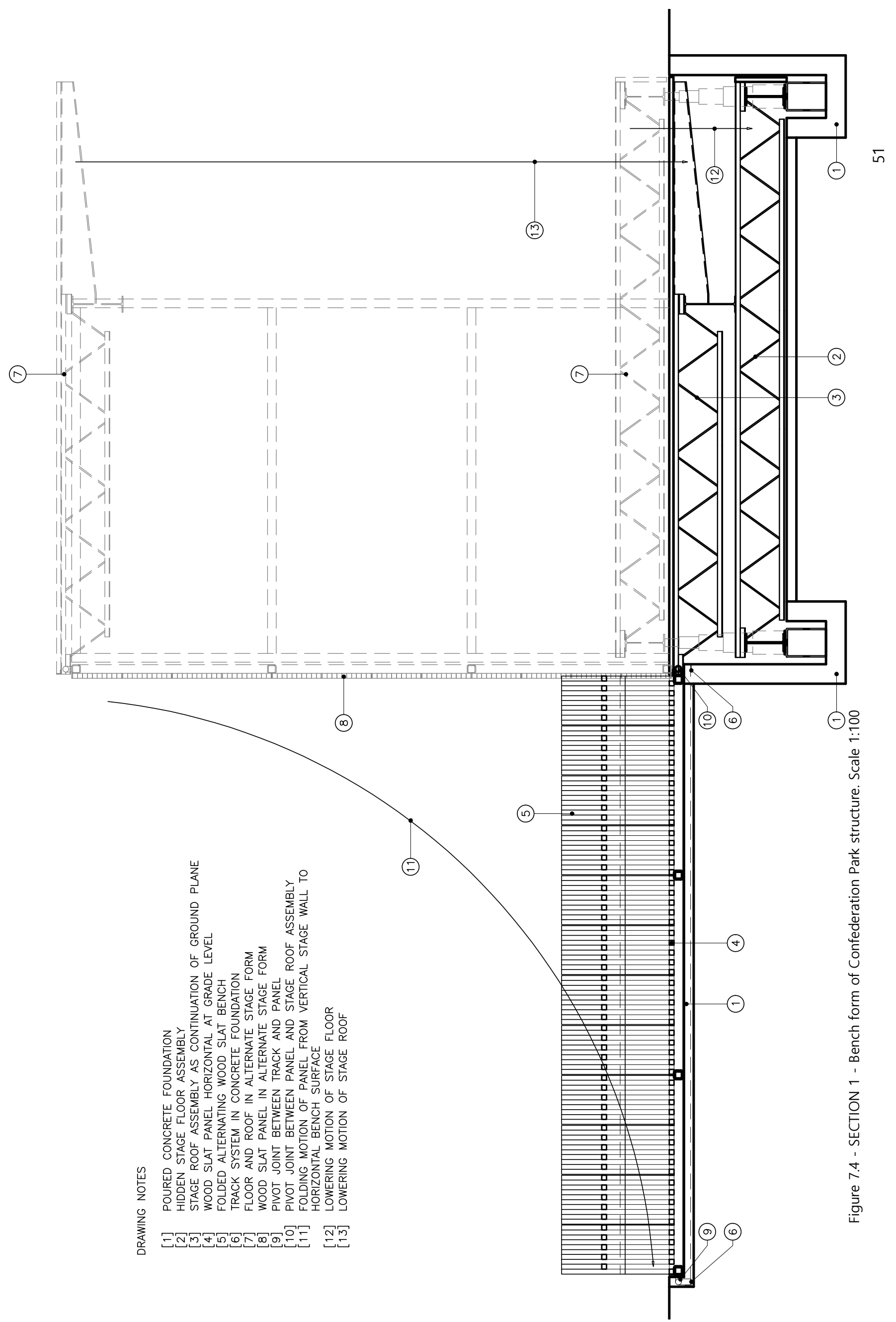




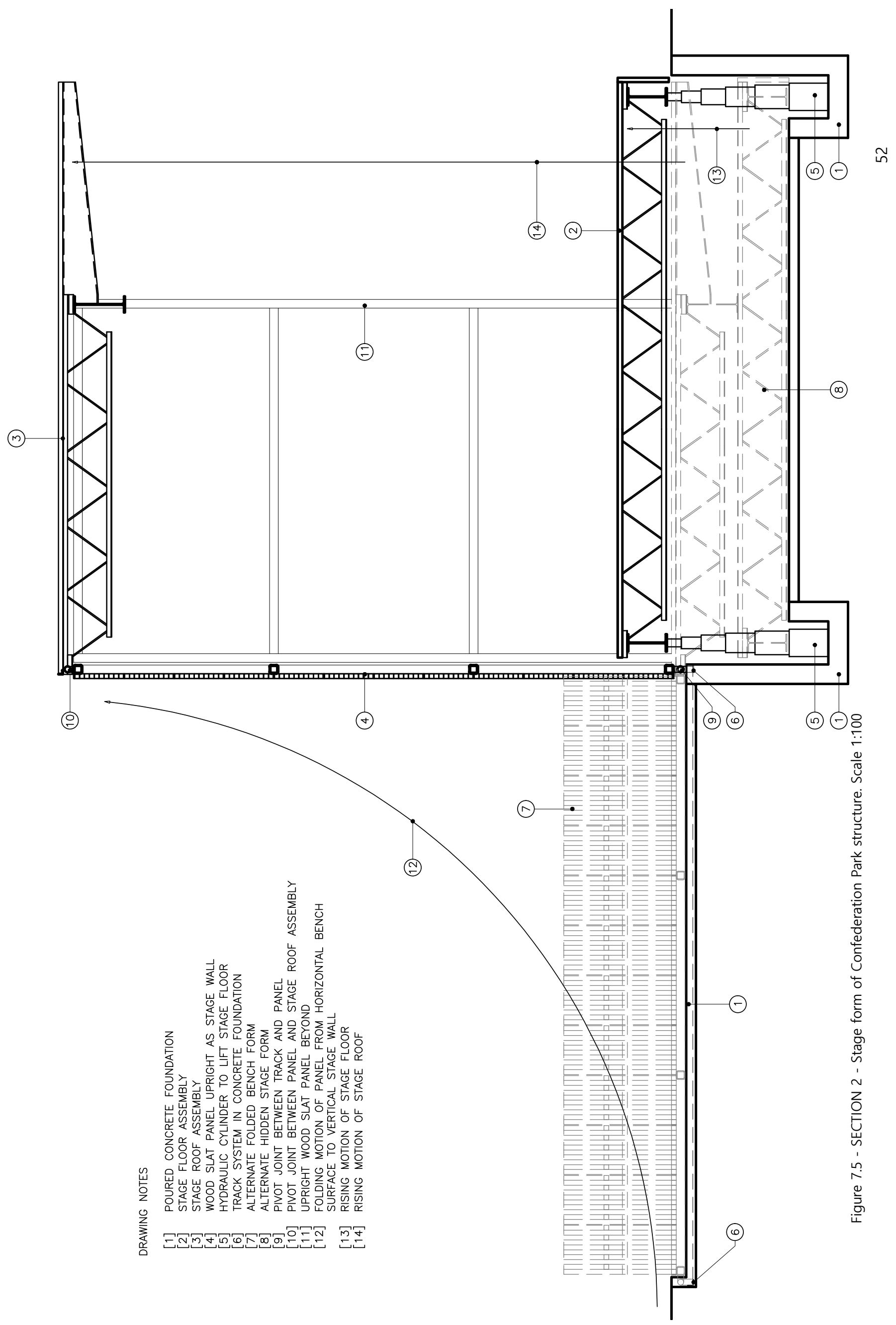




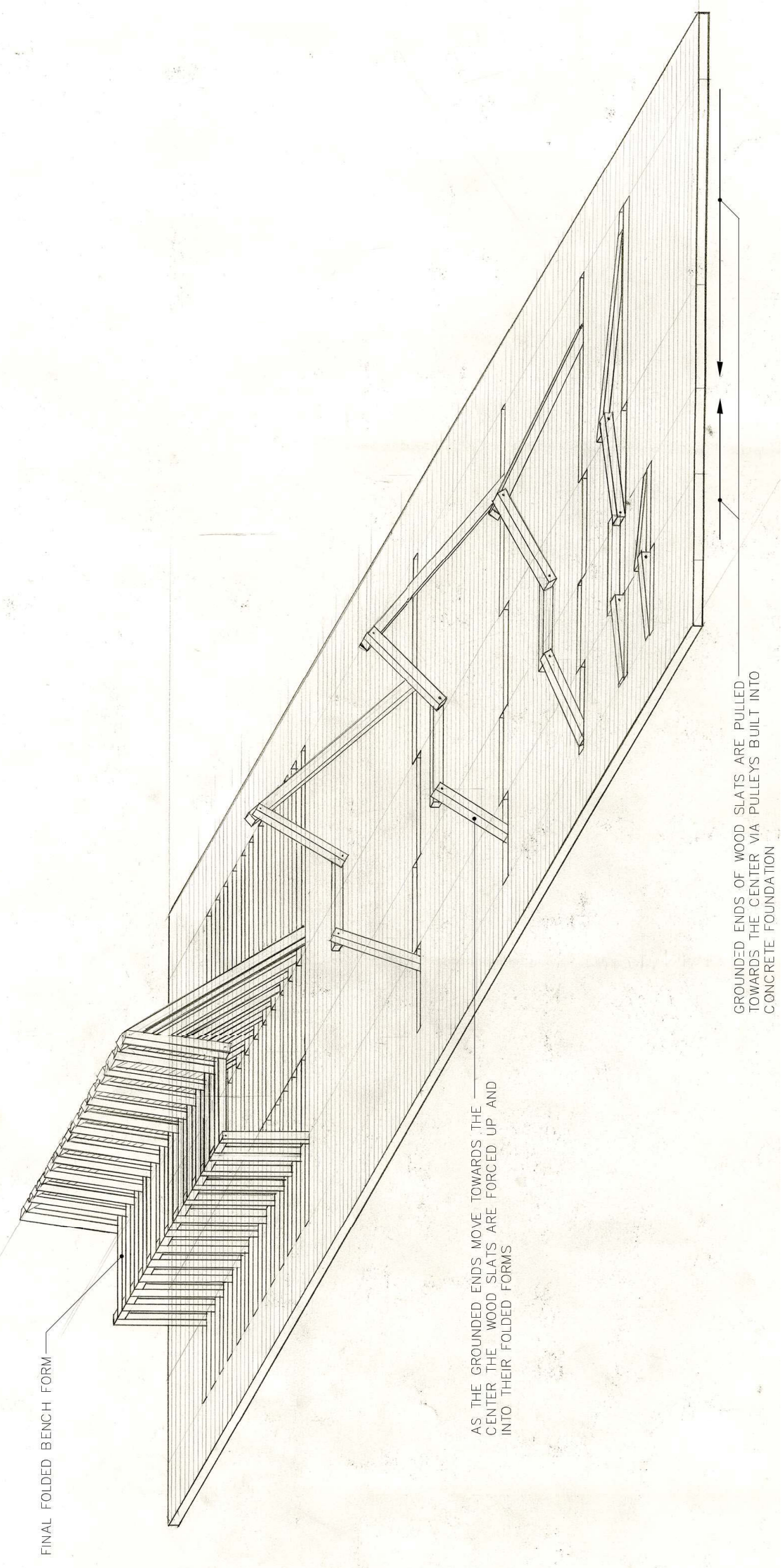


Unfolded Form

- Wood slat panels folded flat

- Stage components hidden in ground

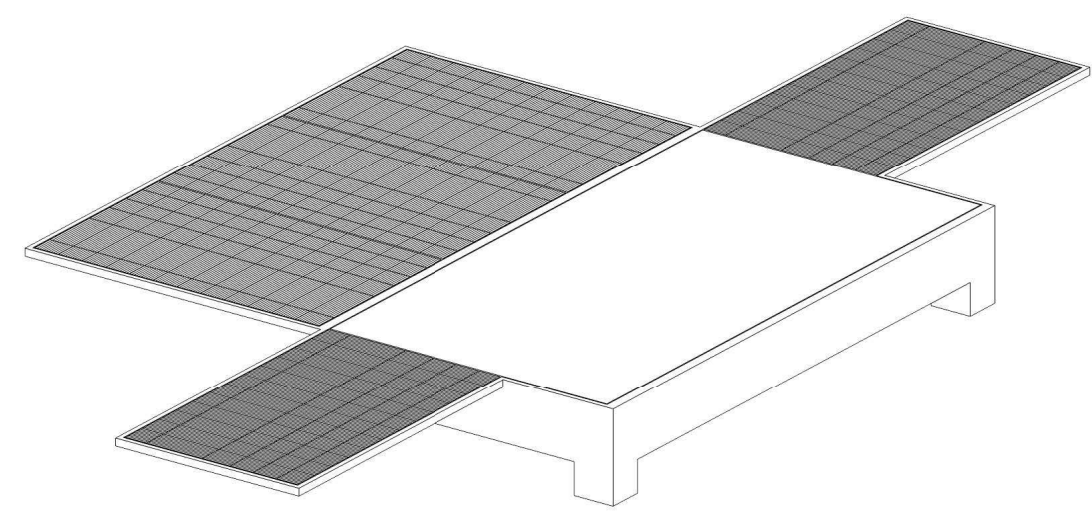

\section{Bench Form}

- Wood slat panels folded into benches

- Stage components hidden in ground

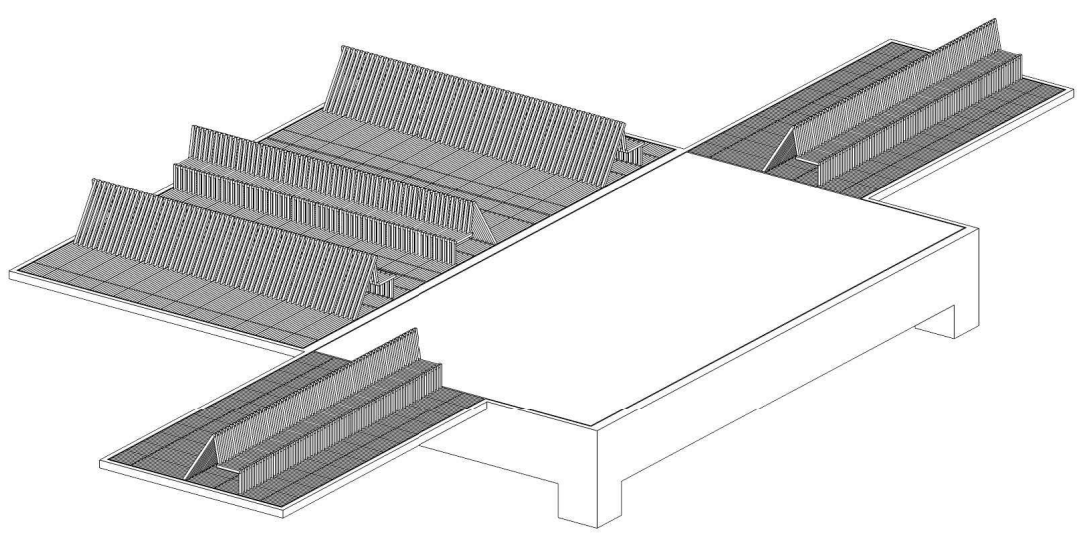

Stage Form

- Wood slat panels folded flat and pulled upright

- Stage components lifted into functioning position

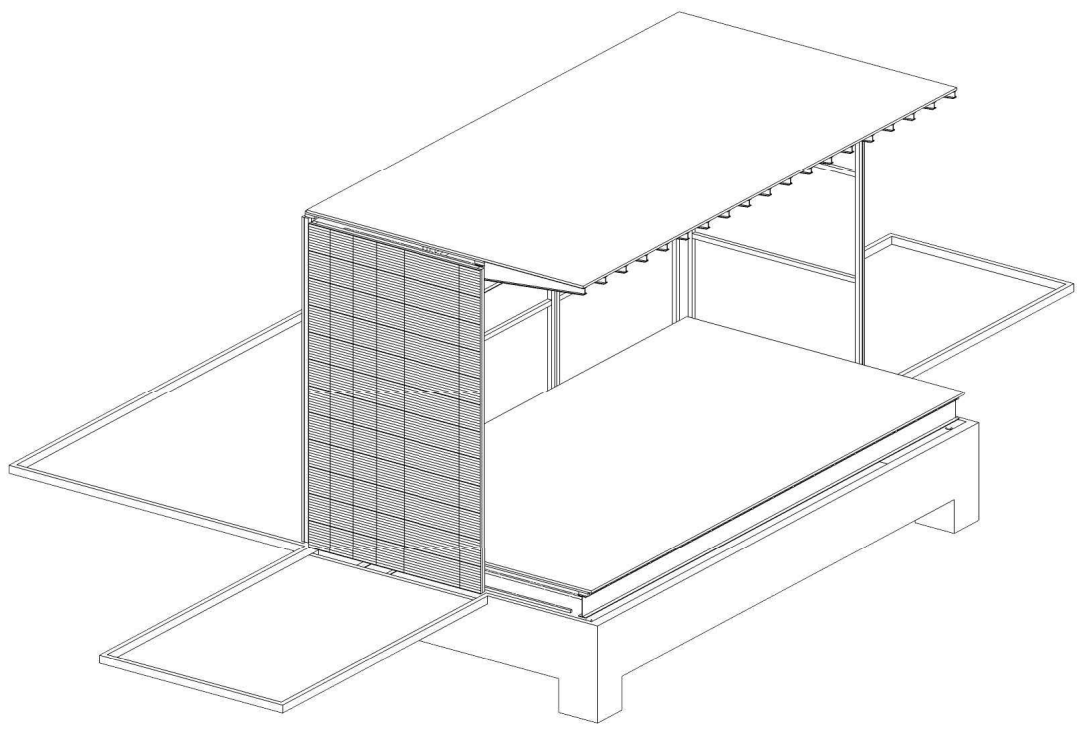

Figure 7.7 - Series of axonometric views of the Confederation Park structure 


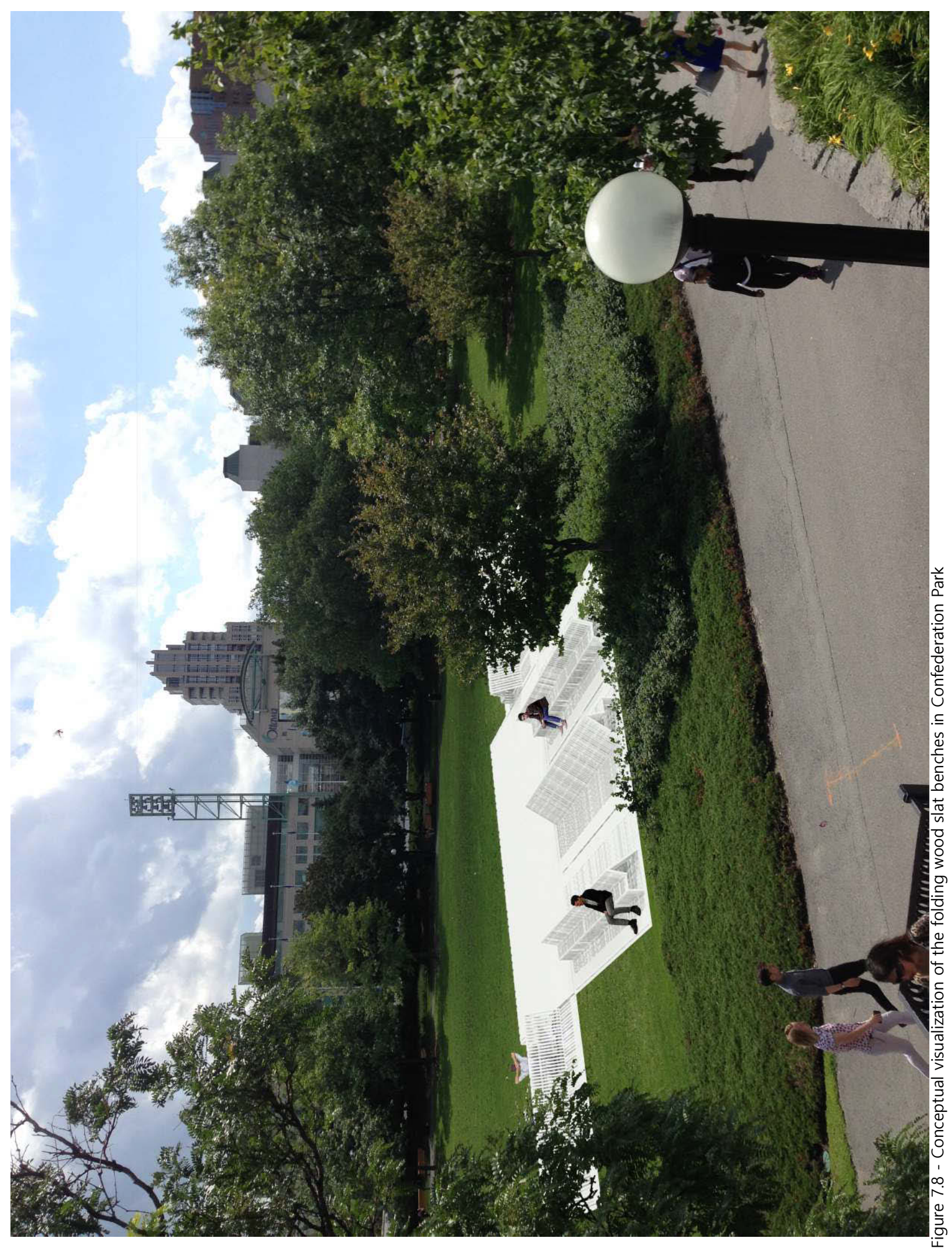




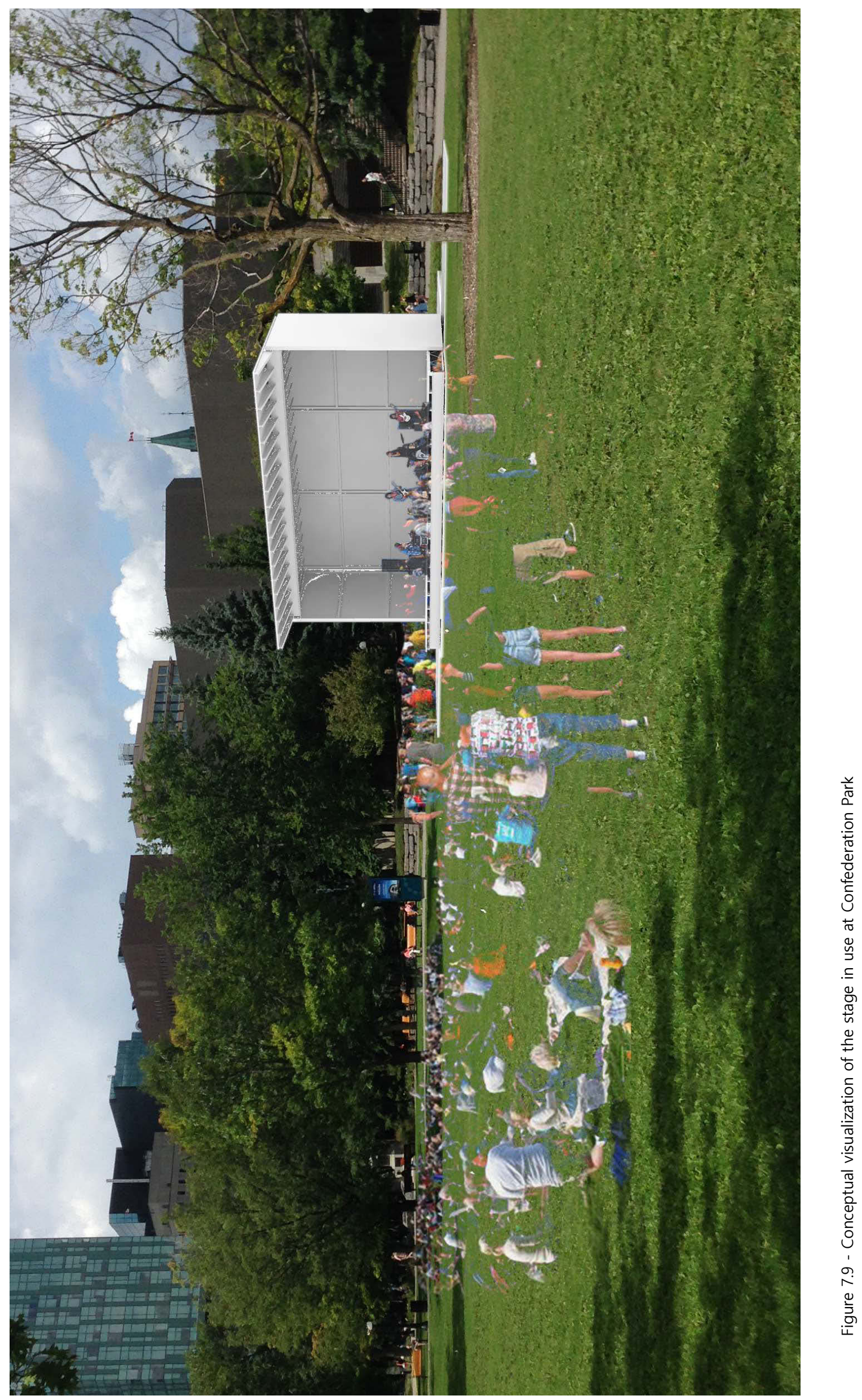




\section{Aberdeen Square}


Aberdeen Square is located in the Lansdowne Live Redevelopment that is bordered partially by the Rideau Canal. Between 2012 and 2016 Lansdowne Park was redeveloped to revitalize the existing football stadium while adding new retail space, services, and condominiums. This included the creation of park and public event space, part of which is Aberdeen Square. ${ }^{43}$ The square is currently one location for the weekly Ottawa Farmer's Market. ${ }^{44}$ Each Sunday during the warmer months in Ottawa a slew of white tents are set up in the morning, each one to become the temporary host of a market vendor for the day. The farmer's market is a popular location when it takes place, in the six other days of the week Aberdeen Square is just a public square. The retail space around the square attracts most of the pedestrian traffic and because vehicles are allowed to drive around all four sides of the square, pedestrian activity within it is limited to people passing through with access to the underground parking garage. The ground surface is flat and hard offering little reason for anyone to spend any extended period of time in the square. The installation of permanent structures that have the ability to take on multiple forms give the square a more diverse opportunity for use. A series of structures that act as shelters for the aforementioned farmer's market are also used to promote non event gathering, rest, and relaxation within Aberdeen Square. These structures remain simple in form and function creating useable covered space, and resting surfaces while also having the ability to fold flat into the ground to retain the open space as it currently exists.

\footnotetext{
$43 \quad$ Gordon E. MacNair, "Lansdowne: A Success Story of Redevelopment in the Heart of Ottawa," in Canadian Property Valuation Volume 59 Book 2, (2015), https://www.aicanada.ca/article/ lansdowne-a-success-story-of-redevelopment-in-the-heart-of-ottawa/

44 "Lansdowne Park - Ottawa," Ottawa Farmer's Market, accessed January 16, 2018, https:// ottawafarmersmarket.ca/lansdowne-park-ottawa/
} 
These structures use a scissor-like folding action in which two parallel scissor frames lift a horizontal panel to designed heights depending on the time of day or year. Each scissor frame is formed by two hollow structural steel sections connected via a pivot joint in their centers. Opposite ends of each steel section are built into a track system in a concrete foundation. This allows the connected bases of each section to slide along the ground. Since the two are connected in their centers, the free ends of each section are forced to move upwards. A horizontal steel framed rectangular panel is connected at its corners to each of the four folding steel sections by a set of four pivot joints. The joints between the horizontal panel and the scissor frames are allowed to slide along the length of the scissor frame. As winches installed into the concrete foundation pull the connected bases towards each other the scissor frames rise, taking the horizontal panel with them. The structures are designed to stop when the horizontal panel reaches three different heights - when it is folded into the ground, when it is $500 \mathrm{~mm}$ above grade as a surface to sit or rest, and when it is $2400 \mathrm{~mm}$ above grade as an overhead shelter.

The structures are responsive to a predetermined schedule. The early mornings before the farmer's market sees the structures rise to shelter form to host a vendor for the day. At the conclusion of the event, the structures return back to either a rest platform or completely flush into the ground. 


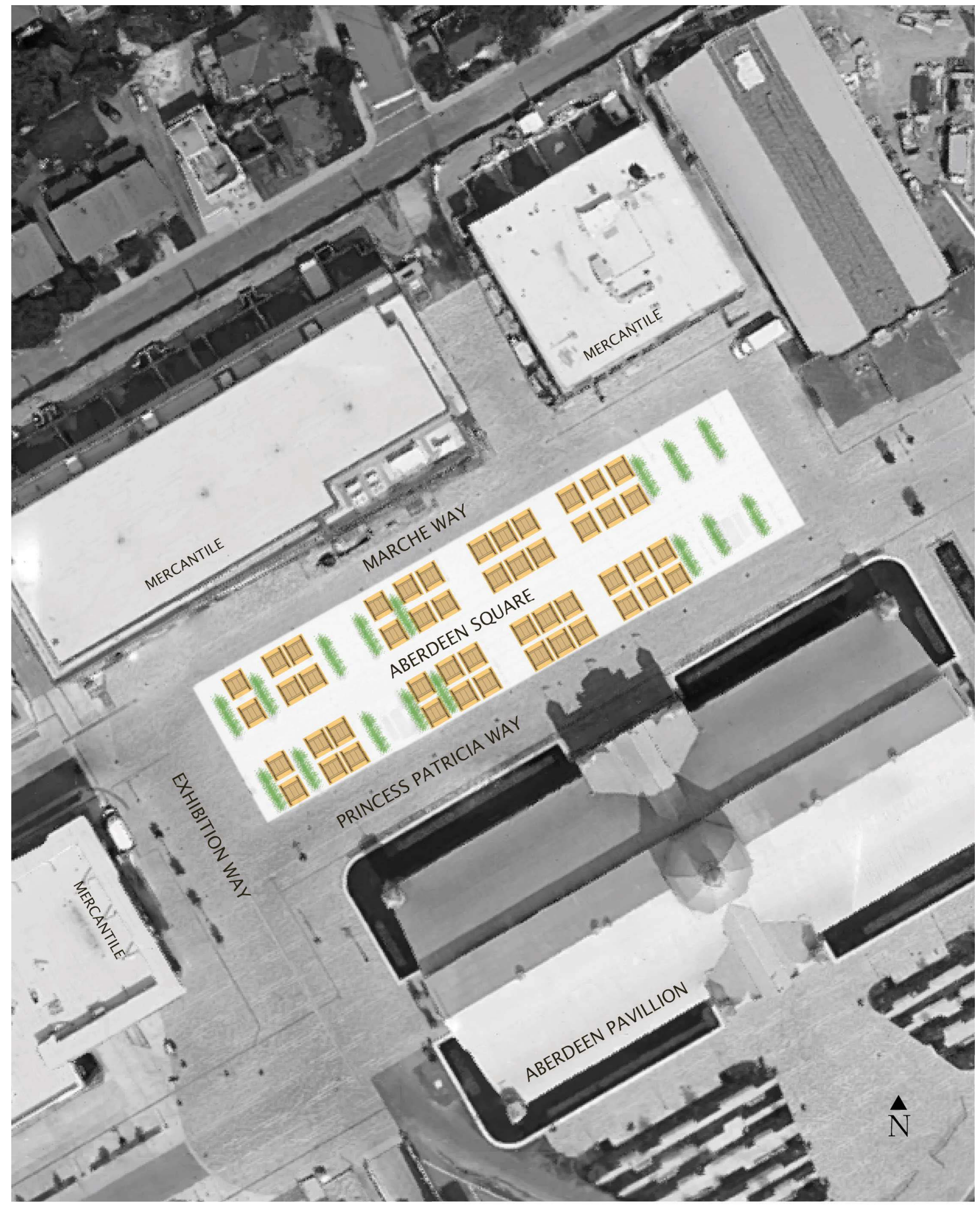

Figure 8.1 - Site plan of Aberdeen Square in Lansdowne Park with folding scissor frame structures 


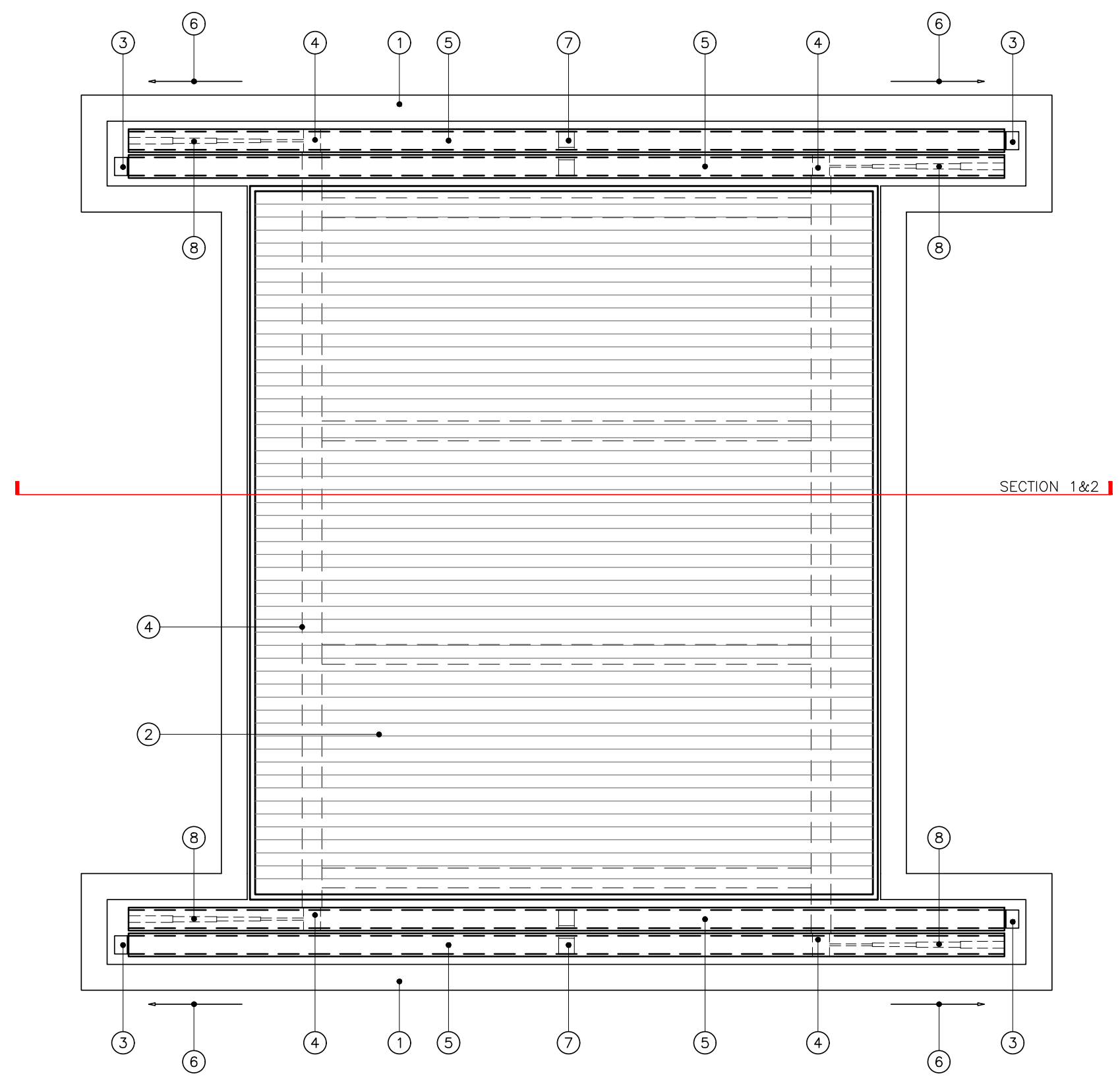

DRAWING NOTES

[1] POURED CONCRETE FOUNDATION

[2] GALVANIZED STRUCTURAL STEEL FRAME FINISHED WITH ALUMINUM EDGING AND WOOD INFILL MOVES VERTICALLY BEING ANCHORED ON BOTH SIDES TO THE SCISSOR FRAME

[3] STEEL SCISSOR FRAME BASE SLIDES ALONG TRACK BUILT INTO CONCRETE FOUNDATION

[4] STEEL STRUCTURE OF HORIZONTAL PANEL CONNECTED TO SCISSOR FRAME VIA PIVOT JOINTS

[5] GALVANIZED STEEL HOLLOW STRUCTURAL SECTION TO FORM SCISSOR FRAME

[6] SLIDING MOTION OF SCISSOR FRAME BASE ALONG TRACK DOWN TO REST SURFACE FORM

[7] PIVOT JOINT CONNECTS TWO STEEL SECTIONS ALLOWING THE FOLDING SCISSOR MOTION OF THE SUPPORTING FRAME

[8] STEEL FRAMED PANEL HELD HORIZONTAL BY EQUALIZING PISTONS BETWEEN PIVOT JOINT AND END OF SCISSOR FRAME

Figure 8.2 - Plan of Aberdeen Square structure as a resting surface. Scale 1:25 


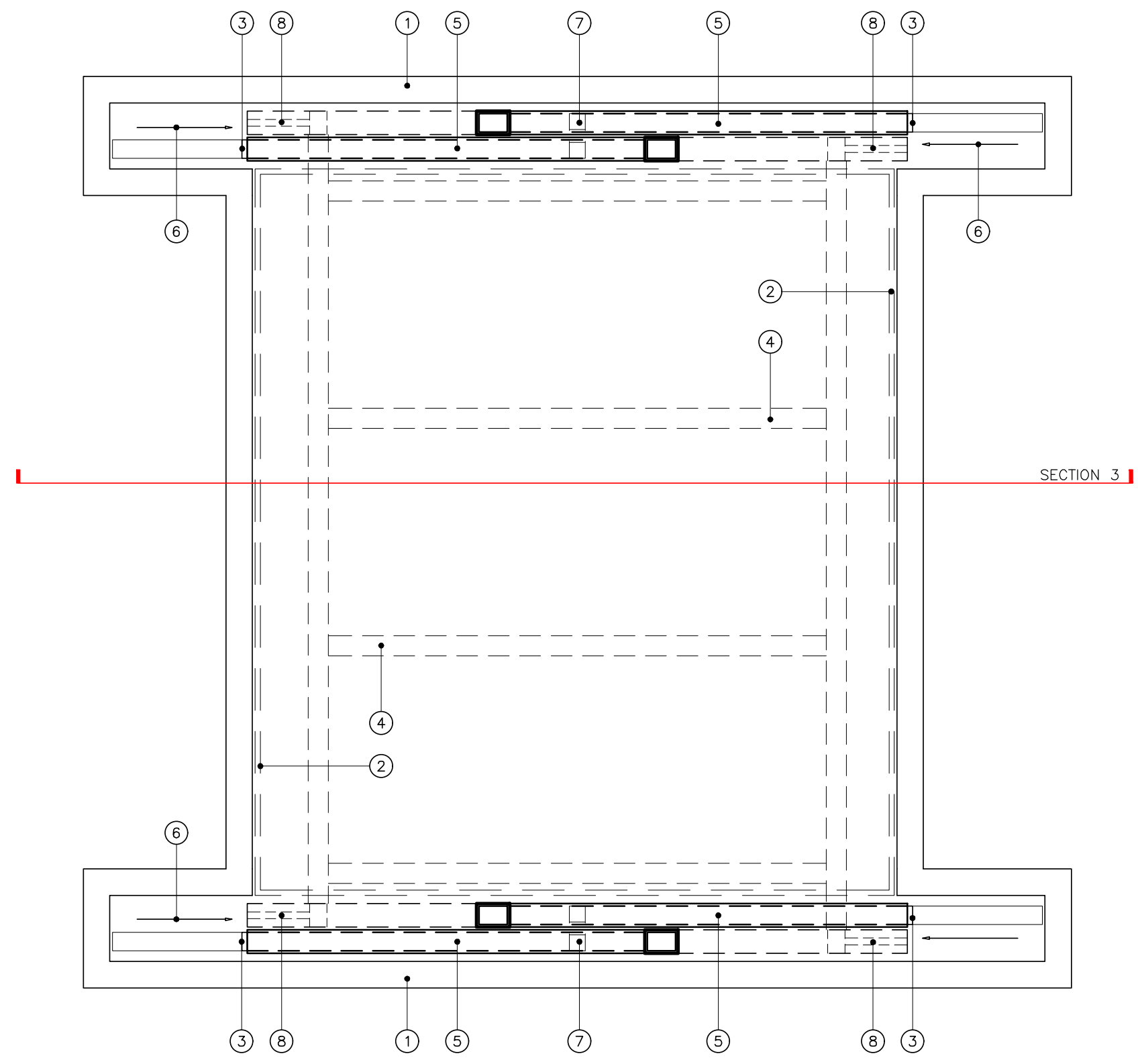

DRAWING NOTES

[1] POURED CONCRETE FOUNDATION

[2] EDGE OF HORIZONTAL PANEL ABOVE SERVING AS OVERHEAD SHELTER

[3] STEEL SCISSOR FRAME BASE SLIDES ALONG TRACK BUILT INTO CONCRETE FOUNDATION

[4] STEEL STRUCTURE OF HORIZONTAL PANEL

[5] GALVANIZED STEEL HOLLOW STRUCTURAL SECTION TO FORM SCISSOR FRAME

[6] SLIDING MOTION OF SCISSOR FRAME BASE ALONG TRACK RAISING UP TO SHELTER FORM

[7] PIVOT JOINT CONNECTS TWO STEEL SECTIONS ALLOWING THE FOLDING SCISSOR MOTION OF THE SUPPORTING

PIVOT JOINT CONNECTS TWO STEEL SECTIONS ALLOWING THE FOLDING SCISSOR MOTION OF THE SUPPORTI
FRAME [8] STEEL FRAMED PANEL HELD HORIZONTAL BY EQUALIZING PISTONS BETWEEN PIVOT JOINT AND END OF
SCISSOR FRAME

Figure 8.3 - Plan of Aberdeen Square structure as an overhead shelter. Scale 1:25 
(8)

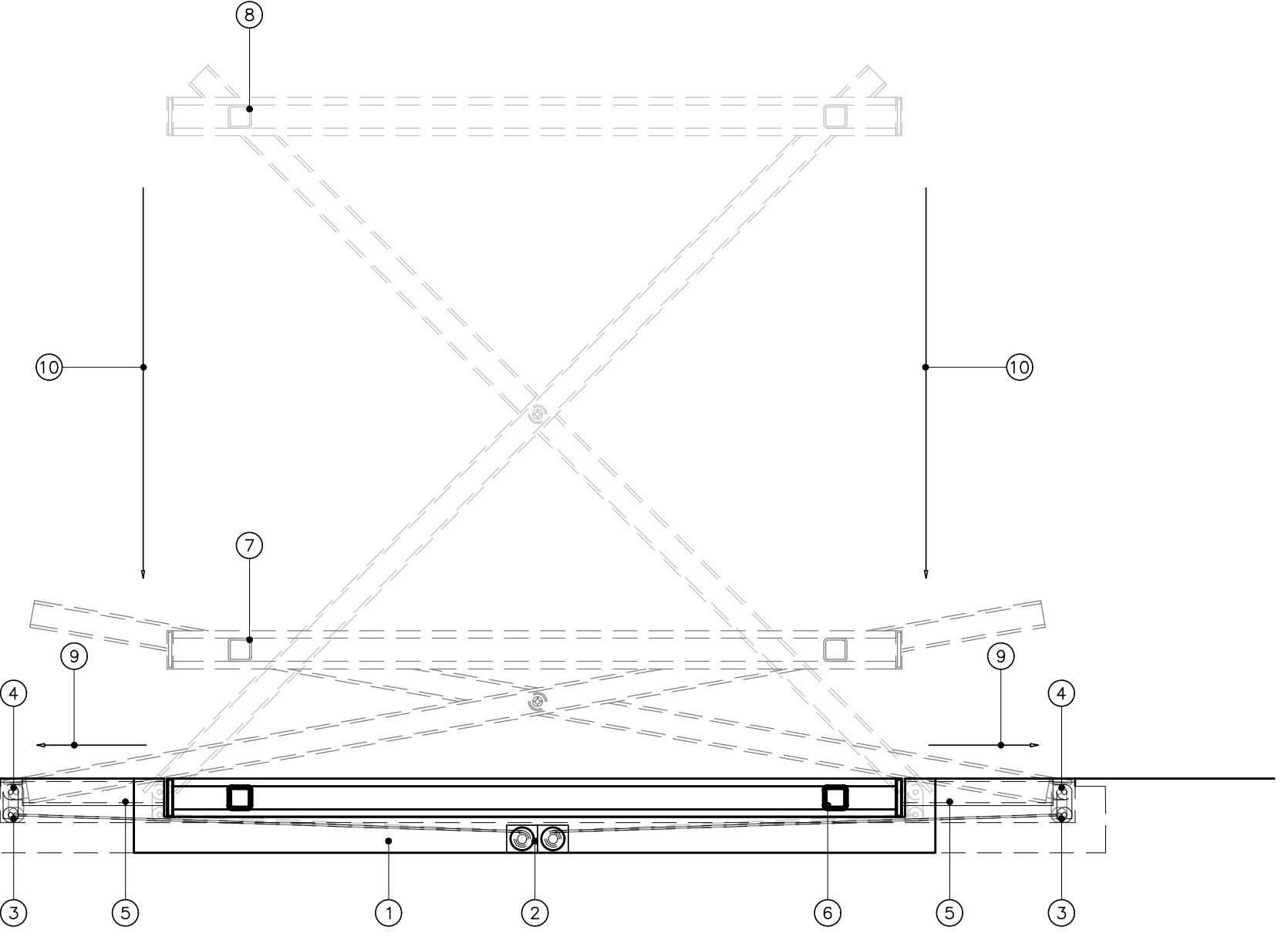

DRAWING NOTES

[1] POURED CONCRETE FOUNDATION

[2] ELECTRIC WINCHES BUILT INTO CONCRETE FOUNDATION

[3] STEEL SCISSOR FRAME BASE SLIDES ALONG TRACK BUILT INTO CONCRETE FOUNDATION

[4] PIVOT JOINT BETWEEN TRACK AND STEEL SCISSOR FRAME

[5] GALVANIZED STEEL HOLLOW STRUCTURAL SECTION TO FORM SCISSOR FRAME

[6] GALVANIZED STRUCTURAL STEEL FRAME FINISHED WITH ALUMINUM EDGING AND WOOD INFILL MOVES VERTICALLY BEING ANCHORED ON BOTH SIDES TO THE SCISSOR FRAME

[7] RAISED SCISSOR FRAME ALTERNATE FORM WITH PANEL SERVING AS A SURFACE FOR REST

[8] RAISED SCISSOR FRAME ALTERNATE FORM WITH PANEL SERVING AS OVERHEAD SHELTER

[9] SLIDING MOTION OF SCISSOR FRAME BASE ALONG TRACK DOWN INTO GROUND PLANE FROM RAISED FORM

[10] LOWERING MOTION OF HORIZONTAL PANEL DOWN INTO GROUND PLANE FROM RAISED FORM

Figure 8.4 - SECTION 1 - Aberdeen Square structure folded flat into ground plane. Scale 1:25 


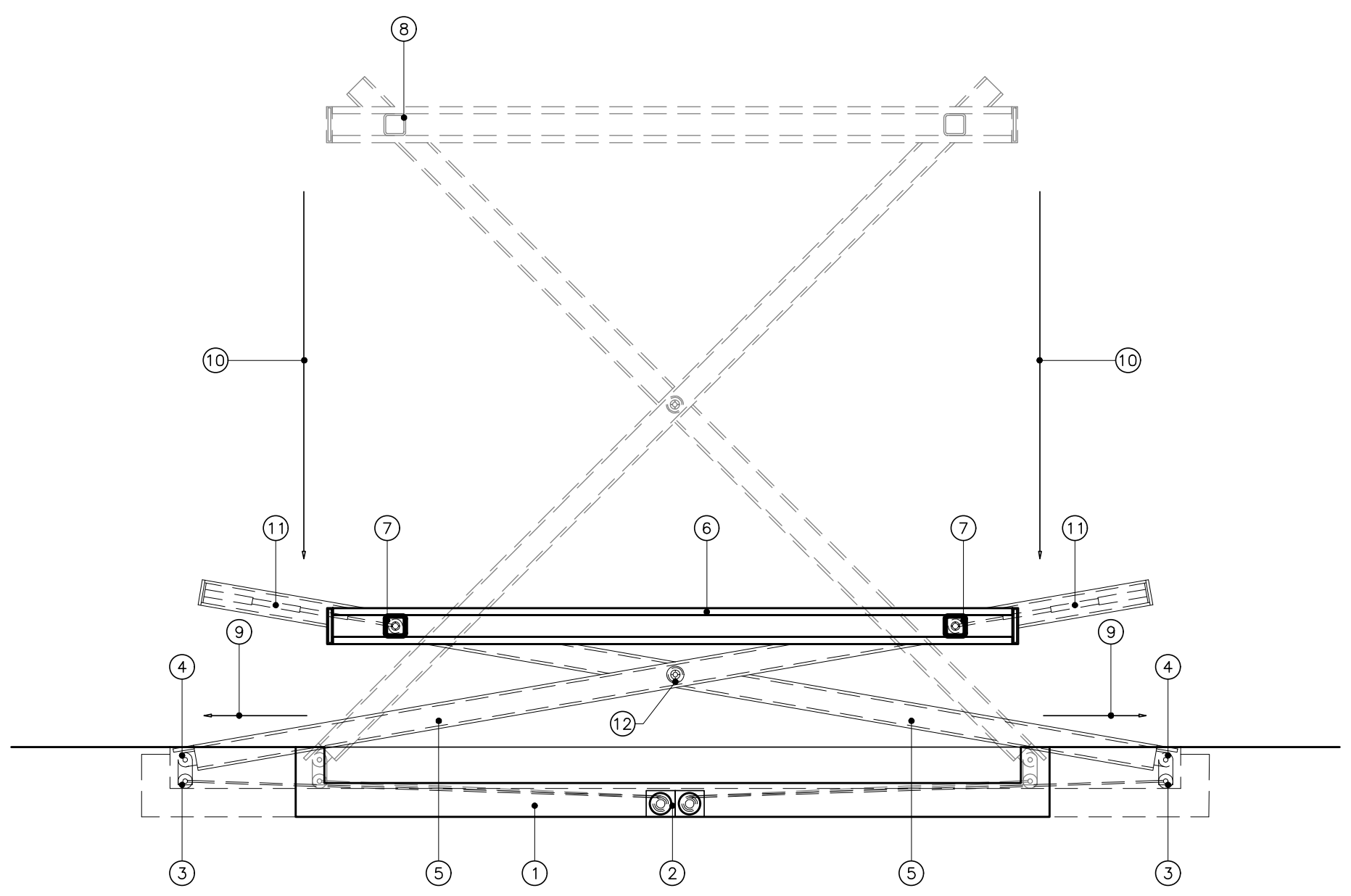

DRAWING NOTES

[1] POURED CONCRETE FOUNDATION

[2] ELECTRIC WINCHES BUILT INTO CONCRETE FOUNDATION

[3] STEEL SCISSOR FRAME BASE SLIDES ALONG TRACK BUILT INTO CONCRETE FOUNDATION

[4] PIVOT JOINT BETWEEN TRACK AND STEEL SCISSOR FRAME

[5] GALVANIZED STEEL HOLLOW STRUCTURAL SECTION TO FORM SCISSOR FRAME

[6] GALVANIZED STRUCTURAL STEEL FRAME FINISHED WITH ALUMINUM EDGING AND WOOD INFILL MOVES VERTICALLY BEING ANCHORED ON BOTH SIDES TO THE SCISSOR FRAME

[7] STEEL FRAME OF HORIZONTAL PANEL CONNECTED TO SCISSOR FRAME VIA PIVOT JOINT AND TRACK SYSTEM

[8] RAISED SCISSOR FRAME ALTERNATE FORM WITH PANEL SERVING AS OVERHEAD SHELTER

[9] SLIDING MOTION OF SCISSOR FRAME BASE ALONG TRACK DOWN INTO REST SURFACE FORM

[10] LOWERING MOTION OF HORIZONTAL PANEL DOWN INTO REST SURFACE FORM

[11] STEEL FRAMED PANEL HELD HORIZONTAL BY EQUALIZING PISTONS BETWEEN PIVOT JOINT AND END OF SCISSOR FRAME

[12] PIVOT JOINT CONNECTS TWO STEEL SECTIONS ALLOWING THE FOLDING SCISSOR MOTION OF THE SUPPORTING FRAME

Figure 8.5 - SECTION 2 - Aberdeen Square structure as a resting surface. Scale 1:25 


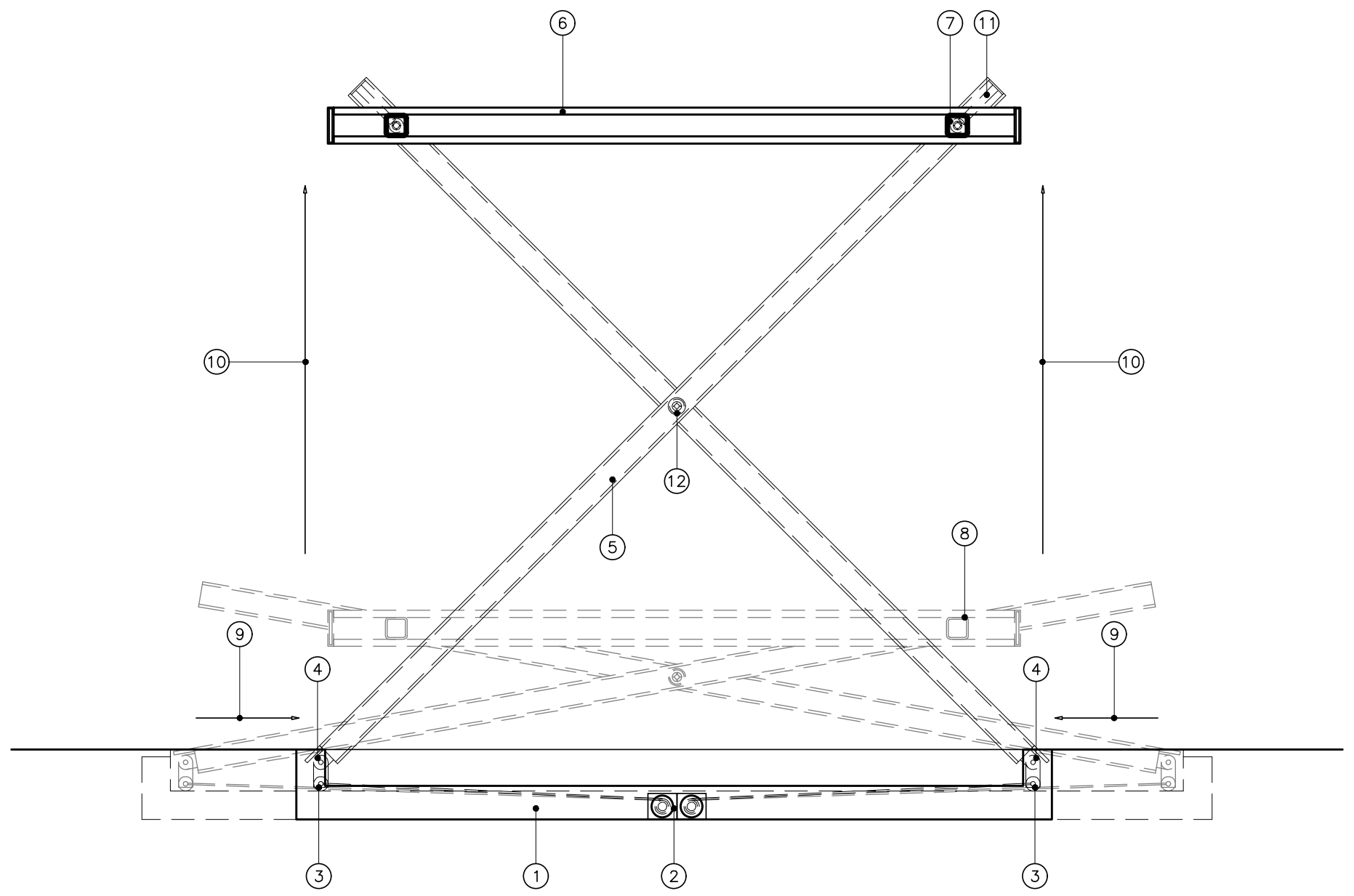

DRAWING NOTES

[1] POURED CONCRETE FOUNDATION

[2] ELECTRIC WINCHES BUILT INTO CONCRETE FOUNDATION

[3] STEEL SCISSOR FRAME BASE SLIDES ALONG TRACK BUILT INTO CONCRETE FOUNDATION

[4] PIVOT JOINT BETWEEN TRACK AND STEEL SCISSOR FRAME

[5] GALVANIZED STEEL HOLLOW STRUCTURAL SECTION TO FORM SCISSOR FRAME

[6] GALVANIZED STRUCTURAL STEEL FRAME FINISHED WITH ALUMINUM EDGING AND WOOD INFILL MOVES VERTICALLY BEING ANCHORED ON BOTH SIDES TO THE SCISSOR FRAME

[7] STEEL FRAME OF HORIZONTAL PANEL CONNECTED TO SCISSOR FRAME VIA PIVOT JOINT AND TRACK SYSTEM

[8] LOWERED SCISSOR FRAME ALTERNATE FORM WITH PANEL SERVING AS REST SURFACE

[9] SLIDING MOTION OF SCISSOR FRAME BASE ALONG TRACK UP INTO SHELTER FORM FORCES THE RAISING OF THE HORIZONTAL PANEL

[10] RAISING MOTION OF HORIZONTAL PANEL UP INTO SHELTER FORM

[11] STEEL FRAMED PANEL HELD HORIZONTAL BY EQUALIZING PISTONS BETWEEN PIVOT JOINT AND END OF SCISSOR FRAME

[12] PIVOT JOINT CONNECTS TWO STEEL SECTIONS ALLOWING THE FOLDING SCISSOR MOTION OF THE SUPPORTING FRAME

Figure 8.6 - SECTION 3 - Aberdeen Square structure as an overhead shelter. Scale 1:25 
Flat, Hidden Form

- The structure acts as a continuation of the ground plane

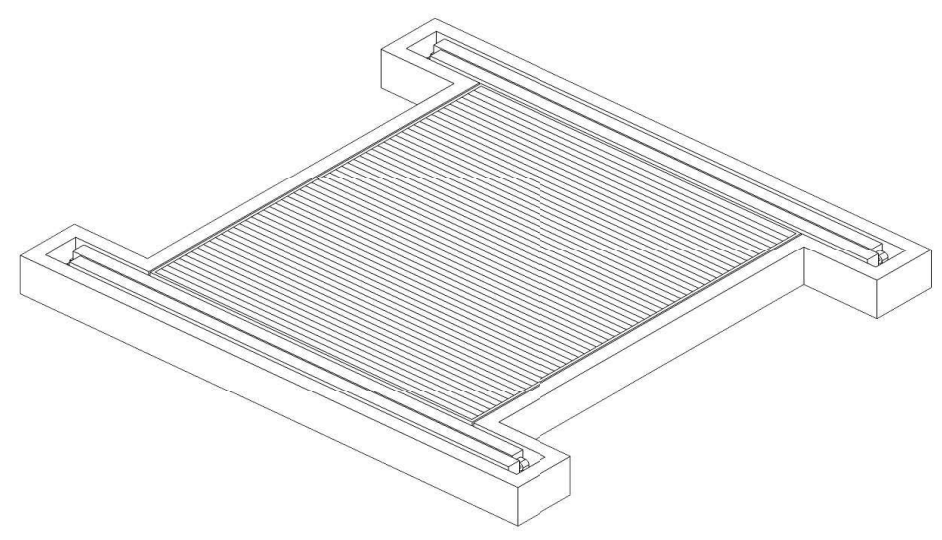

Rest Form

- The horizontal platform is held at $500 \mathrm{~mm}$ above grade to act as a seat/table surface

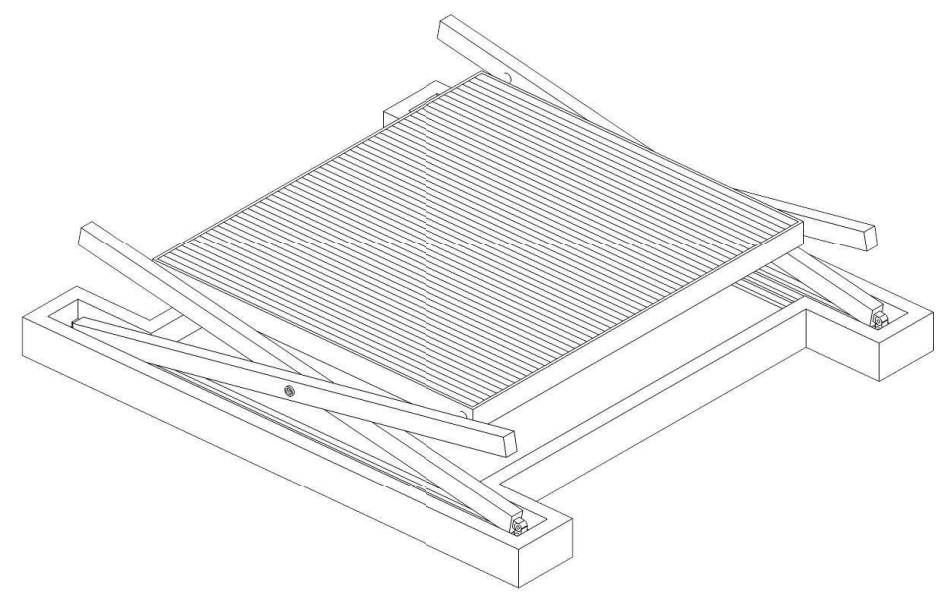

\section{Shelter Form}

- The horizontal panel is raised to $2400 \mathrm{~mm}$ above grade to host vendors at the farmer's market

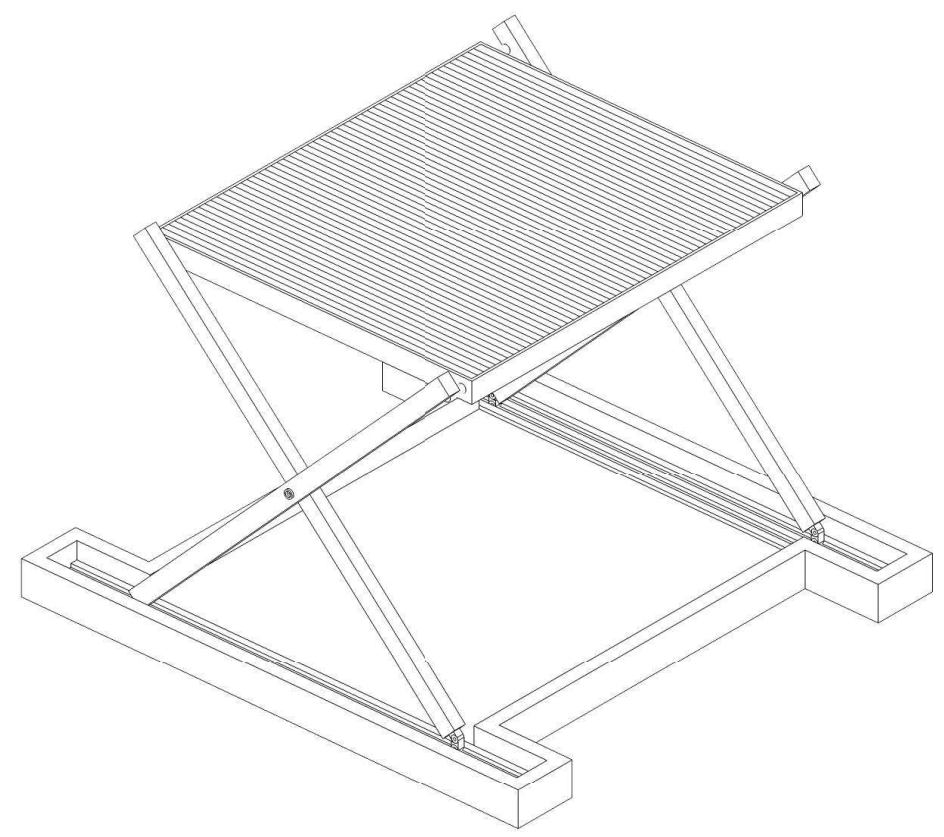

Figure 8.7 - Series of axonometric views of the Aberdeen Square structure 


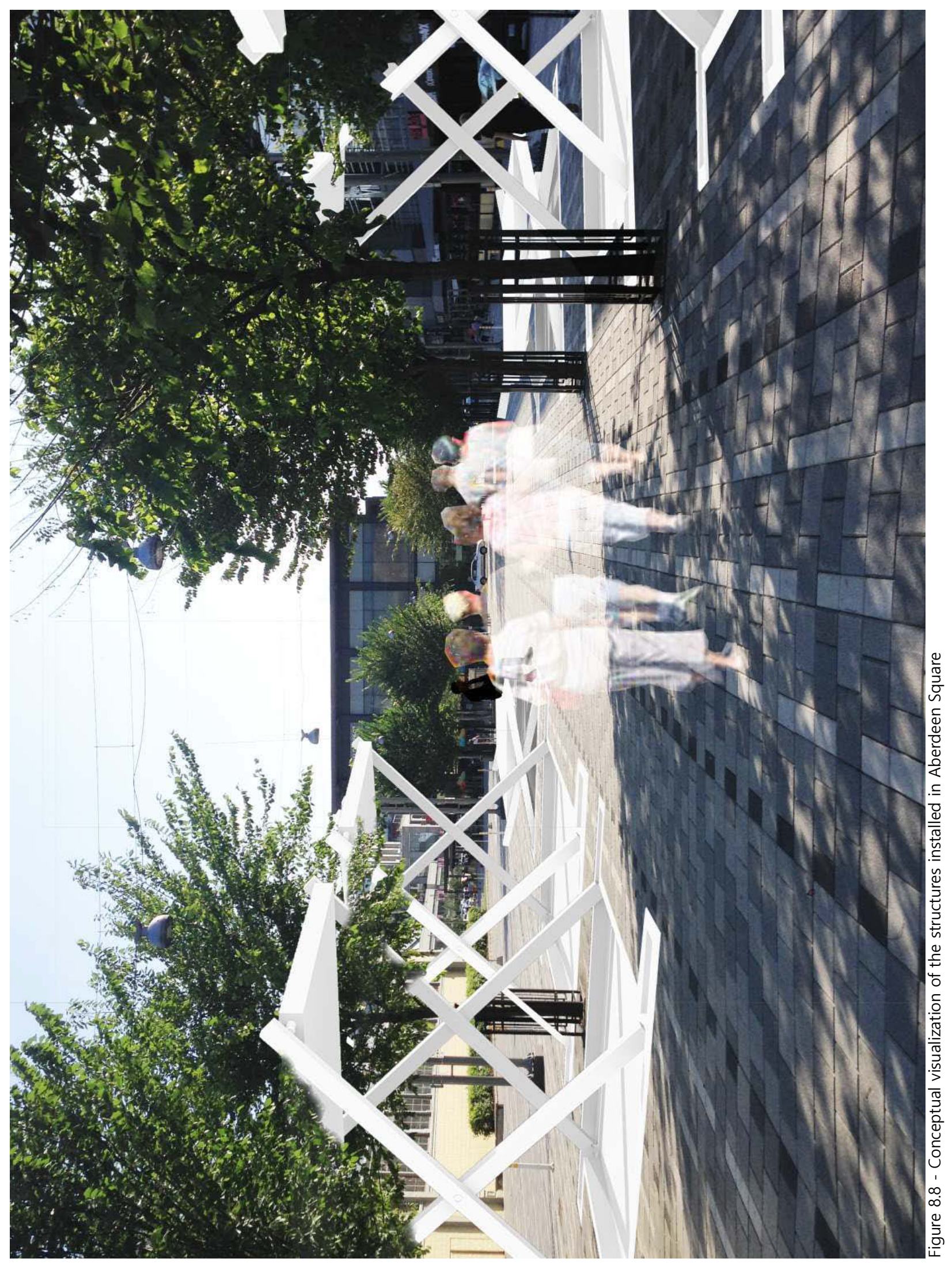


Rideau Canal 
The Rideau Canal is one of Ottawa's oldest feats of engineering and while its original purpose was intended for military transportation today it is an icon of Ottawa, and used for leisure. ${ }^{45}$ In the winter the water is drained down to a depth of approximately one meter and once frozen becomes the "The World's Largest Skating Rink". During the winter months the canal attracts around one million visitors each year. ${ }^{46}$ The skating season on the canal typically lasts for just two months. For the remaining ten months of the year, once the high-water level is returned, the Rideau Canal is used for boating, but access onto the canal from the city is limited. In the summer significant numbers of people walk, run, or cycle along the paths that border the canal. An initiative in recent years by the City of Ottawa has aimed to implement greater water access along the canal particularly in residential neighbourhoods such as the Glebe and Old Ottawa East. The installation of two new docks at Patterson Creek (Glebe) and Clegg Street (Old Ottawa East) has provided easier access to the water. ${ }^{47}$ The city is striving for two distinct and established programs for the Rideau Canal - the already popular winter season that provides skating and a site for many Winterlude activities; and a rejuvenated summer program that sees more paddle powered boats gliding along the water. Both of these programs require infrastructure as a means of access to either the water or ice surface.

The canal structure develops a dock in the summer, and stairs in the winter to step down into the drained canal. Currently these are separate, temporary structures that require installation and removal at the beginning and end of each season. This, in turn, requires additional storage and labour for installation and removal. Folding-unfolding is the strategy used for many storage-use relationships, and could prove useful as a

\footnotetext{
45 "Rideau Canal," The Canadian Encyclopedia, accessed March 25, 2018, http://www.thecanadianencyclopedia. ca/en/article/rideau-canal/

46 "Rideau Canal Skateway," National Capital Commission, accessed March 26, 2018, http://ncc-ccn.gc.ca/places-to-visit/rideau-canal-skateway

47 Paula McCooey, "Rideau Canal gets new launch docks for paddle sports," Ottawa Citizen, May 10, 2016, http://ottawacitizen.com/news/local-news/rideau-canal-gets-new-launch-docks-for-paddle-sports
} 
method of providing both the dock and the stair ingrained in one structure. In this case the folding has natural source of energy to provide motion. The raising and lowering of the water level would provide the motion required to activate the folds. Whether the structure is folded or unfolded it is acting as a useful object and as either of the two programmatic requirements is suspended for the season its potential use is stored in the form of its alternative program.

These folding structures are sited along the two sides of the Rideau Canal in the existing stair locations. Doing so does not disrupt the current function or layout of the canal in the winter season and provides an equal number of summer access points. Just as the frozen canal acts as a transportation route for people in the winter, the water could become a leisurely mode of transportation in the summer. The combination dockstair structure is hinged at the concrete retaining wall that surrounds the canal and is buoyant on the far end. This allows the buoyant end of the structure to rise and fall with the water level and effectively gives form to the flat surface required of the dock and the stepped surface of the stairs. Protruding out from the shore is a rectangular steel tube and one steel angle, this occurs on both sides of the structure. The steel angles are the hinged component while the steel tubes remain fixed and secured back to the shore via tensioned cables. Aluminum rectangular tubes with roughed tactile surfaces sit within the steel angles at the sides of the structure. These tubes are connected via a pivot point to the vertical flange of the steel angle on their ends at the back (the side nearer to the shore). The front sides of each aluminum section are connected via set length steel cables to the fixed steel tube. The result of these connections is that when the water level is up the steel angles are horizontal and all the aluminum tubes are sitting horizontal on the edges of the steel angles creating a wide, level walking surface with space sufficient enough to launch a personal watercraft. When the water is drained 
the ends of the steel angles at the sides lower and the cables between each aluminum section and the fixed steel tube hold the aluminum sections horizontal to create the treads of each stair.

The ratio of the length of the dock to the depth of the canal works well in creating a dock that is an appropriate length for usability and creating a stair that is comfortable to use with a rise in the range of $150 \mathrm{~mm}$ to $175 \mathrm{~mm}$ and a run of about $270 \mathrm{~mm}$. When folded down into a stair the structure is able to maintain a handrail at an appropriate height by fixing the portion nearest shore in position and hinging the remaining section at the fixed steel tube so that as it falls it too is caught by a cable to match the slope of the stair.

The materials used in the makeup of this structure are primarily steel, aluminum, and concrete. The steel used in the supporting frame and structure is required for strength and is galvanized to inhibit the onset of rusting due to the wet environment of the Rideau Canal. Aluminum is used for the planks running between the steel to reduce weight to promote buoyancy in its dock form and avoid unsightly rusting as it ages. Creating a roughed surface on the top of the aluminum planks gives the walking surface some friction to promote better traction when wet. Concrete is used as a foundation for both tying the structure back to the shore and as pillars for the steel angles to rest on as they fall to form a stair.

This dock-stair structure serves as true expression of the intentions behind this research. It is always able to service, and it responds to its surroundings without the need for additional received information. The folding and unfolding actions occur simultaneously with the changing water level of the canal. 


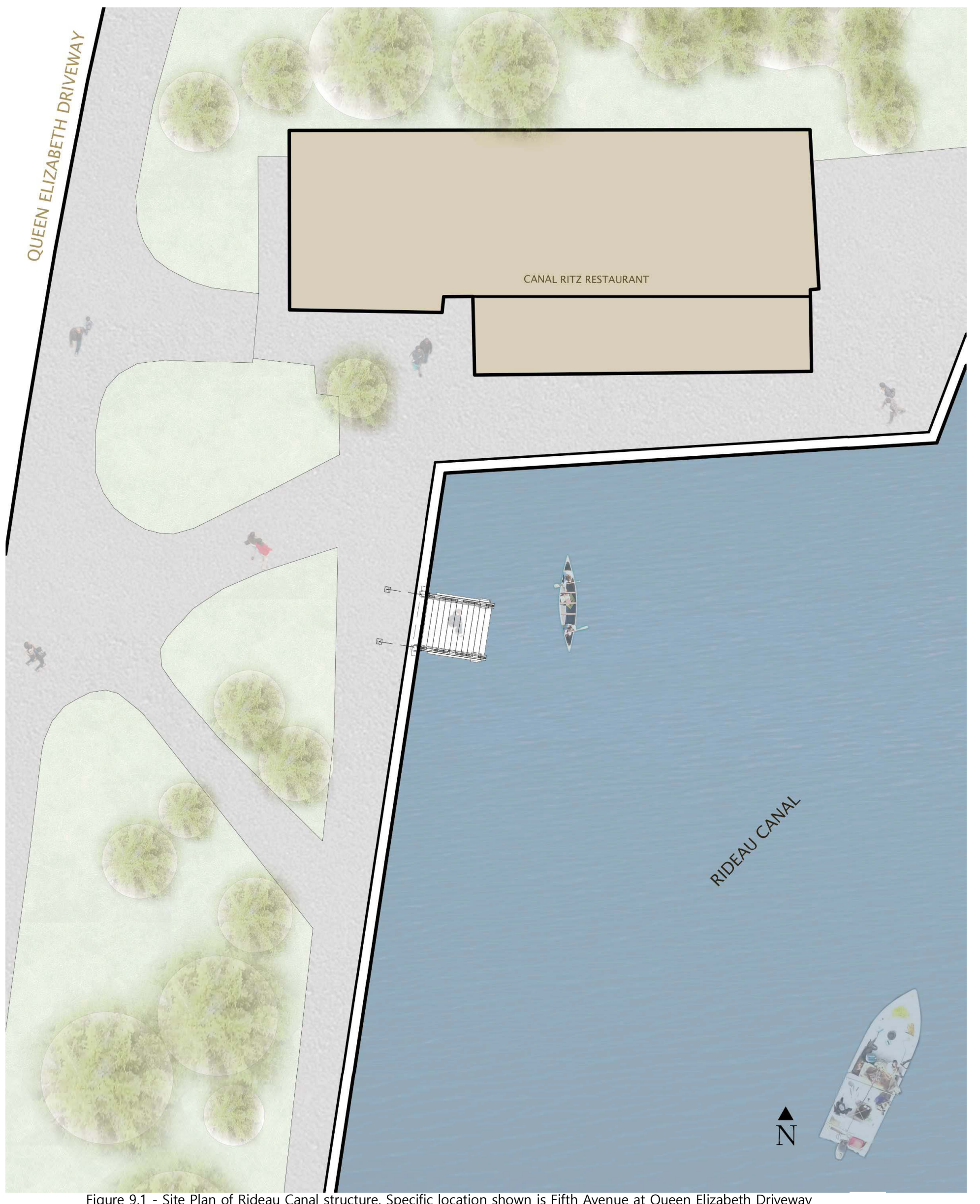

Figure 9.1 - Site Plan of Rideau Canal structure. Specific location shown is Fifth Avenue at Queen Elizabeth Driveway 


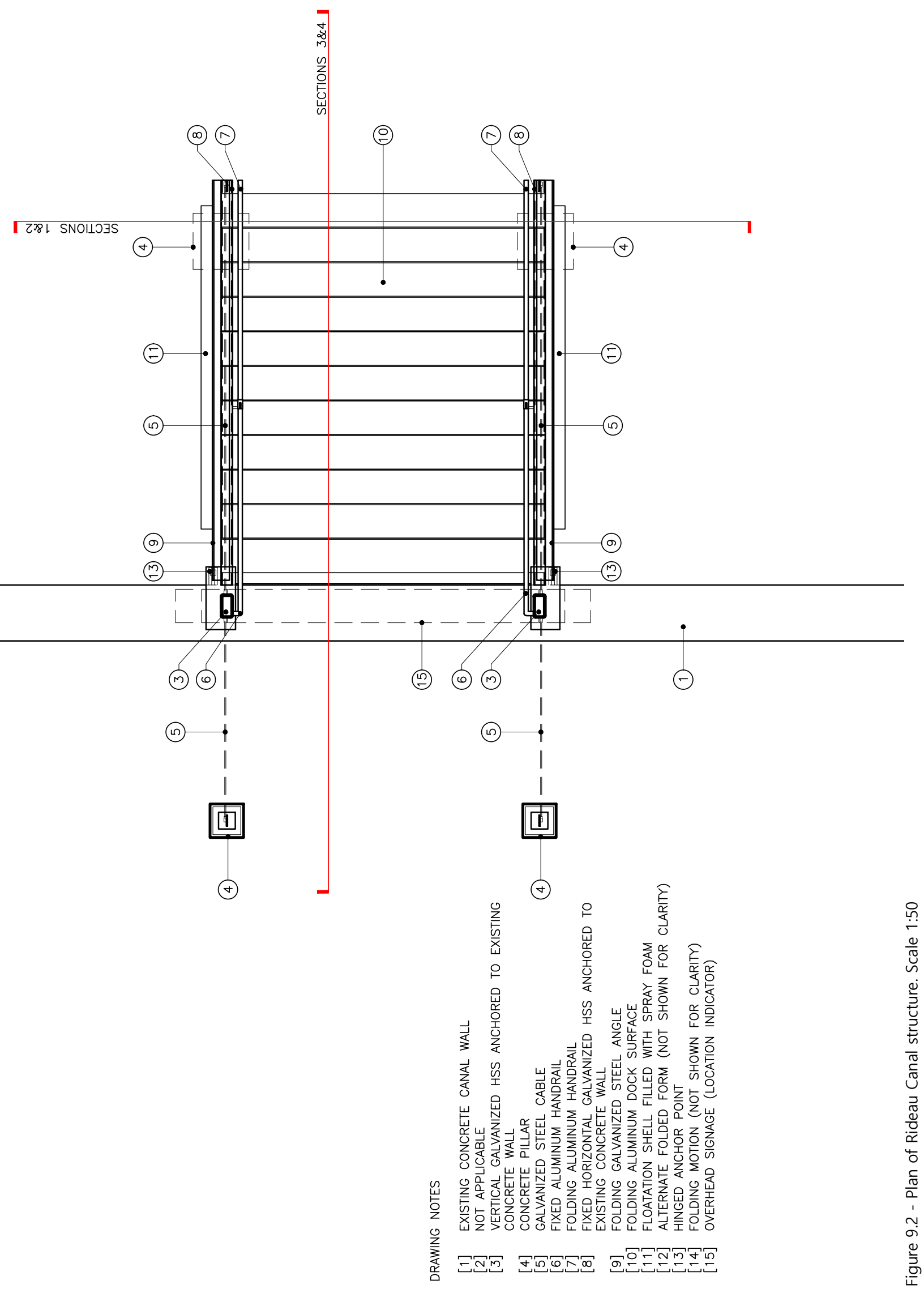




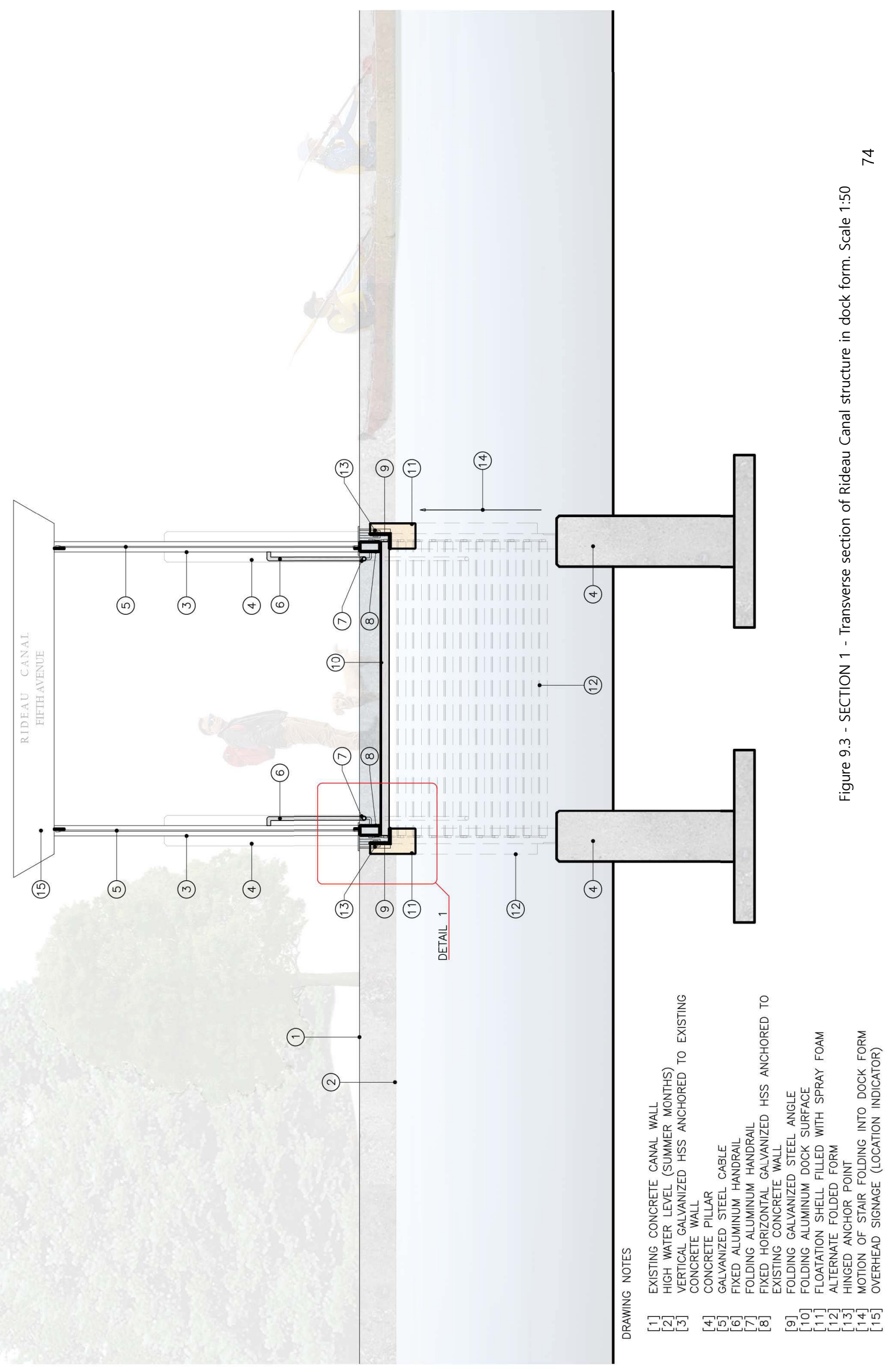




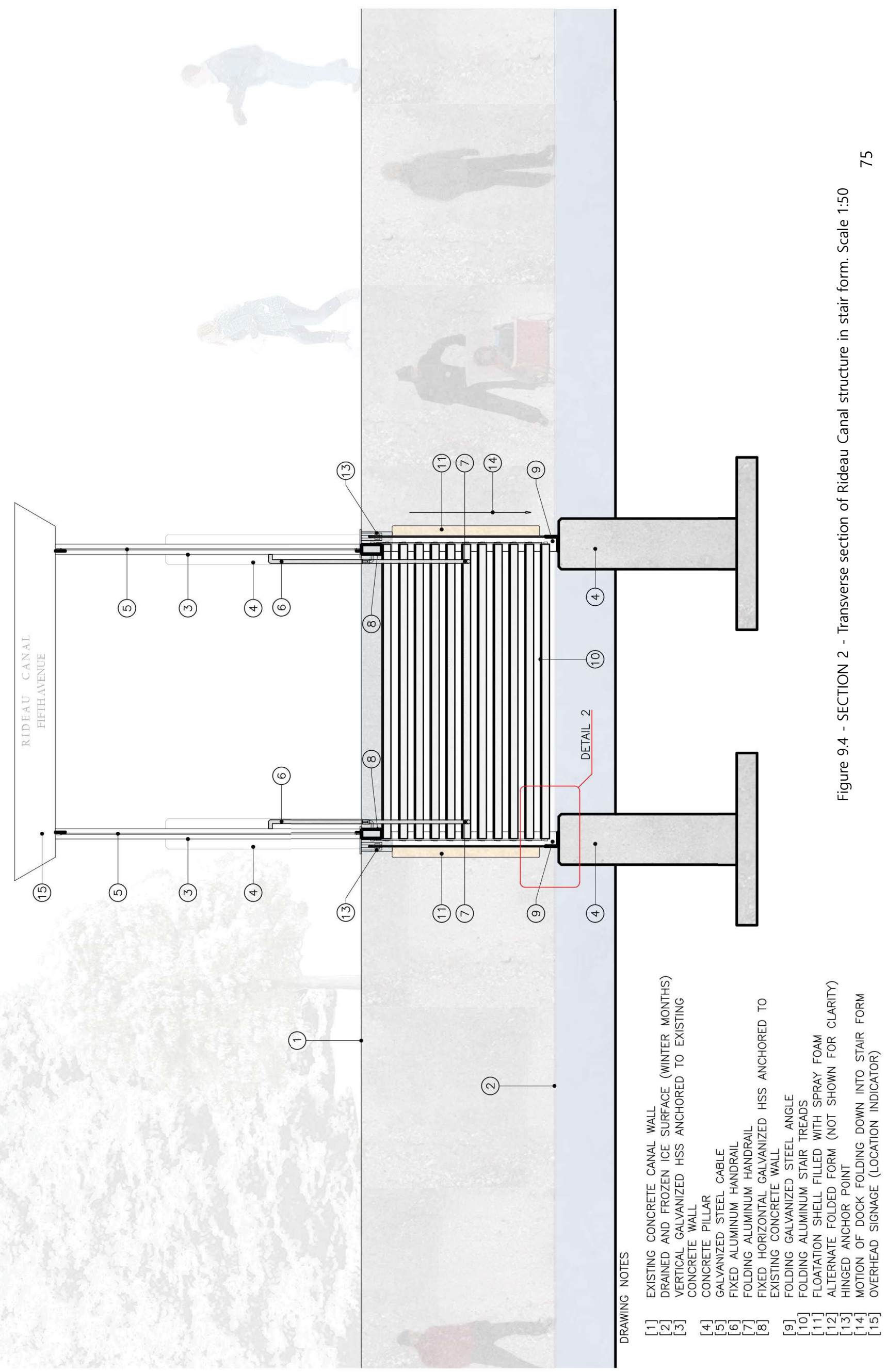




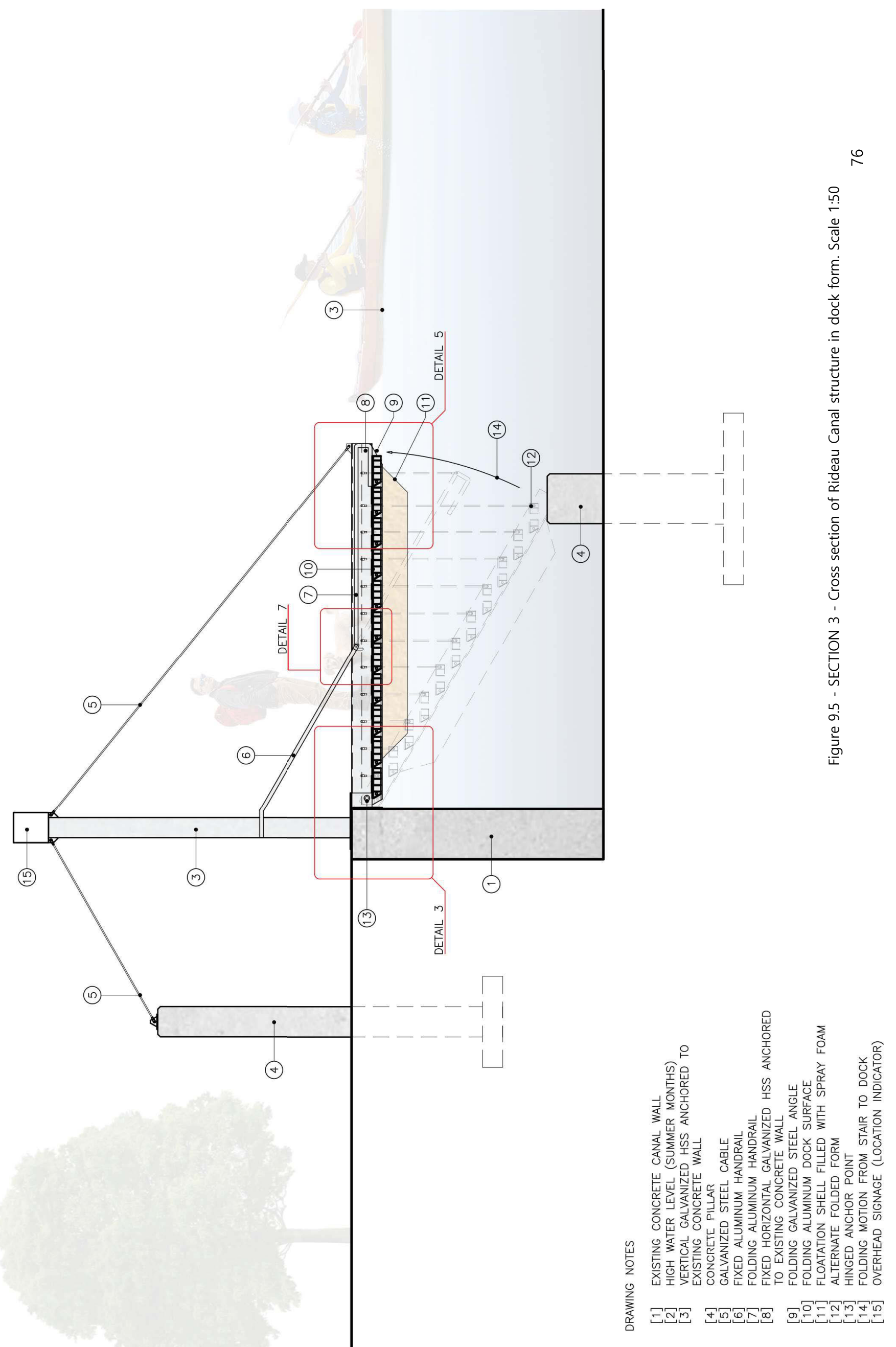




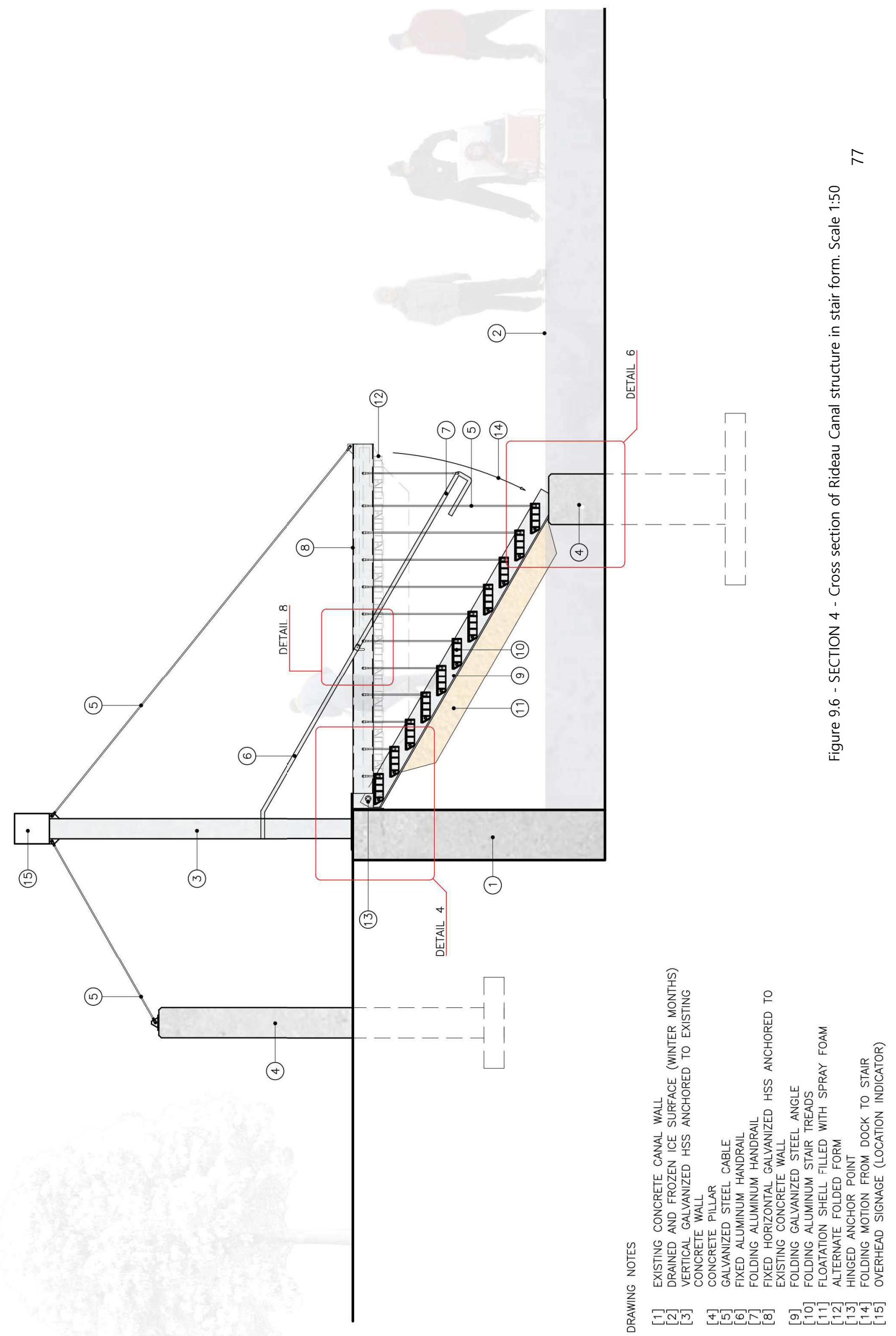




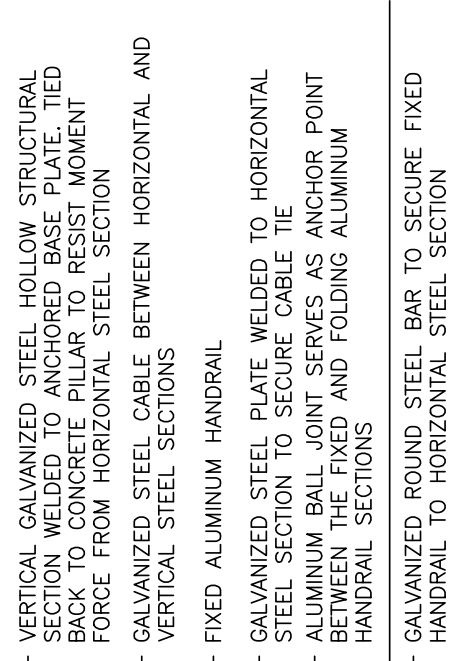

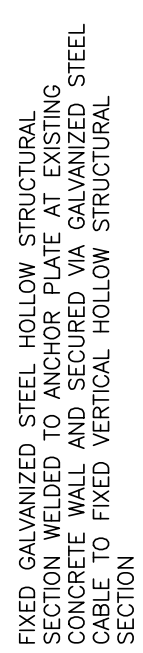

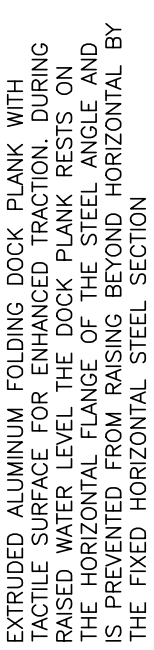

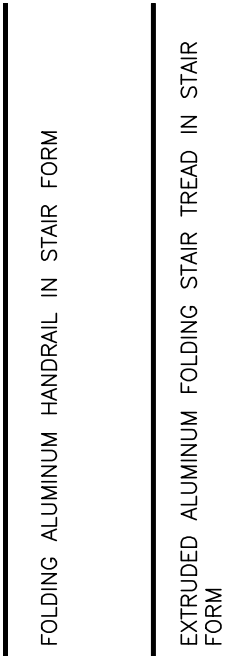
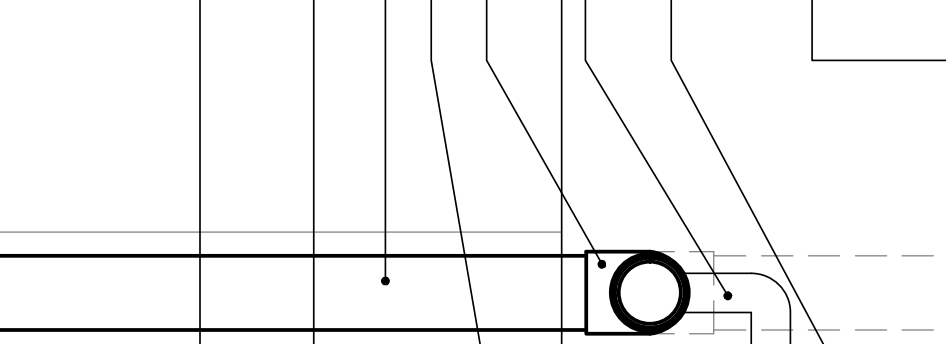

a
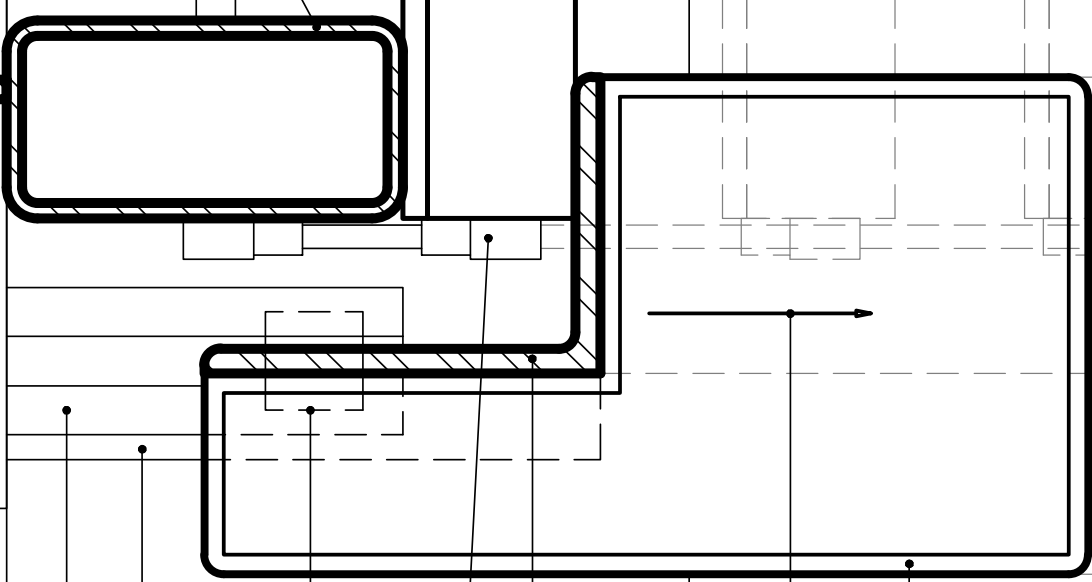

son

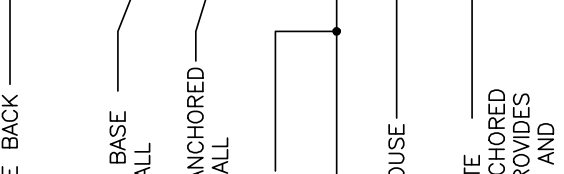

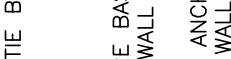

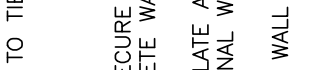

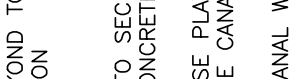

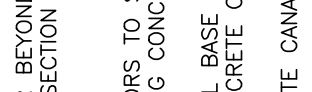

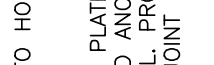

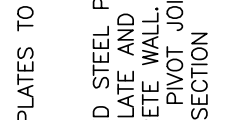

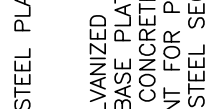

岁 so

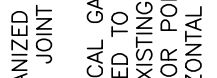

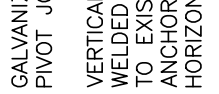

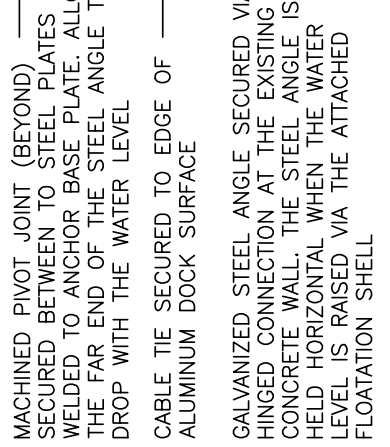

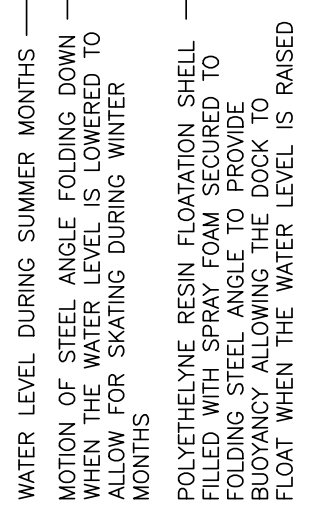

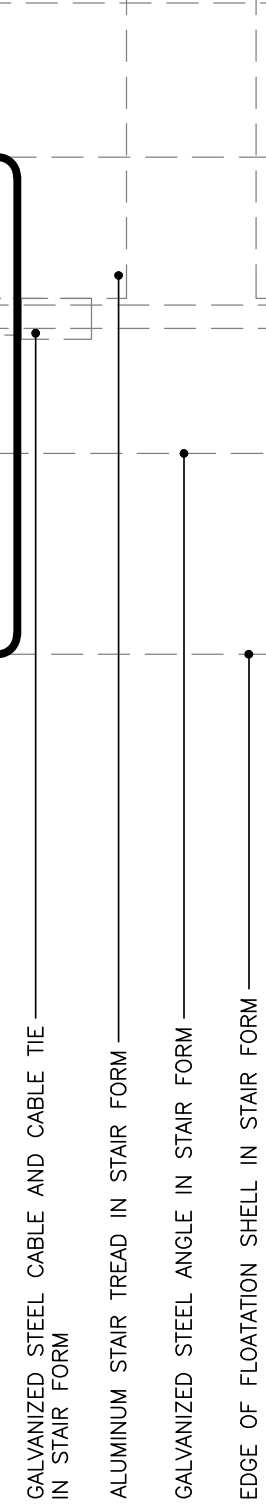




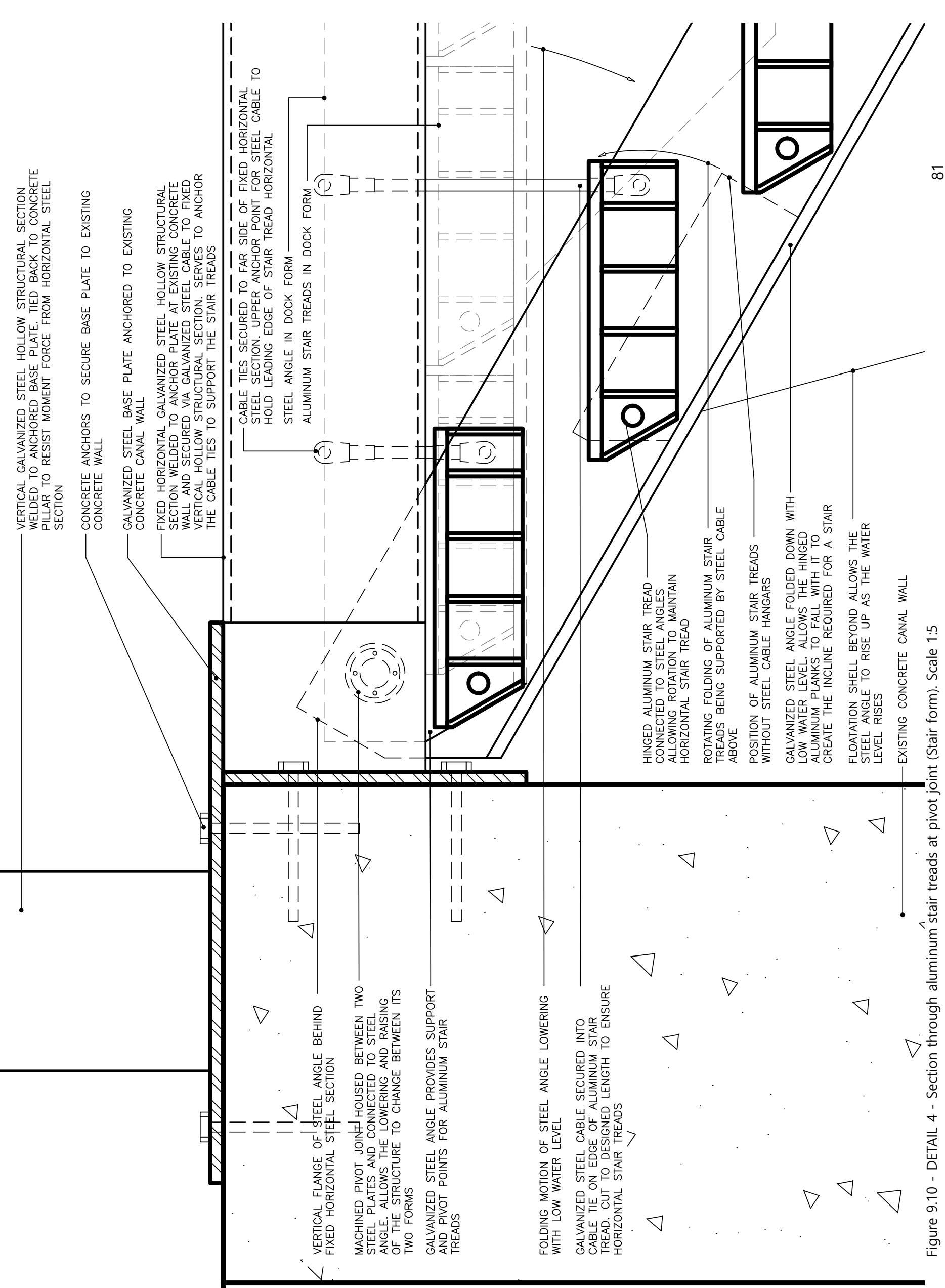



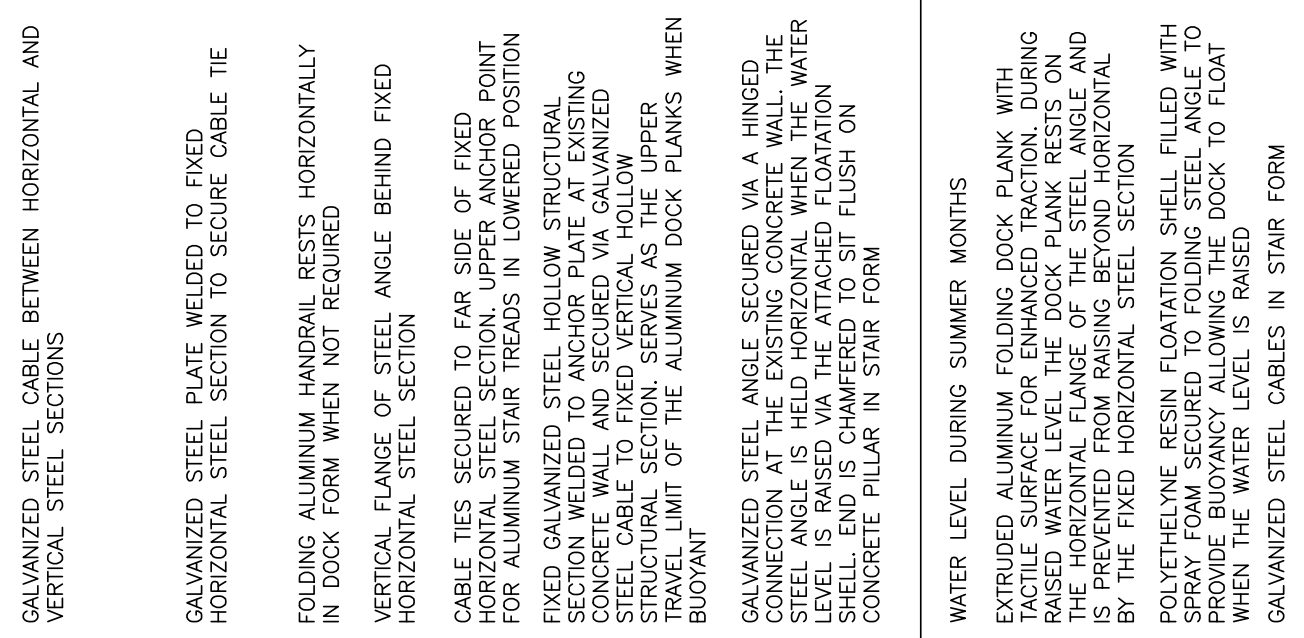


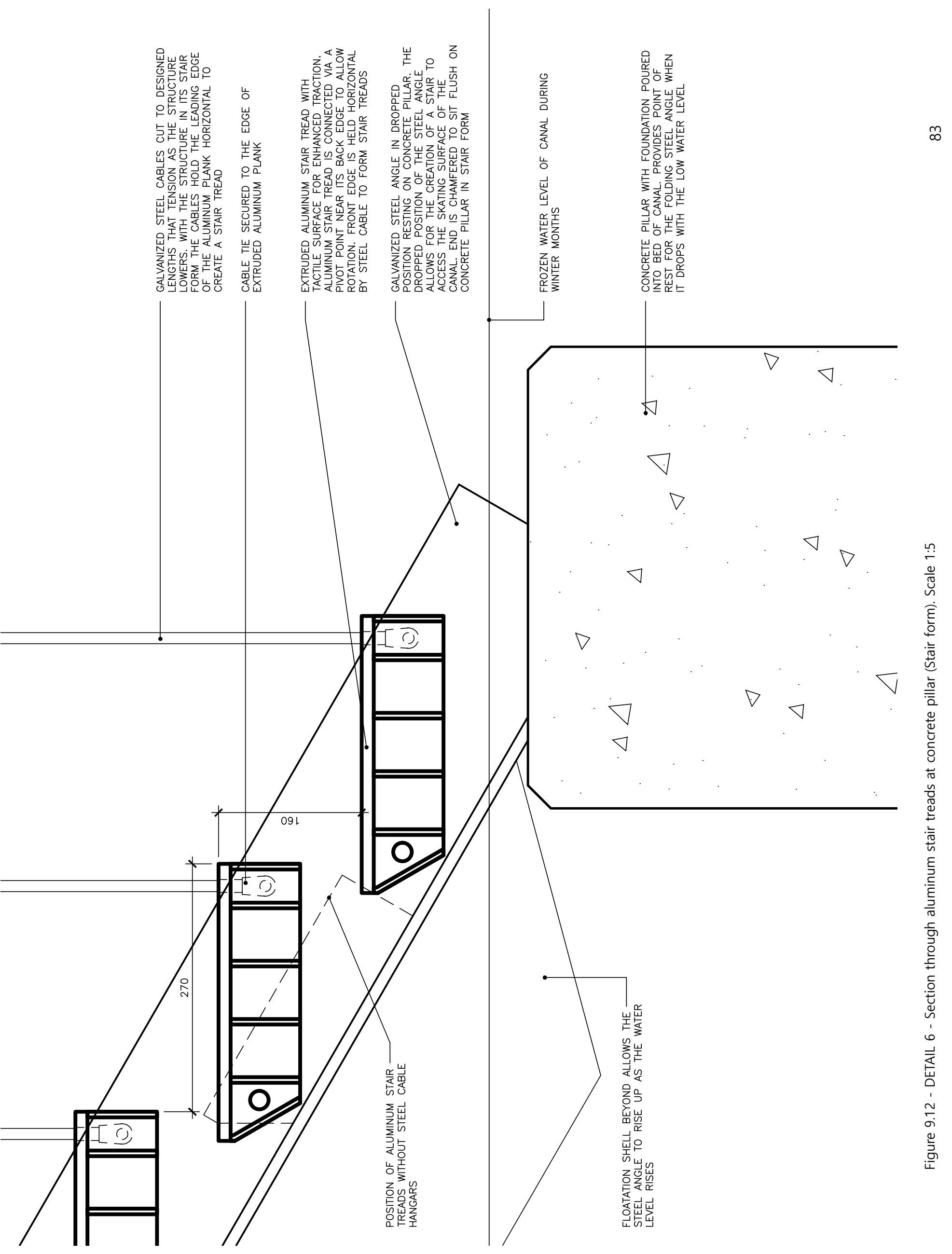




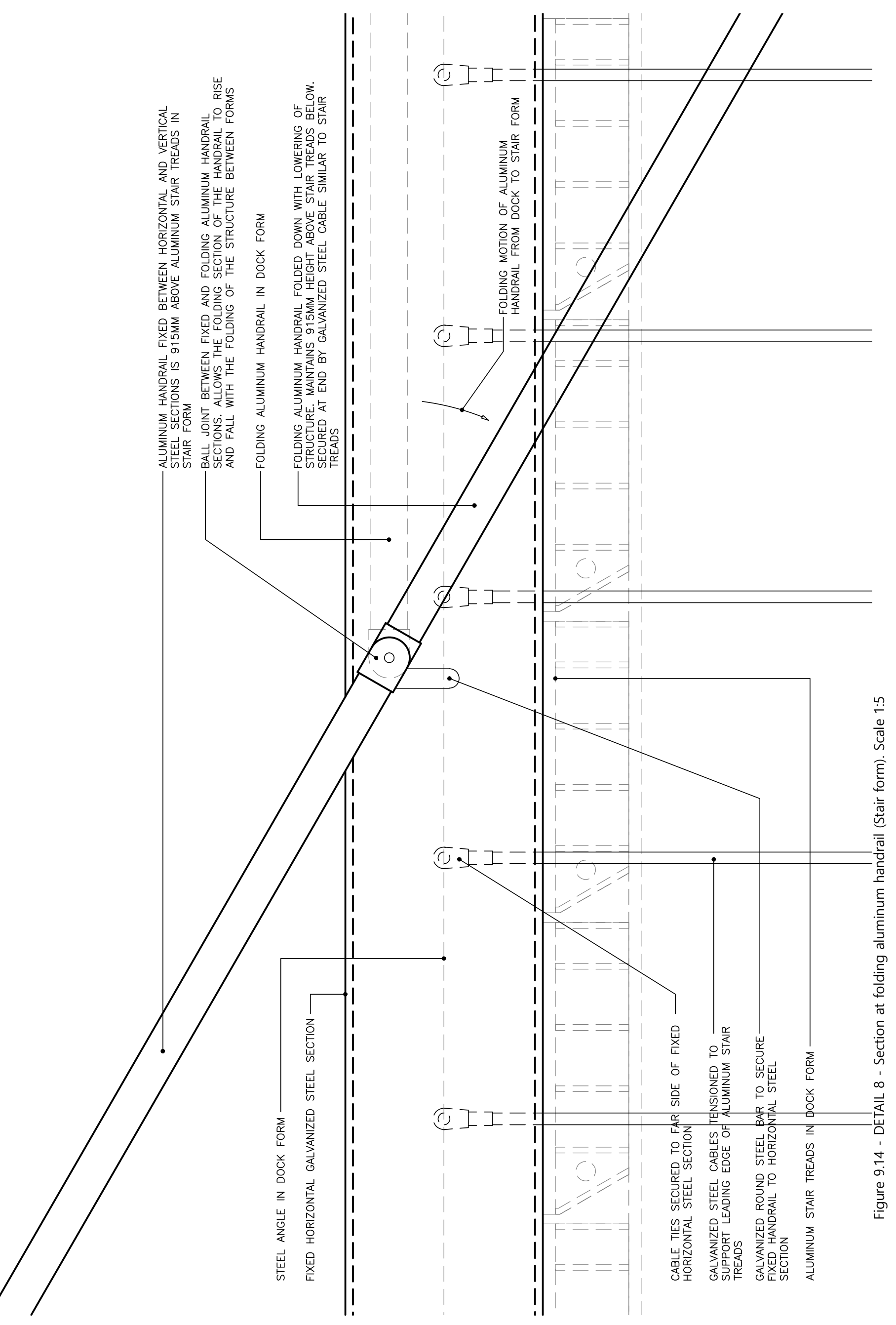




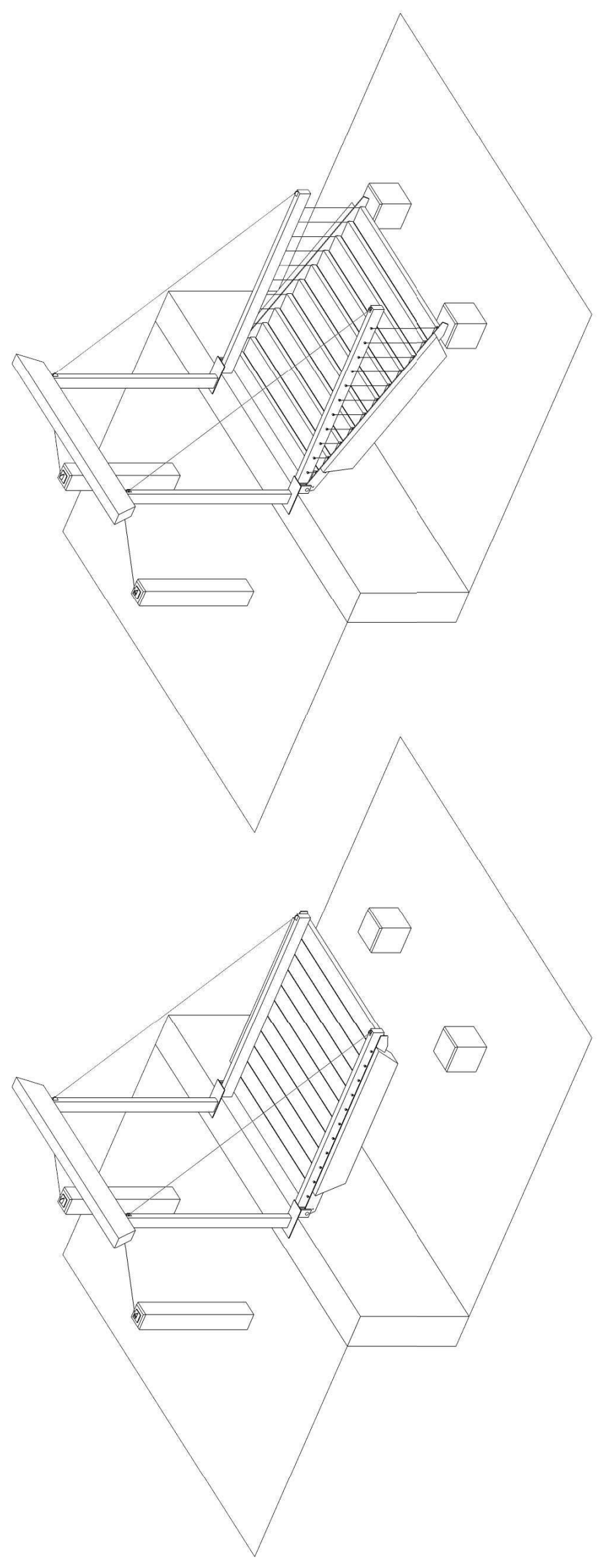

$\infty$

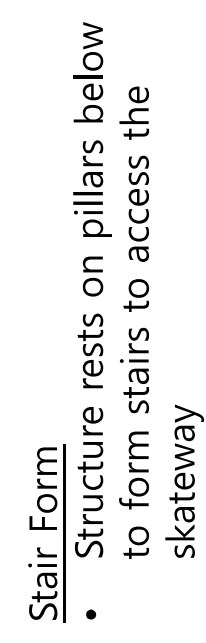

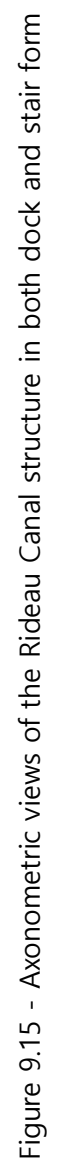




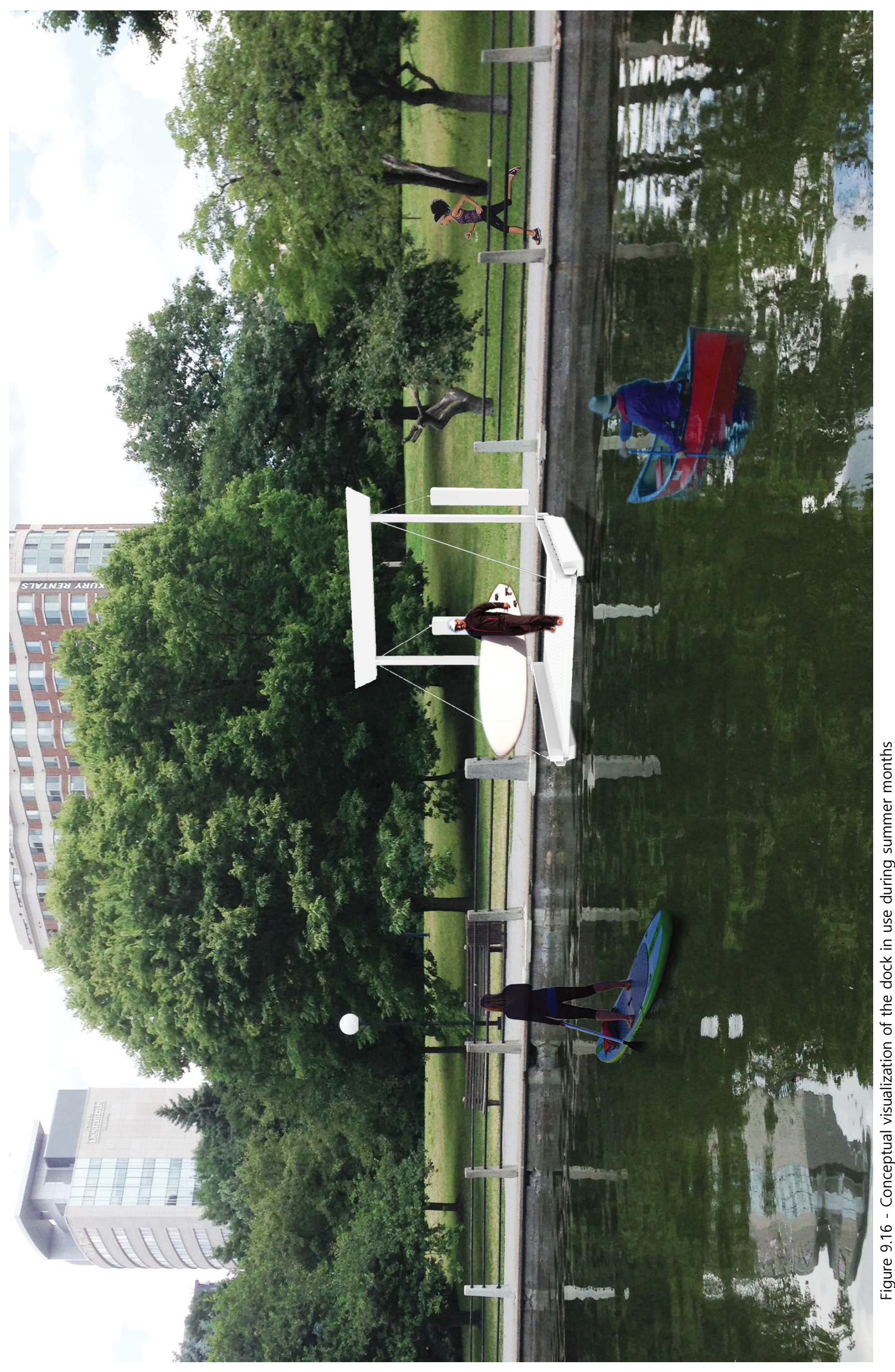

$\widehat{\infty}$ 


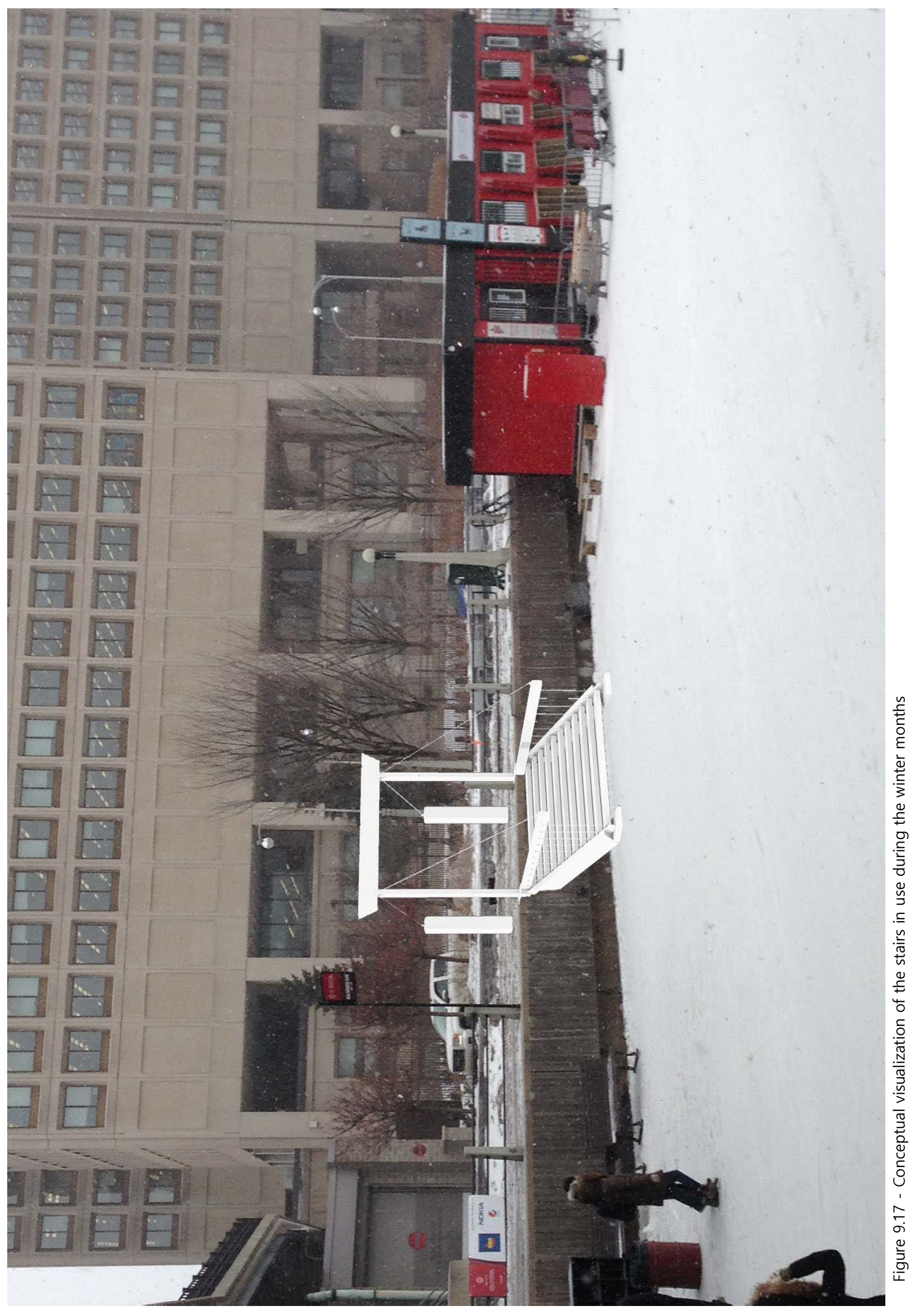




\section{Conclusion}


The culmination of the research, modelling, drawing, and building became three projects that display folding as a utility for multi-use structures. Folding-unfolding is an action; it allows change from one form to another. The ability to change gives opportunity for different uses within the same object. Architects like Eisenman and Lynn have used folding as form generation and as design techniques, however, the moving characteristic of the fold becomes frozen in the final built form. By retaining that action within a structure, the structure holds the potential to change into one of its multiple designed forms; one that is suited best to its current surroundings. This aspect of responsiveness draws from other projects such as the FAZ Pavilion in which a change in the structure is determined by changing environmental factors. Having the ability to fold gives the structures the readiness to be responsive. The forces that promote the folding finish the characteristic of being responsive.

The types of folds implemented in the three developed structures operate through constructed joints rather than the folding of a sheet material. Continual bending of a rigid material eventually breaks down and flexible materials do not stand up to constant outdoor exposure. Constructed joints allow for maintenance of the system and the strength of metals to hold up under these conditions. Beyond material breakdown, the scale at which these developed structures operate does not bode well for the folding of single materials. As Hoberman stated, at smaller scales, some materials can act as their own structure but at the human scale, the materials need to remain 
rigid while folding joints are implanted to provide motion for the structure.

The structures designed through this thesis operate at the human scale, although folding has applications at both smaller and larger scales. The independent study of the folding bench is an example of the smaller scale. Objects at a smaller scale are full of folding elements that provide greater incentive for use, installation, or purchase. Some of these are added features that act as a built-in utility, some of these are required for the proper functioning of the object. Folding as a utility is more common at smaller scales because the human has the ability to power and activate the fold without the need for mechanical or electrical intervention.

What was not explored was folding at much larger scales. In industrial environments, the buildings, tools, and objects can reach very large scales but still require adjustable elements. The folding that occurs within an industrial setting comes more out of necessity rather than as an added utility. The Rideau Canal itself is home to industrial folding elements in the locks used to move boats through the changing elevation of the canal as well as control the water level that allows for the dock-stair structure to function. Folding at this scale is more often a utility as a primary function rather than folding in theory or as aesthetic, it is designed out of necessity

By siting the folding structures in public settings, there is 
opportunity to design the folds with an already dynamic environment. The structures can be interacted with - walked over, sat on, and adapted to events. Chuck Hoberman's folding structures display the beauty of a folding-unfolding structure but are typically viewed from afar. The developed folding structures here emphasize the utility of folding by creating a tactile use that is intended to further the dynamism and activity within a public area.

The temporality of public spaces hosting recurring events presents an opportunity for a folding structure to act in a manner that is more efficient in the deployment and removal of the hosting structures. A permanent structure with multiple temporary forms can act as host to a variety of situations. Responsive folding as a utility to benefit public infrastructure is an idea for a type of structure that supplements public spaces to meet their changing function requirements. The belief is that folding structures can be adapted to not only the one detailed in this thesis, but to many varying situations. Where the fold is most beneficial is in its active state, moving and acting as a utility. 
Epilogue 
I would like to say thank you for reading to this point in my thesis; it is the product of excitement, frustration, happiness, sadness, and everything in between. The biggest realization to come from this is that folding is essentially everywhere. It could be argued that nearly anything that moves is folding or unfolding in some manner. The idea of folding is very broad and narrowing it down to a few specific ideas came as a great challenge in researching for this thesis. There are branches of folding that I did not include in effort to keep the research focused. The art form of origami has inspired several engineering-based disciplines such as biomedical, automotive, and aerospace. While I did examine how origami could provide new inspirations for my research and folding structures, its principles did not fit with the type of folding I was interested in.

When I first began the research process my initial scope involved discovering how naturally occurring geometric forms could create more efficient spaces and structures than the current standard. The shift between that first idea and the ideas of the final thesis share some similar principles, however, my journey from one to the other was not linear. In the midst of trying to pinpoint the focus of my research I perused ideas of self-assembly, 3D printed structures, biomimetics, and central place theory, to name a few. In the end I returned to my desire for developing an idea that could 
be applied to many circumstances rather than a solution to a specific problem. Once I landed on folding as general subject, my goal was always to create an array of demonstrations that all validate the idea as a whole. The more satisfying outcome, to me, is gaining an understanding of a larger idea and having the ability to apply that knowledge to other challenges I might face.

Moving forward from this challenge and on to the next, I take away an enhanced ability to critique my own work and remain accountable for what I produce. I believe this to be an invaluable trait to have as I continue with my professional career in architecture. It is interesting now to look back at the entire process and wonder if perhaps, as Deleuze might have said, this is just one fold in a series of unfolding events that are the seeds for what is growing within. 


\section{Glossary of Folds}

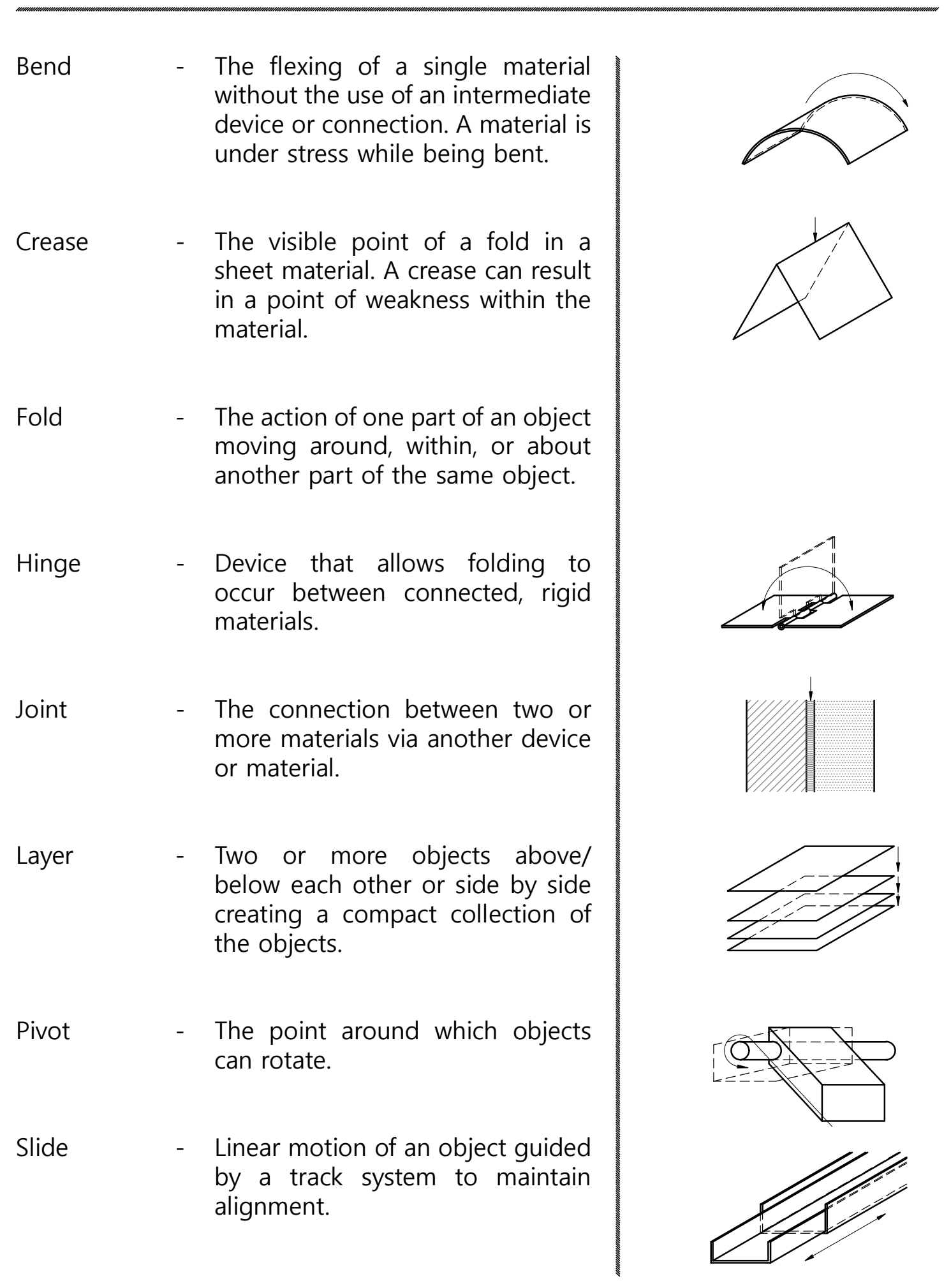




\section{Bibliography}

Abrahams, Tim. "Computers in Theory and Practice." In The Architectural Review. April 26, 2013. https://www.architectural-review.com/essays/viewpoints/computersin-theory-and-practice/8646960.article

Bodenhausen, Galen V. "Consumerism and its Antisocial Effects can be Turned On - or Off." Association for Psychological Science. Accessed March 14, 2018. https:// www.psychologicalscience.org/news/releases/consumerism-and-its-antisocialeffects-can-be-turned-onor-off.html.

Canadian Encyclopedia. "Rideau Canal." Accessed March 25, 2018. http://www. thecanadianencyclopedia.ca/en/article/rideau-canal/

Carpo, Mario. "Ten Years of Folding." In Folding in Architecture, edited by Greg Lynn, 14-19. London: Academy Press, 2004.

Chabrowe, Barbara. "On the Significance of Temporary Architecture." In The Burlington Magazine Vol 116, No. 856, (July 1974): 384-388+391. http://www.jstor. org/stable/877732.

City of Ottawa. "GeoOttawa." Accessed March 24, 2018. http://maps.ottawa.ca/ geoottawa/

City of Ottawa. "Population Projections." Accessed March 19, 2018. https://ottawa. ca/en/city-hall/get-know-your-city/statistics-and-economic-profile/statistics/ growth-projections-2006-0/10-population-projections

Conley, Tom. "Folds and Folding." In Gilles Deleuze: Key Concepts (2nd Edition), edited by Charles J. Stivale, 192-203. Montreal: McGill-Queen's University Press, 2011.

Davidson, Cynthia. Anywise. Cambridge: MIT Press, 1996.

Deleuze, Gilles. The Fold - Leibniz and the Baroque, translated by Tom Conley, Minneapolis: University of Minneapolis Press, 1993. 
Department of Economic Development and Innovation, City of Ottawa. "Economic Development Update Tourism Edition: Visitor Profile." Last modified Winter 2016. http://www. ottawachamber.ca/wp-content/uploads/2017/04/1473.pdf

Eisenman, Peter. "Alteka Office Building." In Folding in Architecture, edited by Greg Lynn, 28. London: Academy Press, 2004.

Eisenman, Peter. "Unfolding Events: Frankfurt Rebstockpark and the Possibility of a New Urbanism." In Written into the Void, edited by Peter Eisenman, 13-17. London: Yale University Press, 2007.

Farshid Moussavi Architecture. "Yokohama International Port Terminal, Yokohama, Japan." Accessed March 22, 2018. https://www.farshidmoussavi.com/node/15\#yokohama_ international_port_terminal_yokohama_japan_15_44

Frichot, Hélène. "Deleuze and the Story of the Superfold." In Deleuze and Architecture, edited by Hélène Frichot and Stephen Loo, 79-95. Edinburgh: Edinburgh University Press, 2013.

Frishberg, Manny. "Origami-inspired Engineering: Fold, Bend, Design, Build." In ResearchTechnology Management, May-June 2016, (accessed February 28, 2018).

http://link.galegroup.com.proxy.library.carleton.ca/apps/doc/A453294433/AONE?u=ocul_ carleton\$sid+AONE\&xid=3d980186.

Gehry, Frank. Sketches of Frank Gehry, directed by Sydney Pollack. New York: Sony Pictures Classics, 2006. Internet Video. https://www.youtube.com/watch?v=049mPHHEiZ4

Hoberman Associates Inc. "Hoberman Company Profile and Selected Works: 1990-2012." Accessed March 22, 2018. http://www.hoberman.com/HobermanPortfolio.pdf

Jackson, Paul. Cut and Fold Techniques for Pop-Up Designs. London: Laurence King Publishing, 2014.

Jackson, Paul. Folding Techniques for Designers: From Sheet to Form. London: Laurence King Publishing, 2011.

Jafri, Amen. "The City That Fun Forgot?" YouTube Video, 33:26, posted by "CityFunForgot," posted August 11, 2014. https://www.youtube.com/watch?v=CKk_kRSTaOc

Kipnis, Jeffrey. "Towards a New Architecture." In Folding in Architecture, edited by Greg Lynn. Academy Press, 2004.

Langdon, David. "AD Classics: Yokohama International Passenger Terminal/Foreign Office Architects (FOA)." Arch Daily, last modified October 7, 2014. https://www.archdaily. com/554132/ad-classics-yokohama-international-passenger-terminal-foreign-officearchitects-foa 
Lanktree, Graham. "Can Boring Ottawa, Shed Its Image as the Town That Fun Forgot." Metro Ottawa, August 30, 2012. http://www.metronews.ca/news/ottawa/2012/08/30/can-boringottawa-shed-its-image-as-the-town-that-fun-forgot.html

Lefebvre, Henri. "The Right to the City." In Writings on Cities. Translated by Eleonore Kofman and Elizabeth Lebas, 147-59. Blackwell Publishers, 1996.

Lynn, Greg. Animate Form. New York: Princeton Architectural Press, 1999.

Lynn, Greg. "Architectural Curvilinearity: The Folded, the Pliant and the Supple." In Folding in Architecture, edited by Greg Lynn, 24-31. London: Academy Press, 2004.

Lynn, Greg. "Introduction." In Folding in Architecture, edited by Greg Lynn, 9-12. London: Academy Press, 2004.

MacNair, Gordon E. "Lansdowne: A Success Story Redevelopment in the Heart of Ottawa." In Canadian Property Valuation Volume 59 Book 2, 2015. https://www.aicanada.ca/article/ lansdowne-a-success-story-of-redevelopment-in-the-heart-of-ottawa/

McCooey, "Rideau Canal Gets New Launch Dock for Paddle Sports." Ottawa Citizen, May 10, 2016. http://ottawacitizen.com/news/local-news/rideau-canal-gets-new-launch-docks-forpaddle-sports

McKeough, Tim. "Chuck Hoberman's Buildings Adapt to the Environment." Fast Company, April 1, 2010. https://www.fastcompany.com/1588653/chuck-hobermans-buildings-adaptenvironment

Menges, Achim. "FAZ Pavilion Frankfurt." Accessed February 21, 2018. http://www. achimmenges.net/?p=4967

National Capital Commission. "Confederation Park." Accessed June 10, 2018. http://ncc-ccn. gc.ca/places-to-visit/parks-paths-and-parkways/confederation-park

National Capital Commission. "Rideau Canal Skateway." Accessed January 29, 2018. https:// ncc-ccn.maps.arcgis.com/apps/View/index.html?appid=795623808c5c49388aa7dc5f94890a40

National Capital Commission. "Rideau Canal Skateway." Accessed March 26, 2018. http://nccccn.gc.ca/places-to-visit/rideau-canal-skateway

O-Train. "Confederation Line." Accessed March 19, 2018. http://www.ligneconfederationline. $\mathrm{ca} /$

Ottawa Farmer's Market. "Lansdowne Park - Ottawa." Accessed January 16, 2018. https:// ottawafarmersmarket.ca/lansdowne-park-ottawa/ 
Pestana, Mariana. "Building Alternative Possible Worlds." In This is Temporary, How Transient Projects are Redefining Architecture, edited by Cate St.Hill, 141-43. Newcastle: RIBA Publishing, 2016.

Rajchman, John. "Out of the Fold." In Folding in Architecture, edited by Greg Lynn, 77-79. London: Academy Press, 2004.

Speaks, Michael. "It's Out There... The Formal Limits of the American Avant Garde." In Architectural Design Profile no.133, Hyper Surface Architecture. 1998.

The Canadian Encyclopedia. "Rideau Canal." Accessed March 25, 2018. http://www. thecanadianencyclopedia.ca/en/article/rideau-canal/

Vyzoviti, Sophia. Soft Shells: Porous and Deployable Architectural Screens. Amsterdam: BIS Publishers, 2011.

Waters, Tom. "The Unfolding World of Chuck Hoberman. Discover, March 1, 1992. http:// discovermagazine.com/1992/mar/theunfoldingworl6

Zuk, William; Clark, Robert H. Kinetic Architecture, New York: Van Nostrand Reinhold Company, 1970. 